\title{
PROBABILISTIC DESIGN OF FREEWAY ENTRANCE SPEED \\ CHANGE LANES CONSIDERING ACCELERATION AND GAP ACCEPTANCE BEHAVIOUR
}

\author{
A thesis submitted to \\ the Faculty of Graduate and Postdoctoral Affairs \\ in Partial Fulfillment of the requirements for the degree \\ Master of Applied Science in Civil Engineering
}

by

TAZEEN FATEMA

B.Sc, Bangladesh University of Engineering and Technology

\author{
Department of Civil and Environmental Engineering \\ Carleton University
}

Ottawa-Carleton Institute of Civil and Environmental Engineering

September, 2012

C2012 Tazeen Fatema 
Library and Archives

Canada

Published Heritage

Branch

395 Wellington Street

Ottawa ON K1A ON4

Canada
Bibliothèque et

Archives Canada

Direction du

Patrimoine de l'édition

395 , rue Wellington

Ottawa ON K1A ON4

Canada
Your file Votre référence

ISBN: 978-0-494-93483-8

Our file Notre référence

ISBN: $978-0-494-93483-8$
NOTICE:

The author has granted a nonexclusive license allowing Library and Archives Canada to reproduce, publish, archive, preserve, conserve, communicate to the public by telecommunication or on the Internet, loan, distrbute and sell theses worldwide, for commercial or noncommercial purposes, in microform, paper, electronic and/or any other formats.

The author retains copyright ownership and moral rights in this thesis. Neither the thesis nor substantial extracts from it may be printed or otherwise reproduced without the author's permission.
AVIS:

L'auteur a accordé une licence non exclusive permettant à la Bibliothèque et Archives Canada de reproduire, publier, archiver, sauvegarder, conserver, transmettre au public par télécommunication ou par l'Internet, prêter, distribuer et vendre des thèses partout dans le monde, à des fins commerciales ou autres, sur support microforme, papier, électronique et/ou autres formats.

L'auteur conserve la propriété du droit d'auteur et des droits moraux qui protege cette thèse. $\mathrm{Ni}$ la thèse ni des extraits substantiels de celle-ci ne doivent être imprimés ou autrement reproduits sans son autorisation.
In compliance with the Canadian Privacy Act some supporting forms may have been removed from this thesis.

While these forms may be included in the document page count, their removal does not represent any loss of content from the thesis.
Conformément à la loi canadienne sur la protection de la vie privée, quelques formulaires secondaires ont été enlevés de cette thèse.

Bien que ces formulaires aient inclus dans la pagination, il n'y aura aucun contenu manquant. 


\begin{abstract}
An adequate length of entrance speed change lanes (SCL) is required for vehicles' acceleration and gap searching purpose so that they can merge onto the freeway comfortably. The current design guides use a deterministic approach and consider the entrance speed, merging speed and acceleration factors for the determination of SCL length. The present research introduces a reliability-based probabilistic design approach for the SCL length considering both acceleration and gap searching behaviour of drivers during the merging process. A microscopic simulation technique is developed for the application of the probabilistic approach, and the outcome provides the probability of non-compliance (PNC) that quantifies the SCL drivers' uncomfortable merging. Different PNC measures are attached to the study sites considered in the present research work, which can be potentially used for evaluating the sites' safety performance. A case study is presented for the determination of PNC associated with the SCL length recommended in the North American design guides. A sensitivity analysis is also presented to examine the effect of the different model parameters.
\end{abstract}




\section{ACKNOWLEDGEMENT}

I would like to convey special thanks to my thesis supervisor Dr. Yasser Hassan whose excellent guidance, invaluable advice and inspiration helped me to materialise the thesis work. He provided me a creative environment through continuous discussions and arguments that enriched my growth as a researcher.

I would like to extend my thanks to other professors in the department of civil engineering in the Carleton University for giving me a cordial and friendly environment for learning.

I appreciate all of my friends who helped me in solving numerous problems during the implementation of research work.

I would like to express my deepest gratitude to my belated father who always inspired me to acquire knowledge. My appreciation goes to my mother who encouraged me and continuously prayed for me.

Finally, the thesis is dedicated to my two daughters Arisha and Arzin who sacrificed immensely during the course of my study, and my beloved husband whose unconditional love, support, and patience helped me to complete this research work. 


\section{TABLE OF CONTENTS}

ABSTRACT ....................................................................................................................................II

ACKNOWLEDGEMENT......................................................................................................................III

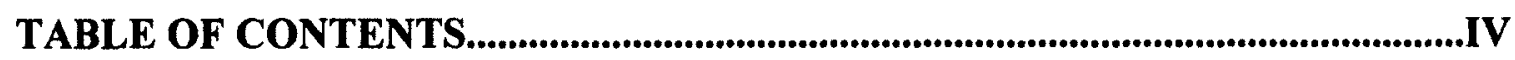

LIST OF TABLES............................................................................................................................IX

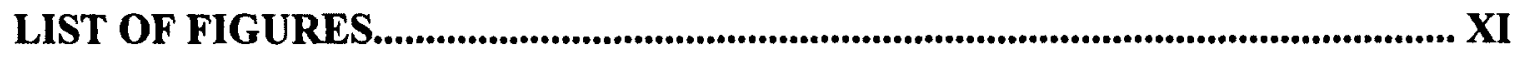

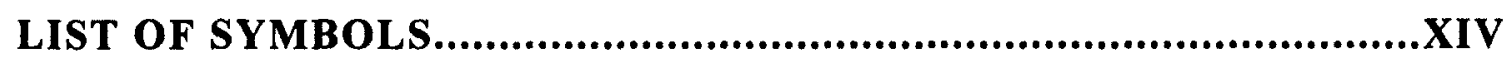

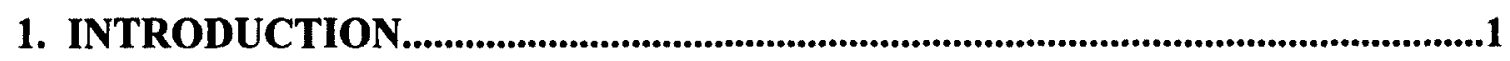

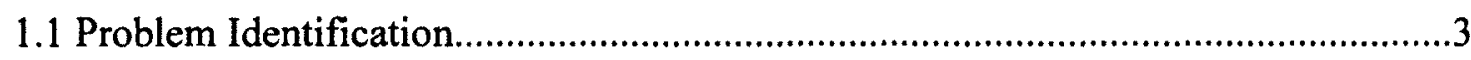

1.2 Objective and Scope

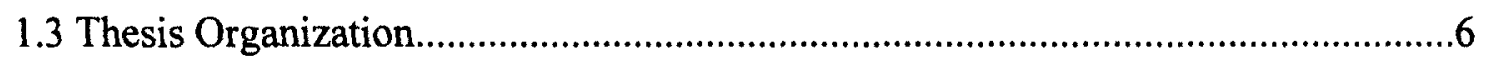

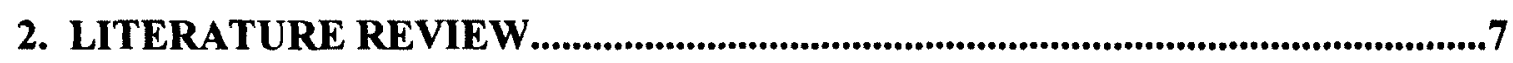

2.1 Review of Current SCL Design Practice............................................................

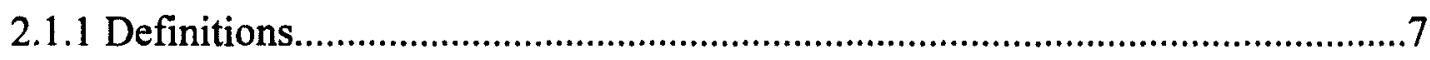

2.1.2 Current Design Guides for SCL length........................................................10

2.1.3 Previous Research Based on Current Design Assumptions...............................13

2.2 Reliability Approach in Highway Geometric Design............................................14

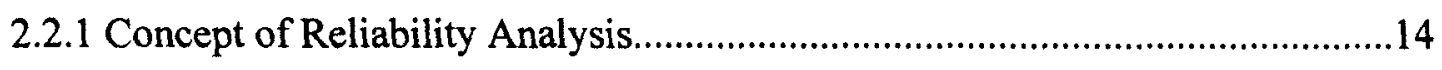


2.2.2 Types of Reliability Analysis

2.2.3 Previous Research on Reliability and Risk Assessment......................................18

2.3 Freeway Merging Behaviour...........................................................................21

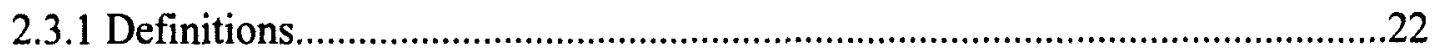

2.3.2 Previous Research Related to Merging Behaviour of Driver..............................24

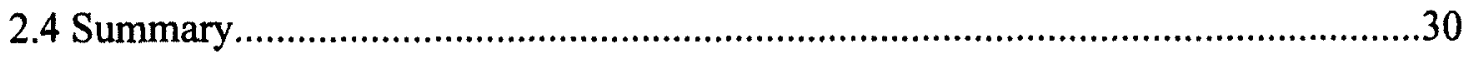

3. DATA COLLECTION AND PRELIMINARY ANALYSIS...................................32

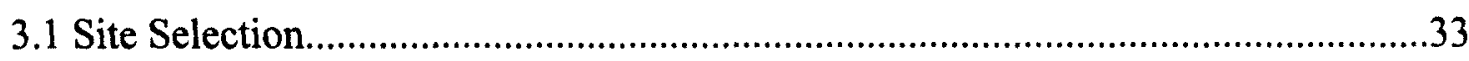

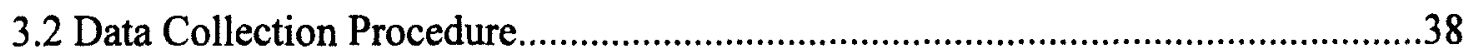

3.3 Statistical Characteristics of Parameters..............................................................40

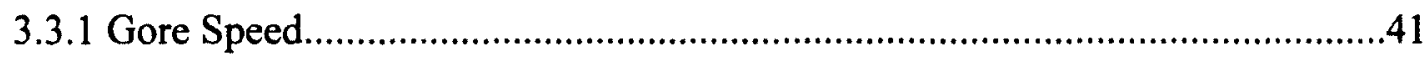

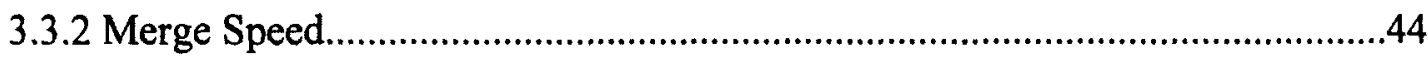

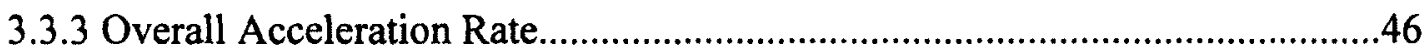

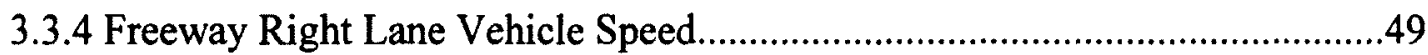

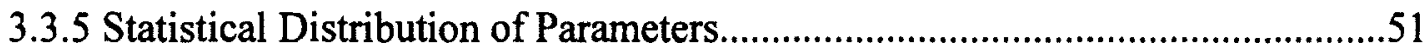

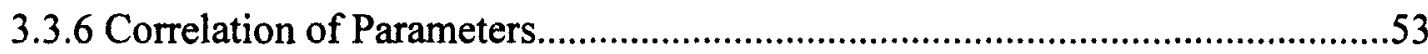

3.3.7 Traffic Volume

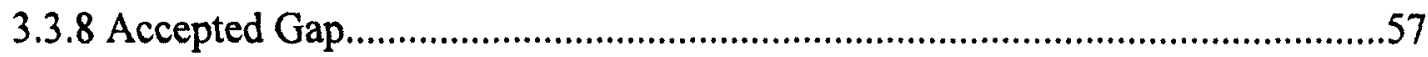

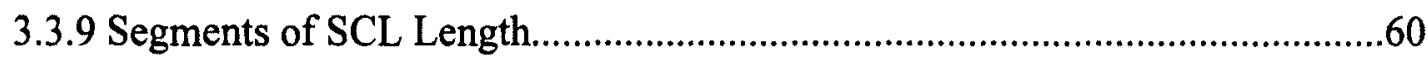

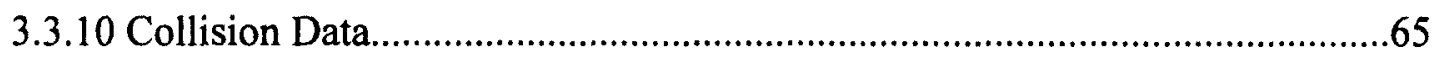


4.1 Introduction

4.2 Simulation Technique. .69

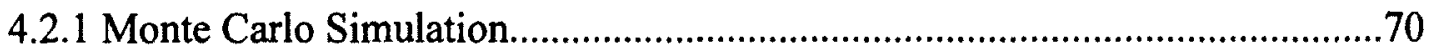

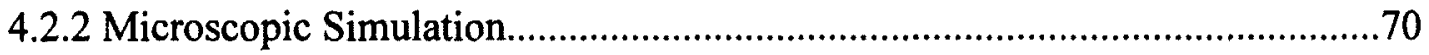

4.3 Modelling of Merging Scenario..........................................................................

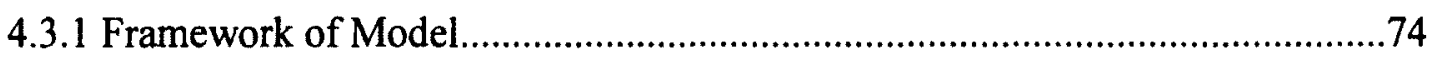

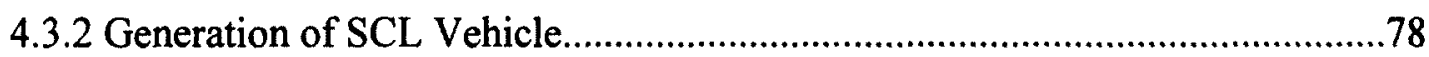

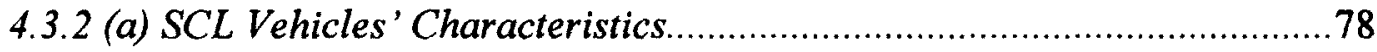

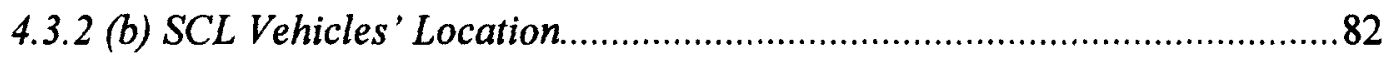

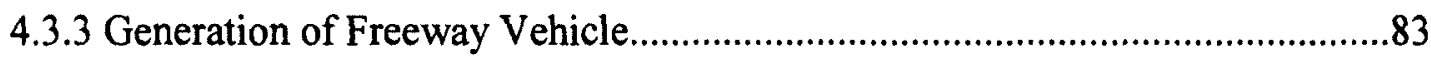

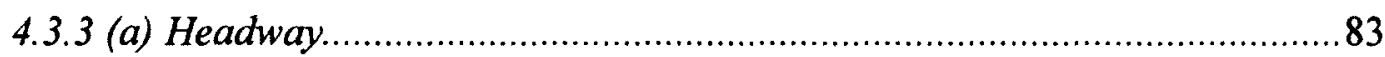

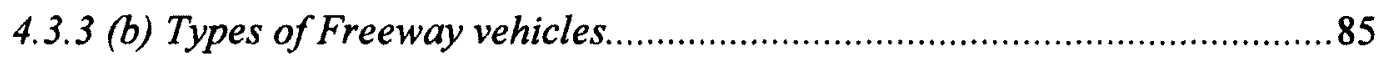

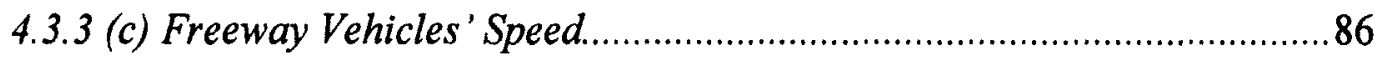

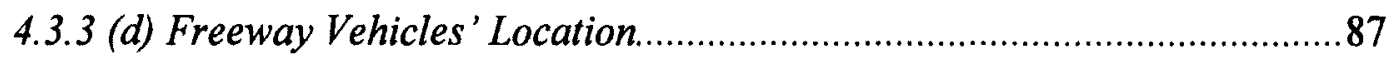

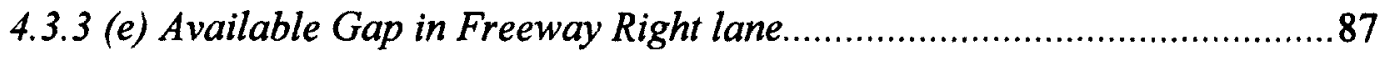

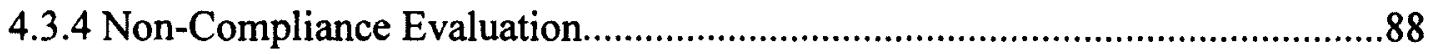

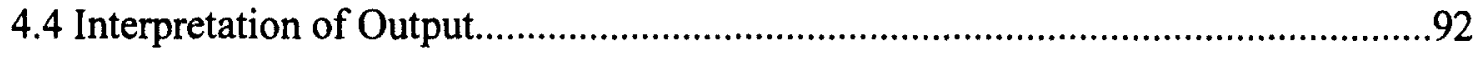

5. REGRESSION ANALYSIS AND SIMULATION PARAMETERS.......................94 


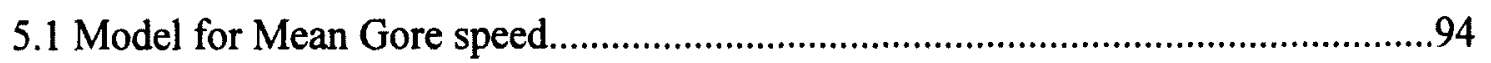

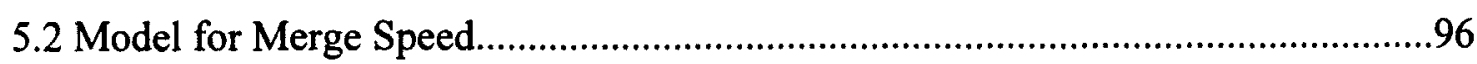

5.3 Model for Acceleration Rate..............................................................................96

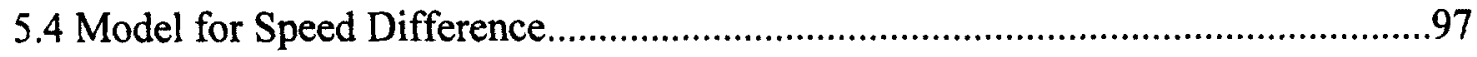

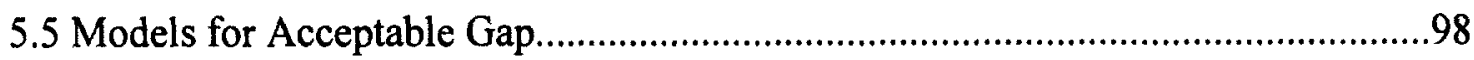

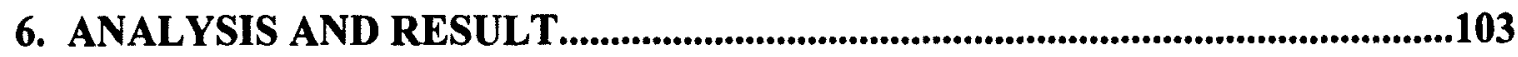

6.1 Required Number of Model Iterations..............................................................103

6.2 Probability of Non-compliance (PNC) at Study Sites..........................................105

6.3 Collisions and PNC ...................................................................................110

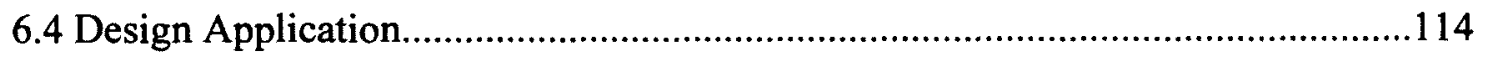

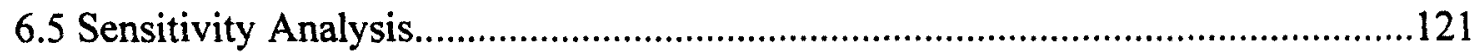

6.5.1 Change in Acceleration Rate.........................................................................124

6.5.2 Change in Gore Speed...........................................................................126

6.5.3 Change in Freeway Right Lane Traffic Volume...........................................128

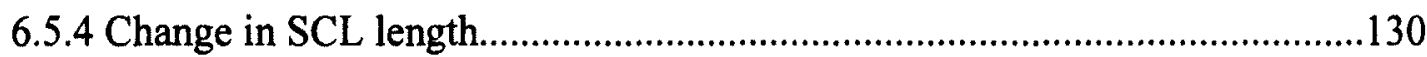

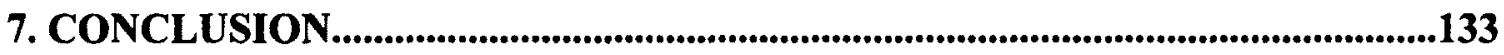

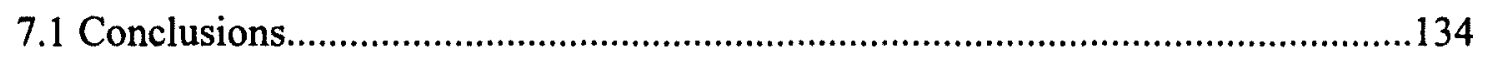

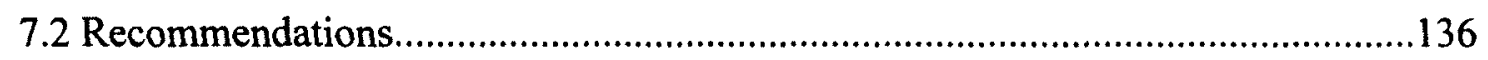

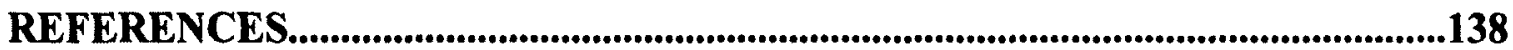

APPENDIX A 
CORRELATION COEFFICIENTS OF PARAMETERS AT EIGHT SCL

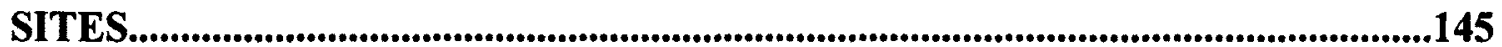

APPENDIX B

SUMMARY OF PARAMETERS AT EIGHT SCL SITES..........................................147

APPENDIX C

SUMMARY OF ACCEPTED GAPS AT EIGHT SCL SITES....................................150

APPENDIX D

PASSENGER CAR LENGTHS............................................................................152 


\section{LIST OF TABLES}

Table 2.1 AASHTO (2011) Guidelines for Minimum Acceleration Lane Lengths (Meter)

Table 2.2 TAC (1999) Guidelines for Minimum Entrance Acceleration Lengths (Meter)

(TAC 1999, Table 2.4.6.5) 12

Table 3.1: Description of Data Collection Sites [Source: Ahammed 2005].....................35

Table 3.2: Geometric Features of Selected Eight SCLs [Source: Ahammed ..................37

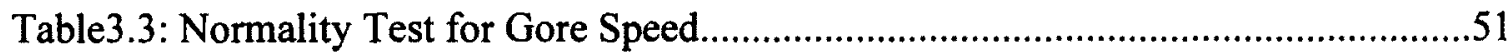

Table 3.4: Normality Test for Merge Speed.........................................................52

Table 3.5: Normality Test for Freeway Speed....................................................52

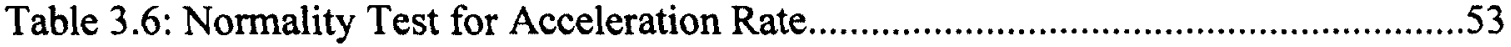

Table 3.7: Summary of Correlation Coefficients among Parameters...............................54

Table 3.8: The Number of Segments for Each SCLs..................................................58

Table 3.9: The Normality Test Results for Each Segment of Eight SCLs.....................61

Table 3.10: Test Summary for Comparison of Accepted Gap Distribution across Eight

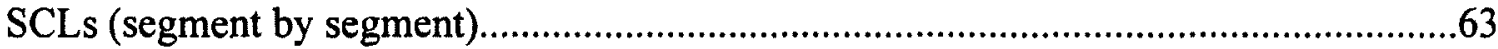

Table 3.11: Test Summary for Pair wise Comparison of Gap Data Samples ..................65

Table 5.1: Model Summary for Acceptable Gap Size at Segment 1on SCL...................99

Table 5.2: Model Summary for Acceptable Gap Size at Segment 2 on SCL.................100

Table 5.3: Model Summary for Acceptable Gap Size at Segment 3 on SCL..................100

Table 5.4: Model Summary for Acceptable Gap Size at Segment 4 on SCL.................101

Table 6.1: Number of SCL Vehicles Generated.......................................................105 
Table 6.2: Input Parameters and Output of the Model for Eight SCLs............................107

Table 6.3: Percentage of SCL Vehicles Having Different PNC Range...........................109

Table 6.4: Mean and Standard deviation of PNC for SCL Lengths Recommended by

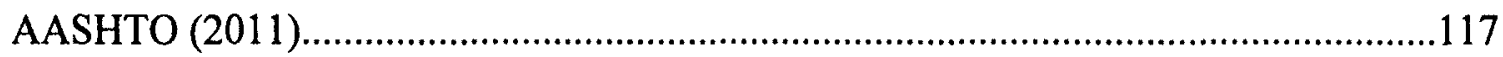

Table 6.5: Mean and Standard deviation of PNC for SCL lengths Recommended by TAC

(1999)

Table 6.6: The Values of Input Parameters for the Sensitivity Analysis.........................123

Table 6.7: The Values of Mean PNC for Corresponding Assigned Input Parameters....123 


\section{LIST OF FIGURES}

Figure 2.1: Typical gore area. .9

Figure 2.2: Parallel and Taper type speed change lane (TAC 1999, 2.4.6.1).................10

Figure 2.3: Prediction of probability of hazard in terms of supply and demand [Adapted

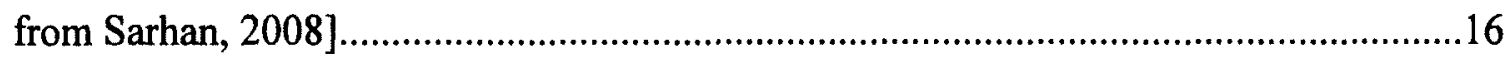

Figure 2.4: Illustration of lag gap, lead gap, lead vehicle and lag vehicle......................23

Figure 3.1: Map of the study area [Source: Google map] .........................................33

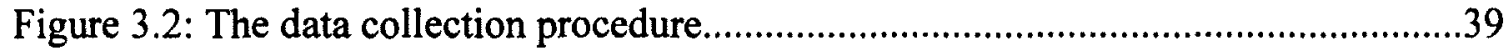

Figure 3.3: Comparison of mean gore speed among all SCLs...................................42

Figure 3.4: Comparison of $85^{\text {th }}$ percentile gore speed among all SCLs..........................43

Figure 3.5: Comparison of standard deviation of gore speed among all SCLs...............43

Figure 3.6: Comparison of mean merge speed among all SCLs.................................45

Figure 3.7: Comparison of $85^{\text {th }}$ percentile merge speed among all SCLs.......................45

Figure 3.8: Comparison of standard deviation of merge speed among all SCLs.............46

Figure 3.9: Comparison of mean overall acceleration rate among all SCLs...................47

Figure 3.10: Comparison of $85^{\text {th }}$ percentile overall acceleration rate among all SCLs.....48

Figure 3.11: Standard deviation of overall acceleration rate among eight SCLs............ 48

Figure 3.12: Comparison of freeway RL speed among eight SCLs............................49

Figure 3.13: Comparison of $85^{\text {th }}$ percentile freeway speed among all SCLs...................50

Figure 3.14: Comparison of standard deviation of freeway RL speed among all SCLs...50

Figure 3.15: Hourly traffic volume $(\mathrm{pc} / \mathrm{h} / \mathrm{ln})$ on SCL and freeway right lane.................55

Figure 3.16: Percentage of passenger cars and heavy vehicles on the SCL...................56

Figure 3.17: Percentage of passenger cars and heavy vehicles on the freeway right ane.57 


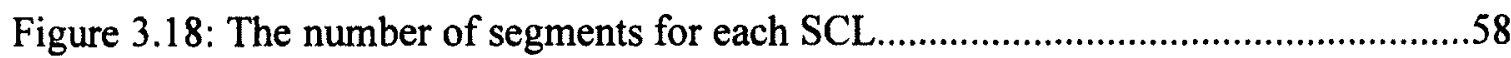

Figure 3.19: Mean accepted gap at different segments of eight SCLs.............................59

Figure 3.20: Collision frequency on the acceleration lane.............................................66

Figure 4.1: The relationship between headway and available gap..................................73

Figure 4.2: Flow chart of the simulation logic...............................................................77

Figure 4.3: Illustration of linear regression assumption..................................................82

Figure 4.4: Different passenger cars length...................................................................86

Figure 4.5: The concept of calculating probability of uncomfortable merging................90

Figure 6.1: Percentage of SCL drivers having different PNC for study sites................. 110

Figure 6.2: Mean PNC vs number of collisions at each study site.................................112

Figure 6.3: Percentage of SCL vehicles having PNC ]0 1] vs number of collision.........112

Figure 6.4: Percentage of SCL vehicles having PNC] 0.11 1] vs number of collision.....113

Figure 6.5: Percentage of SCL vehicles having PNC ]0.9 1] vs number of collision.....113

Figure 6.6: Percentage of SCL vehicles having $\mathrm{PNC}=0$ against number of collision. 114

Figure 6.7: Comparison of the mean PNC for different traffic volume (AASHTO 2011).

Figure 6.8: Comparison of the mean PNC for different traffic volume (TAC 1999).... 120

Figure 6.9: Mean PNC vs change in mean acceleration rate (\%).................................125

Figure 6.10: Change in mean PNC vs change in mean accelration rate (\%)..................125

Figure 6.11: Mean PNC vs change in mean gore speed (\%)..........................................127

Figure 6.12: Change in Mean PNC vs change in mean gore speed (\%)........................127

Figure 6.13: Mean PNC vs change in traffic volume...............................................128

Figure 6.14: Change in Mean PNC vs change in traffic volume...................................129 
Figure 6.15: Mean PNC vs different traffic volume...................................................129

Figure 6.16: Mean PNC vs change in SCL length.....................................................130

Figure 6.17: Change in mean PNC vs. change in SCL length (\%)................................131

Figure 6.18: The mean PNC vs. different SCL length under different traffic volume....132 


\section{LIST OF SYMBOLS}

$A A S H T O=$ American Association of State Highway and Transportation Officials.

$D=$ Demand

$D L C=$ Discretionary lane change.

FOSM $=$ First-order second-moment method

FORM $=$ First-order reliability method

$G(X)=$ Performance or limit state function.

$H C M=$ Highway Capacity Manual.

$M L C=$ Mandatory lane change

$R^{2}=$ Coefficient of determination

$P N C=$ Probability of non-compliance

$P O H=$ Probability of hazard.

$S=$ Supply

Stdev $=$ Standard deviation

$S D=$ Sight distance

$S O R M=$ Second-order reliability method

$S C L=$ Speed-change lane. 
$S D=$ Standard deviation

$S E E=$ Standard error of estimate.

$T A C=$ Transportation Association of Canada.

$T C o l=$ Total collisions on the section along the SCL.

$T c o l A c c=$ Total collision on acceleration lane.

$V_{G}=$ Speed at the gore, $(\mathrm{km} / \mathrm{h})$.

$V_{M}=$ Speed at the merge point, $(\mathrm{km} / \mathrm{h})$.

$V_{R L}=$ Freeway right lane vehicle speed $(\mathrm{km} / \mathrm{h})$.

$V_{G, 85 t h}=85^{\text {th }}$ percentile of gore speed, $(\mathrm{m} / \mathrm{s})$.

$a=$ Overall acceleration rate $\left(\mathrm{m} / \mathrm{s}^{2}\right)$.

$\mu_{V, G}=$ Mean gore speed $(\mathrm{km} / \mathrm{h})$.

$\mu_{V, M}=$ Mean merge speed, $(\mathrm{km} / \mathrm{h})$.

$\mu_{a}=$ Mean acceleration rate, $\left(\mathrm{m} / \mathrm{s}^{2}\right)$.

$\mu_{\mu_{V, M}-\mu_{V, G}}=$ Mean speed difference, $(\mathrm{km} / \mathrm{h})$.

$\sigma_{\sigma_{V, M}-\sigma_{V, G}}=$ Mean speed difference, $(\mathrm{km} / \mathrm{h})$. 
$\mu_{G A P, \text { Segment } 1}=$ Predicted mean acceptable gap (s) at segment 1 .

$\mu_{G A P, \text { Segment } 2}=$ Predicted mean acceptable gap (s) at segment 2 .

$\mu_{G A P, S e g m e n t 3}=$ Predicted mean acceptable gap (s) at segment 3.

$\mu_{G A P, S e g m e n t 4}=$ Predicted mean acceptable gap (s) at segment 4.

$\mu_{A C C, G a p}=$ Acceptable gap for merging (sec).

$\sigma_{V, G}=$ Standard deviation of gore speed, $(\mathrm{km} / \mathrm{h})$.

$\sigma_{V, M}=$ Standard deviation of merge speed, $(\mathrm{km} / \mathrm{h})$.

$\sigma_{a}=$ Standard deviation of acceleration rate, $\left(\mathrm{m} / \mathrm{s}^{2}\right)$.

] 0 1] = Range of PNC value greater than zero and equal to or less than one.

] 0.11 ] = Range of PNC value greater than 0.1 and equal to or less than one.

] 0.21 ] = Range of PNC value greater than 0.2 and equal to or less than one.

] 0.3 1] = Range of PNC value greater than 0.3 and equal to or less than one.

] 0.41 1] = Range of PNC value greater than 0.4 and equal to or less than one.

] 0.51 1] = Range of PNC value greater than 0.5 and equal to or less than one. 
] 0.61$]$ = Range of PNC value greater than 0.6 and equal to or less than one

] 0.71 1] = Range of PNC value greater than 0.7 and equal to or less than one.

] 0.8 1] = Range of PNC value greater than 0.8 and equal to or less than one.

] 0.9 1] = Range of PNC value greater than 0.9 and equal to or less than one. 


\section{INTRODUCTION}

Road network is the major element in any transportation system and it has manifold impact on any country's economic and social life. Transportation engineers are facing challenges as the number of collisions are increasing on the road network and causing great loss of human lives and property damages. According to the National Highway Traffic Safety Administration (NHTSA 2010), more than 5.42 million motor vehicle collisions occurred on roadways, about 32,885 people died in motor vehicle collisions and around 2.24 million people were injured in the United States in 2010 (Traffic Safety Facts, 2012). Transport Canada also reported that there were 2,011 motor vehicle fatal collisions and 123,192 personal injury collisions occurred on roadways in 2009 (Canadian Motor Vehicle Traffic Collision Statistics, 2009). Therefore, the main focus of the transportation experts is to diagnose and identify the causes of collisions as well as to find possible remedies to minimize the problem. Fuller et al. (2002) stated that the major cause of collisions on the road network is due to the driving errors which can be minimized if the drivers' behaviour could be properly understood.

Based on the highway classification system, roadways are classified into four main categories: locals, collectors, arterials, and freeways. The Transportation Association of Canada (TAC 1999) has included two more categories namely public lanes and expressways. The primary functions of all roads are to provide mobility and land access at various degrees corresponding to the road classification. Freeways, arterials, and expressways are used exclusively for through traffic movement while public 
lanes and local roads provide mainly land access service. Because of the full control of access on freeways, traffic movement into and out of a freeway is allowed only at interchanges. Because of the intensity of tasks and complexity of manoeuvres to be performed by the drivers at the interchange areas, these areas have the inherent potential for increasing driver error, driver workload, and traffic collisions. McCartt et al. (2004) mentioned that according to the U.S Fatality Analysis Reporting Systems (FARS) and General Estimates System (GES), there were approximately 82,609 reported collisions at interchanges in 2001. According to this article, even though interchanges cover only less than $5 \%$ of the total freeway space, around $18 \%$ of all interstate collisions, $17 \%$ of injury collisions, and $11 \%$ of fatal collisions occurred at interchanges.

An interchange consists of loops and ramps with speed change lanes. A speed change lane (SCL) at the ramp terminal is a secondary lane used mainly for acceleration or deceleration in order to enter onto or leave the freeway. At the entrance ramp terminals, merging is generally executed by moving the vehicle laterally into a gap between the through vehicles without disrupting or interrupting the through traffic. During the merging manoeuvre, a merging driver needs to perform a series of multiple tasks: observe traffic action in the adjacent freeway rightmost lane, accelerate the vehicle, look for the available gap, monitor the remaining length of acceleration lane, and simultaneously keep a safe distance from the front vehicle on the SCL. When an acceptable merging speed is reached and an acceptable gap is found, the merging driver merges onto the freeway. If the merging driver cannot find any acceptable gap over the entire length of SCL, the driver would perform a forced merge during which drivers on 
the freeway through lane would have to accommodate the merging vehicle through lane changes or speed adjustment.

\subsection{Problem Identification}

In the current design guides, such as American Association of State Highway and Transportation Officials (AASHTO 2011) and Transportation Association of Canada (TAC 1999), entrance SCL lengths are recommended based mainly on the acceleration performance of SCL vehicles. The design guides considered the vehicle's entrance speed or initial speed, merge speed, and acceleration rate as the design inputs for the determination of SCL length. However, the AASHTO (2011) emphasizes the need to provide SCL length that would permit drivers of the entering vehicles to manoeuvre into an acceptable gap. Therefore, a minimum gap acceptance length of $150 \mathrm{~m}$ is specified in the AASHTO (2011). Yet, the basis for recommending this minimum gap acceptance length is not clear. Similarly, although the TAC (1999) guide lists merging with through traffic as one of the criteria in determining the SCL length, it has not explained how this criterion has been considered in the guide.

The current design guides have also been criticized for adopting a deterministic approach in which a single and usually conservative design value is selected for each parameter. Usually, the selected value of each design parameter is conservative, such as a high percentile speed or a low percentile acceleration rate. The accumulation of such conservative assumptions may create design scenarios that correspond to cases that do 
not exist in real life and can produce an overestimated design (Ismail et al. 2009, Sarhan et al. 2008).

Therefore, the length of an acceleration speed change lanes (SCL) at the entrance ramp terminals should be designed to allow drivers to accelerate to a proper merging speed, search for an acceptable gap in the freeway traffic, and perform a comfortable merge. On the other hand, an inadequate SCL length will force SCL drivers to merge onto the freeway at a relatively low speed or short gap or will force the freeway drivers to adjust their speed or perform a lane change to accommodate the merging vehicles.

\subsection{Objective and Scope}

The objective of this study is to develop a realistic, reliability-based simulation model of the merging process onto the freeways.

The developed model adopts the probabilistic design approach, where each design parameter is considered as a full distribution rather than a single value. The model simulates the merging process from the SCL to freeway considering the drivers' acceleration and gap searching behaviour. The adequacy of SCL length for comfortable merging is checked in the model and the output of the model would reflect the adequacy of SCL based on the expected drivers' acceleration and merging behavior. The model checks for two criteria to determine the probability of uncomfortable merging for any SCL vehicle: (a) whether the SCL vehicle can attain an acceptable speed before merging, 
and (b) whether there is an acceptable gap for merging in the adjacent freeway lane. In this research, the probability of uncomfortable merging is referred to as probability of non-compliance (PNC) which will be explained later. In order to develop the simulation model, the following associated tasks needed to be done:

- To review the related studies on the design of acceleration lane, existing models for gap acceptance behaviour of driver during merging, and the probabilistic approach in the highway geometric design.

- To collect gap data accepted by the driver at different locations of SCL from the study site.

- To propose a methodology for the determination of PNC of each SCL vehicle after accelerating and searching gap for a specific SCL length.

- To check the trend of PNC measures associated with the SCL length against collision frequency.

- To present a case study for the determination of PNC associated with the SCL lengths provided in AASHTO (2011) and TAC (1999) design guides.

- To examine the sensitivity of the model output for the effect of different input parameters.

The proposed model is only applied to single lane SCL with limited length that ended with a taper. In this model, freeway vehicles do not perform any accommodating manoeuvres to allow SCL vehicle to merge onto the freeways. 


\subsection{Thesis Organization}

An introduction and objective of the research have been already presented in this chapter.

In Chapter 2, a literature review of SCL design, reliability-based approach in highway geometric design, and existing studies for freeway merging behavior on SCL will be presented. Chapter 3 will provide information about the study area and data collection procedure. Parameters selection and characteristics of parameters will also be presented in this chapter. Chapter 4 will provide a detailed description of the proposed model. Processing of parameters in order to be incorporated in the model will be presented in Chapter 5. Findings of the research and a design application of the proposed model will be provided in Chapter 6. Conclusions and some recommendations for future research will be given in Chapter 8 . 


\section{LITERATURE REVIEW}

This chapter presents a review of the literature related to the design of SCL, driver behaviour while merging from the SCL to freeway, and reliability-based approach applied in the highway geometric design. Section 2.1 presents a brief review of the SCL design criteria as stated by the American Association of State Highway and Transportation Officials (AASHTO 2011) and Transportation Association of Canada

(TAC 1999). Section 2.2 presents a review of the previous studies where the probabilistic approach has been considered for the design of highway components. Section 2.3 presents literature review related to the drivers' merging behaviour on the SCL.

\subsection{Review of Current SCL Design Practice}

\subsubsection{Definitions}

This section presents a brief overview of the design elements at the ramp terminal.

\section{Interchange}

According to TAC (1999), an interchange is a system that interconnects roadways or highways with one or more grade separations. The purpose of this system is to provide traffic movement on different levels of roadways or highways. According to AASHTO (2011), interchange configurations vary widely in shape and scope depending upon the 
existing site condition, cost, safety, and efficiency. In this regard, TAC (1999) stated that the selection of interchange configuration depends upon the adjacent land use patterns, traffic volume, traffic mix, traffic control devices, topography of the area, availability of right of way, environmental, and economic factors etc.

\section{Ramp}

According to TAC (1999), a ramp connects two grade-separated throughways. A ramp has three components namely entrance ramp terminal, exit ramp terminal, and ramp proper. Ramp terminal travels adjacent to the throughways. It includes speed change lane, islands and taper portion.

\section{Gores}

The gore area is located as an area where freeway shoulder and ramp shoulder intersect. Physical nose is located where the distance between ramp shoulder and freeway shoulder ranges from $1.2 \mathrm{~m}$ to $2.4 \mathrm{~m}$. Physical nose is generally located upstream of the gore area. Figure 2.1 shows a typical entrance gore area which is drawn on the basis of exit gore area provided in AASHTO 2011, Figure 10-61. 


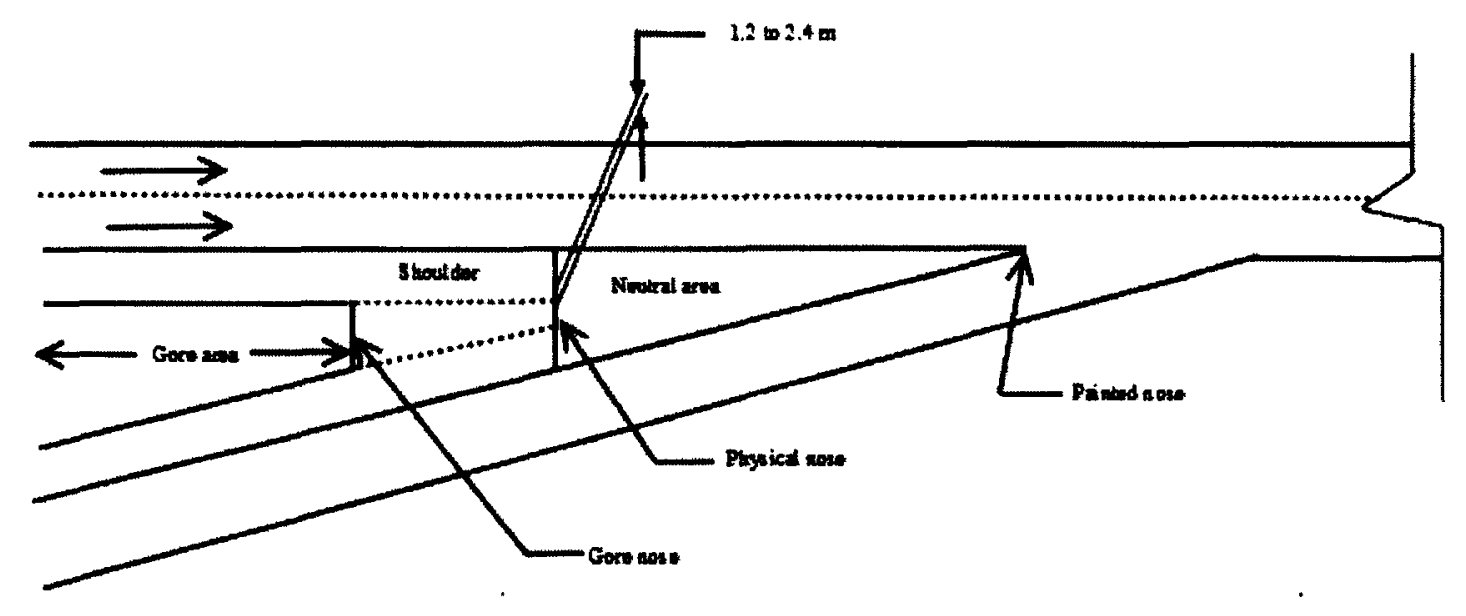

Figure 2.1: Typical gore area (Adapted from AASHTO 2011, Figure 10-61)

\section{Speed Change Lane}

Speed change lane (SCL) is an auxiliary lane used by drivers for the purpose of acceleration or deceleration. It is termed as acceleration lane when drivers enter from roadways to high speed freeways. In this case, drivers accelerate their vehicles in order to attain their desired speed. It is termed as deceleration lane when drivers leave the freeway. According to TAC (1999), there are two types of SCL: parallel and taper. The parallel SCL length is measured from the entrance gore to beginning of the taper, while the taper SCL length is measured from the entrance gore to the point where SCL width is $3.5 \mathrm{~m}$. Figure 2.2 shows parallel and taper type SCL length. 

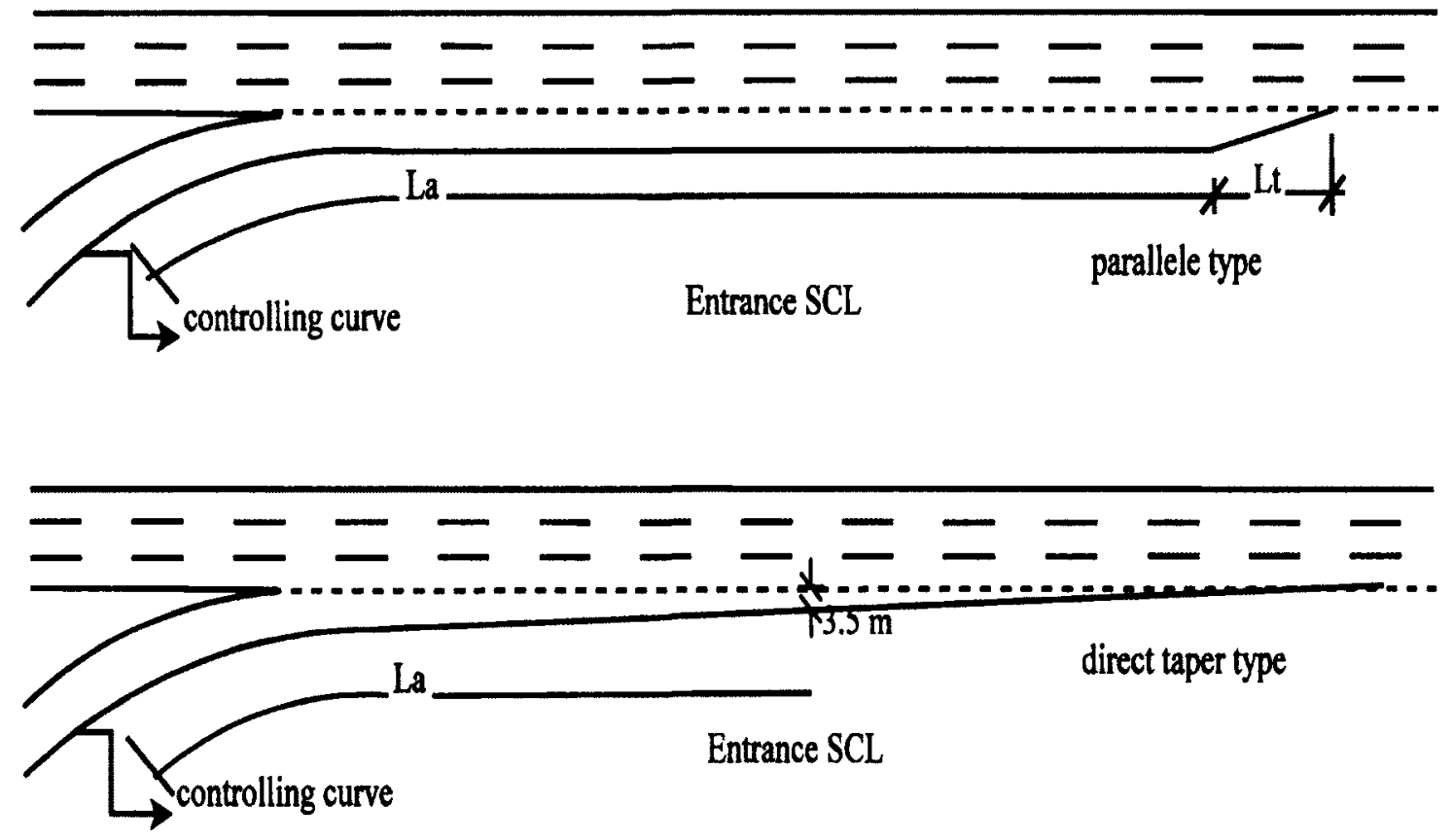

Figure 2.2: Parallel and Taper type speed change lane (TAC 1999, 2.4.6.1)

\subsubsection{Current Design Guides for SCL length}

SCL length should be adequate to allow drivers to accelerate smoothly in order to attain speed close to freeway speed and find a suitable gap for merging. Tables 2.1 and 2.2 show minimum speed change lengths (SCL) as recommended in AASHTO (2011) and TAC (1999). 
Table 2.1 AASHTO (2011) Guidelines for Minimum Acceleration Lane Lengths (Meter)

\begin{tabular}{|c|c|c|c|c|c|c|c|c|c|}
\hline \multicolumn{10}{|c|}{ Metric } \\
\hline \multicolumn{10}{|c|}{ Acceleration length, $L(\mathrm{~m})$ for entrance curve design speed $(\mathrm{km} / \mathrm{h})$} \\
\hline \multicolumn{2}{|c|}{ Highway } & $\begin{array}{c}\text { Stop } \\
\text { Condition }\end{array}$ & 20 & 30 & 40 & 50 & 60 & 70 & 80 \\
\hline \multirow{2}{*}{$\begin{array}{c}\text { Design } \\
\text { Speed, } \\
\mathrm{V} \\
(\mathrm{km} / \mathrm{h})\end{array}$} & \multirow{2}{*}{$\begin{array}{c}\text { Speed } \\
\text { Reached, Va } \\
(\mathrm{km} / \mathrm{h})\end{array}$} & \multicolumn{8}{|c|}{$\begin{array}{l}\text { And initial speed, } \\
\mathrm{Va}^{\prime}(\mathrm{km} / \mathrm{h})\end{array}$} \\
\hline & & 0 & 20 & 28 & 35 & 42 & 51 & 63 & 70 \\
\hline 60 & 45 & 95 & 80 & 65 & 45 & - & - & - & - \\
\hline 70 & 53 & 150 & 130 & 110 & 90 & 65 & - & - & - \\
\hline 80 & 60 & 200 & 180 & 165 & 145 & 115 & 65 & - & - \\
\hline 90 & 67 & 260 & 245 & 225 & 205 & 175 & 125 & 35 & - \\
\hline 100 & 74 & 345 & 325 & 305 & 285 & 255 & 205 & 110 & 40 \\
\hline 110 & 81 & 430 & 410 & 390 & 370 & 340 & 290 & 200 & 125 \\
\hline 120 & 88 & 545 & 530 & 515 & 490 & 480 & 410 & 325 & 245 \\
\hline Note: & Uniform $50: 1$ & to $70: 1$ taper & Ire rec & men & $\mathrm{d}$ wh & & & & \\
\hline
\end{tabular}


Table 2.2 TAC (1999) Guidelines for Minimum Entrance Acceleration Lengths (Meter)

(TAC 1999, Table 2.4.6.5)

\begin{tabular}{|c|c|c|c|c|c|c|c|c|c|c|}
\hline \multicolumn{2}{|c|}{$\begin{array}{c}\text { Speed of Roadway } \\
(\mathrm{km} / \mathrm{h})\end{array}$} & \multirow{3}{*}{$\begin{array}{l}\text { Length } \\
\text { of } \\
\text { Taper } \\
\text { (m) }\end{array}$} & \multirow{2}{*}{\multicolumn{8}{|c|}{$\begin{array}{l}\text { Length of Acceleration Lane excluding Taper (m) } \\
\text { La } \\
\text { Design Speed of Turning Roadway Curve }(\mathrm{km} / \mathrm{h})\end{array}$}} \\
\hline \multirow{2}{*}{$\begin{array}{l}\text { Design } \\
\text { Speed }\end{array}$} & \multirow{2}{*}{$\begin{array}{c}\text { Assumed } \\
\text { Operating } \\
\text { Speed }\end{array}$} & & & & & & & & & \\
\hline & & & $\begin{array}{l}\text { Stop } \\
\text { Condition }\end{array}$ & 20 & 30 & 40 & 50 & 60 & 70 & 80 \\
\hline 60 & $55-60$ & 55 & $\begin{array}{l}85- \\
115\end{array}$ & $\begin{array}{l}70- \\
100\end{array}$ & $\begin{array}{l}60- \\
80\end{array}$ & $\begin{array}{l}45- \\
60\end{array}$ & $\begin{array}{l}20- \\
35\end{array}$ & - & - & - \\
\hline 70 & $63-70$ & 65 & $\begin{array}{c}120 \\
- \\
160\end{array}$ & $\begin{array}{c}115 \\
- \\
150\end{array}$ & $\begin{array}{c}100 \\
- \\
135\end{array}$ & $\begin{array}{c}80 \\
- \\
115\end{array}$ & $\begin{array}{l}50 \\
- \\
85\end{array}$ & $\begin{array}{l}15 \\
- \\
40\end{array}$ & - & - \\
\hline 80 & $70-80$ & 70 & $\begin{array}{c}160 \\
- \\
225\end{array}$ & $\begin{array}{c}150 \\
- \\
215\end{array}$ & $\begin{array}{c}130 \\
- \\
200\end{array}$ & $\begin{array}{c}115 \\
- \\
185\end{array}$ & $\begin{array}{c}85 \\
- \\
160\end{array}$ & $\begin{array}{c}40 \\
- \\
100\end{array}$ & - & - \\
\hline 90 & $77-90$ & 80 & $\begin{array}{l}215 \\
- \\
325\end{array}$ & $\begin{array}{c}200 \\
- \\
310\end{array}$ & $\begin{array}{c}180 \\
- \\
300\end{array}$ & $\begin{array}{c}160 \\
- \\
285\end{array}$ & $\begin{array}{c}140 \\
- \\
250\end{array}$ & $\begin{array}{c}50 \\
- \\
200\end{array}$ & $\begin{array}{c}40 \\
- \\
145\end{array}$ & - \\
\hline 100 & $85-100$ & 85 & $\begin{array}{c}275 \\
- \\
450\end{array}$ & $\begin{array}{c}250 \\
- \\
440\end{array}$ & $\begin{array}{c}240 \\
- \\
420\end{array}$ & $\begin{array}{l}225 \\
- \\
405\end{array}$ & $\begin{array}{c}200 \\
- \\
375\end{array}$ & $\begin{array}{c}140 \\
- \\
325\end{array}$ & $\begin{array}{c}100 \\
- \\
285\end{array}$ & $\begin{array}{c}40 \\
- \\
230\end{array}$ \\
\hline 110 & $91-110$ & 90 & $\begin{array}{c}330 \\
- \\
650 \\
\end{array}$ & $\begin{array}{c}320 \\
- \\
645\end{array}$ & $\begin{array}{c}305 \\
- \\
630 \\
\end{array}$ & $\begin{array}{c}290 \\
- \\
600\end{array}$ & $\begin{array}{c}260 \\
- \\
575\end{array}$ & $\begin{array}{c}210 \\
- \\
525\end{array}$ & $\begin{array}{c}150 \\
- \\
475\end{array}$ & $\begin{array}{c}100 \\
- \\
410\end{array}$ \\
\hline 120 & $98-120$ & 95 & $\begin{array}{c}410 \\
- \\
730 \\
\end{array}$ & $\begin{array}{c}400 \\
- \\
725\end{array}$ & $\begin{array}{c}375 \\
- \\
710\end{array}$ & $\begin{array}{c}370 \\
- \\
690\end{array}$ & $\begin{array}{c}340 \\
- \\
660 \\
\end{array}$ & $\begin{array}{c}285 \\
- \\
590 \\
\end{array}$ & $\begin{array}{l}250 \\
- \\
515\end{array}$ & $\begin{array}{c}195 \\
- \\
430 \\
\end{array}$ \\
\hline
\end{tabular}


Both the design guides consider three variables to calculate the SCL length: operating speed of freeway, controlling curve speed of ramp and acceleration rate. It is observed from Tables 2.1 and 2.2 that TAC (1999) allows a range of SCL length corresponding to a range of operating speed while only one design SCL length is mentioned in AASHTO (2011) for each operating speed. It is also observed from the design tables that upper limit of SCL length as recommended in TAC (1999) is longer than that in AASHTO (2011).

\subsubsection{Previous Research Based on Current Design Assumptions}

Fitzpatrick et al. (2007) stated that the following formula was used to calculate the acceleration length in the AASHTO (1965) design guide.

$L=\frac{\left(0.278 V_{1}\right)^{2}-\left(0.278 V_{2}\right)^{2}}{2 a}$

Where

$L=$ minimum acceleration length $(\mathrm{m})$.

$V_{l}=$ speed of highway $(\mathrm{km} / \mathrm{h})$.

$V_{2}=$ speed of entrance curve $(\mathrm{km} / \mathrm{h})$.

$a=$ acceleration rate $\left(\mathrm{m} / \mathrm{s}^{2}\right)$

AASHTO (2011) assumes operating freeway speed which varies from 23 to 32 $\mathrm{km} / \mathrm{h}$ lower than the design speed of freeway, while TAC (1999) considers operating speed that are 13 to $25 \mathrm{~km} / \mathrm{h}$ lower than the design speed of freeway. However, 
Seneviratene et al. (1992) mentioned that operating freeway speed is close to or sometimes exceeds the design speed of freeway. Similarly, Ahammed et al. (2006) observed that the $85^{\text {th }}$ percentile merge speed for passenger cars is $105 \mathrm{~km} / \mathrm{h}$ for a posted speed limit of $100 \mathrm{~km} / \mathrm{h}$. Thus, the assumption used in the current design guides would underestimate the required acceleration length.

Fitzpatrick et al. (2007) revealed that the current design guides assume design value of acceleration rate from 1930-1940 studies. However, the performance of vehicles has been improving day by day. Fitzpatrick et al. (2007) also suggested acceleration lengths based on the most recent research findings and realistic vehicle performance. . The suggested SCL lengths were found longer than corresponding length in AASHTO (2004) by as much as $153 \mathrm{~m}$.

Ahammed et al. (2008) collected speed data from 23 entrance SCLs on 15 interchanges and observed that the distance travelled by the drivers is used for acceleration and for searching a reasonable gap to merge onto the freeway. However, the design guides do not consider gap searching needs in determining the SCL length.

\subsection{Reliability Approach in Highway Geometric Design}

\subsubsection{Concept of Reliability Analysis}

The main purpose of reliability theory is to assess the uncertainty of an engineering system by observing the ability of the system to accommodate a specific purpose according to the operational condition of that system. As stated by Ismail (2009), the 
reliability analysis deals with the $\mathrm{N}$ dimensional vector of input variables $X=x_{1}, x_{2}, x_{3}, \ldots$, $x_{n}$. using limit state function or performance function. The limit state function or performance function is generally expressed in terms of difference between supply and demand. Both supply and demand depend upon the number of input variables which vary in terms of location, time and other conditions. The variability of input parameters are captured by expressing each input parameter $\left(x_{1}, x_{2}, x_{3}, \ldots, x_{n}\right)$ in terms of its probability distribution function $f(x)$. The reliability analysis evaluates the probability of the system failure and system survival. According to Sarhan (2008),"the probability of failure generally occurs in the reliability system when both supply and demand distributions overlap with a probability of having the value of supply less than demand. Figure 2.3 shows that for a given value of supply $y$, the probability of hazard is the product of density function of $\mathrm{f}_{\mathrm{s}}(\mathrm{y})$ by the probability $\left[1-\mathrm{F}_{\mathrm{D}}(y)\right]$ that the demand is exceeding this y value." Mathematically

$$
P O H=\int_{0}^{\infty} f_{s}(y)\left[1-\mathrm{F}_{\mathrm{D}}(y)\right] \mathrm{dy}
$$




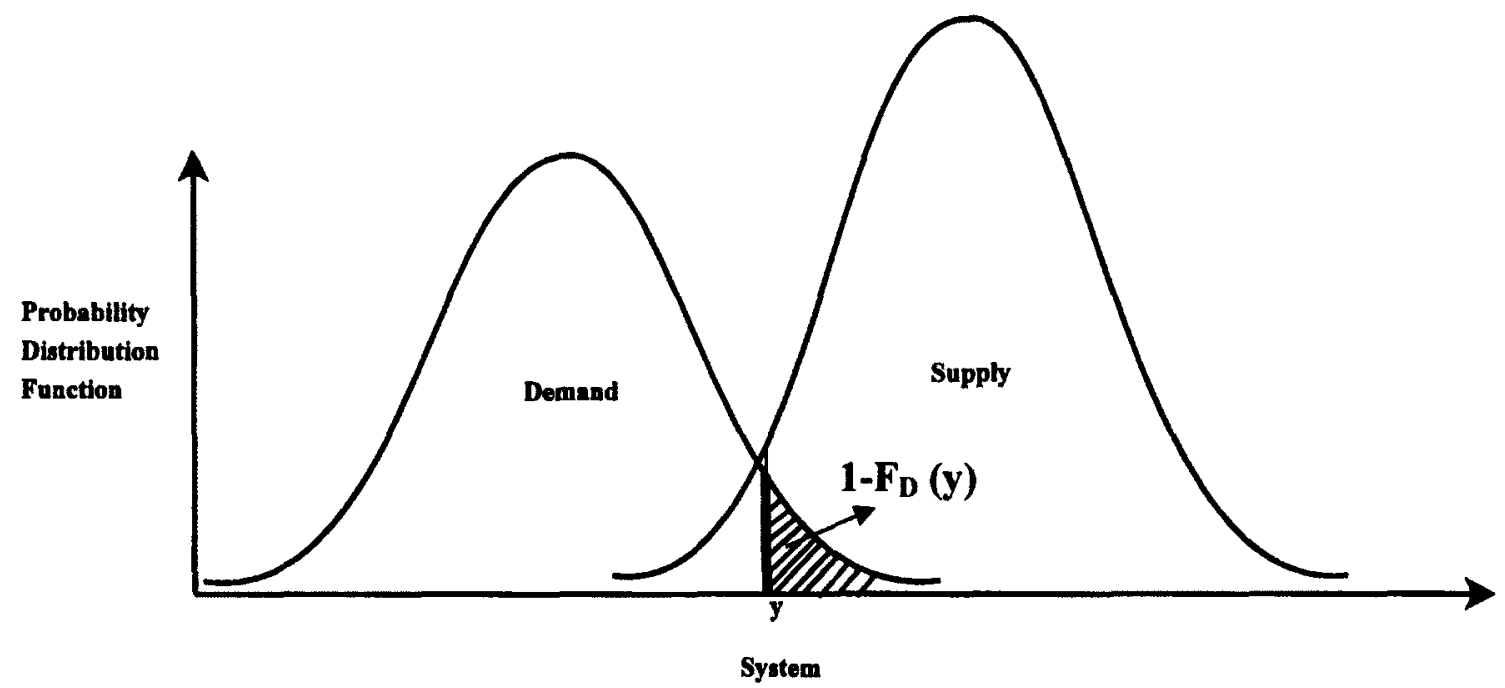

Figure 2.3: Prediction of probability of hazard in terms of supply and demand

[Adapted from Sarhan, 2008]

\subsubsection{Types of Reliability Analysis}

Harr (1987) stated that existing reliability analysis lies on three categories: (i) exact method, (iii) first-order second-moment method (FOSM), and (iii) point-estimate method.

The exact method uses the shape of the distribution of component variables in the performance function. This method is conducted using numerical and simulation techniques (Evans, 1972; and Marek et al., 1995). The simulation technique such as Monte Carlo simulation method is a popular reliability approach in transportation related research. Detailed information of the method will be presented in Chapter 5 .

Instead of using the shape of the distribution of performance function, only mean and variance of the distribution of performance function have been used in the first- 
order-second moment method (FOSM) (Ditlevsen, 1981; Hasofer et al., 1974). This reliability method is simple and straightforward as closed-form mathematics is approximated using truncated Taylor series expansion. Equation 2.3 shows truncated Taylor series expansion and Equation 2.4 shows the mean of the distribution which is approximated taking only first term of truncated Taylor series expansion. Equation 2.5 shows the variance of distribution.

$f\left(x_{1}, x_{2} \ldots \ldots x_{n}\right)=f\left(\bar{x}_{1}, \bar{x}_{2}, \bar{x}_{3}, \ldots \ldots . \bar{x}_{n}\right)+\frac{1}{1 !} \sum_{i=1}^{n}\left(x_{i}-\bar{x}_{i}\right)\left(\frac{\partial f}{\partial x_{l}}\right)+\frac{1}{2 !} \sum_{i=1}^{n} \sum_{j=1}^{n}\left(x_{i}-\right.$

$\left.\bar{x}_{i}\right)\left(x_{j}+\bar{x}_{j}\right)\left(\frac{\partial^{2} f}{\partial x_{i} \partial x_{j}}\right)+\ldots$

Mean $=E(y)=f\left(\mu_{x_{1}}, \mu_{x_{2}}, \mu_{x_{3}}, \ldots \ldots \ldots \ldots \ldots \ldots \mu_{x_{n}}\right)$

Variance $=V(y)=\sum_{i=1}^{n}\left(\frac{\partial f}{\partial x_{i}}\right)^{2}\left(\sigma_{x_{i}}^{2}\right)+\sum \sum_{i \neq j}^{n}\left(\frac{\partial f}{\partial x_{i}}\right)\left(\frac{\partial f}{\partial x_{j}}\right) \operatorname{cov}\left[x_{i}, x_{j}\right]$

Where

$\operatorname{cov}\left[x_{i}, x_{j}\right]=\rho_{x_{i}, x_{j} * *} \sigma_{x_{i}} * \sigma_{x_{j}}$

In the FOSM, each variable in the performance function is assumed to follow the normal distribution. FOSM analysis approximates the first order expansion around the mean point. First-order reliability method (FORM) is more appropriate over FOSM as FORM attempts to transform the original distribution of all the variables in the model to a standard normal distribution (Choi et al., 2006). Therefore, the variation of the output can be expressed within the same space of input variables. Again, instead of approximation of the limit state function, this method performs the calculation of probability analysis in more accurate point. 
In the second-order reliability method (SORM), the precision of mean value of the distribution is enhanced by considering the second derivative terms of truncated Taylor series expansion. In that case, the calculation of the mean might become more complicated because of complex equation.

Point estimated method is not widely used in transportation related research. Detailed description of this method is not provided in this section.

\subsubsection{Previous Research on Reliability and Risk Assessment}

In order to address uncertainty in highway geometric design, reliability theory has been widely used particularly for sight distance restriction on a horizontal curve, sight distance restriction due to presence of a median, sight distance at a rail road grade crossing, and length of acceleration lane.

The concept of margin of safety and safety index were proposed by Navin (1990) as a meaningful and convenient safety measure for isolated highway geometric components. Margin of safety was defined by Navin (1990) as the difference between expected demand and expected supply where the vehicles' or drivers' demand was estimated using first-order second moment (FOSM) method and highway supply parameter represents the minimum design requirements recommended by AASHTO (1984) and ITE Handbook(1982).. Safety index or reliability index was defined as the ratio of margin of safety and square root of combined variance. Navin (1990) estimated the reliability index for stopping sight distance, decision sight distance, passing sight 
distance, horizontal and crest vertical curves. His study also proposed a general framework in order to address the uncertainty in the design of highway components.

Easa (1994) studied the problem of sight distance $(S D)$ at rail road grade crossing where randomness of input variables and their correlations were considered. A probabilistic approach based on first-order reliability method (FORM) was used to estimate the required $S D$ for approaching driver at road-rail grade crossings. Two cases were considered: (i) required sight distance for a moving vehicle along the highway (ii) required sight distance for a stopping vehicle at rail-road grade crossing. The probability of sight distance limitation at road-rail crossing was named as probability of failure. Sensitivity of the reliability index under variation of the design parameters was also evaluated. The verification of the proposed probabilistic method was done by Monte Carlo simulation technique due to lack of real data.

Easa (2000) proposed reliability-based method for designing intersection sight distance of Case I, and II as provided in the AASHTO (1990) design guide. The proposed method considered the moments (mean and variance) and the correlations of the design variables instead of using extreme value of all design variables. The method was developed based on the first-order reliability method (FORM) which requires no assumption regarding the distribution of the variables. The proposed method evaluated the failure of a specific approach when required sight distance exceeds the available sight distance. Easa (2000) stated that a collision is expected to occur in an intersection when system failure occurs. 
Richl et al. (2006) used first-order reliability (FORM) analysis to evaluate the risk due to sight distance limitation caused by narrow median on horizontal curve. In this study, the probability of sight distance limitation was termed as probability of noncompliance (PNC). This probability was referred to as failure to stop within the available sight distance when sight distance is constricted due to narrow median combined with horizontal curve. Various scenarios on a series of horizontal curve have been considered in order to estimate the probability of being failure to stop within the available sight distance. The output of the study revealed that, tight horizontal curve with narrow median provides the largest probability of non-compliance.

Khoury et al. (2007) used Monte Carlo simulation technique to assess the risk associated with various passing sight distances for a specified speed. A microscopic simulation model was developed using ARENA software which replicated the passing scenario on two-lane two-way roads. The movement of three vehicles such as the impending vehicle, the passing vehicle and the opposing vehicle were monitored in the simulation. Two scenarios were considered to measure risk: the pass scenario and abort scenario. In the pass scenario, the passing vehicle started to accelerate in order to pass the impending vehicle and in the abort scenario, the passing vehicle started to decelerate in order to achieve safe distance behind the impending vehicle. In every case, the risk index was computed based on the clearance time gap between the passing and the opposing vehicle at the end of pass or abort manoeuvre. Final risk index was computed by adding the two risk indexes. In this research, the risk index was also evaluated for the current PSD standard values recommended in AASHTO (2001) and Manual on Uniform Traffic Control Devices (2000). 
Sarhan et al. (2008) applied the reliability approach using Monte Carlo simulation technique to evaluate the risk due to restriction of sight distance on horizontal curves. The probability of sight distance restriction was referred to as the probability of hazard $(\mathrm{POH})$, which was evaluated as the percentage of drivers whose demand sight distance exceeds the supply sight distance.

Hassan et al. (2012) applied the probabilistic approach for the determination of drivers' acceleration distance on freeway SCLs. Both FOSM and simulation model were developed based on reliability theory where all parameters were assigned based on collected data from 15 entrance SCLs on Highway 417, Ottawa. The output of the model was to provide a distribution of acceleration distance on SCL considering variations in all contributing variables. Based on FOSM method, the study also developed an application design guideline in order to determine the SCL length for a freeway speed of $120 \mathrm{~km} / \mathrm{h}$.

\subsection{Freeway Merging Behaviour}

The main objective of this research is to develop a probabilistic model considering the acceleration and gap acceptance behaviour of drivers on the SCL. In this section, the definitions of various terms and existing literature related to the drivers' freeway merging behaviour are presented. 


\subsubsection{Definitions}

\section{Headway and Gap}

Headway is the time interval between two consecutive vehicles moving in the same direction at same time. The difference between gap and headway is that gap is measured from back of the front vehicle to front of the next arriving vehicle, and headway is measured from front of the front vehicle to front of the next arrival vehicle.

\section{Freeway lead vehicle}

The freeway vehicle which is immediately in front of the subject vehicle when viewed from the subject vehicle is referred to as freeway lead vehicle. Here, subject vehicle refers to the vehicle that attempts to change lane.

\section{Freeway lag vehicle}

The freeway vehicle which is behind the subject vehicle when viewed from the subject vehicle is referred to as freeway lag vehicle.

\section{Lead Gap}

Lead gap is defined as the space gap which is measured from rear end of the lead vehicle to front end of the subject vehicle at the time of lane change.

\section{Lag Gap}

Lag gap is defined as the space gap which is measured from the rear end of the subject vehicle to the front end of the lag vehicle at the time of merging. The concept of lead gap and lag gap is shown in Figure 2.4: 


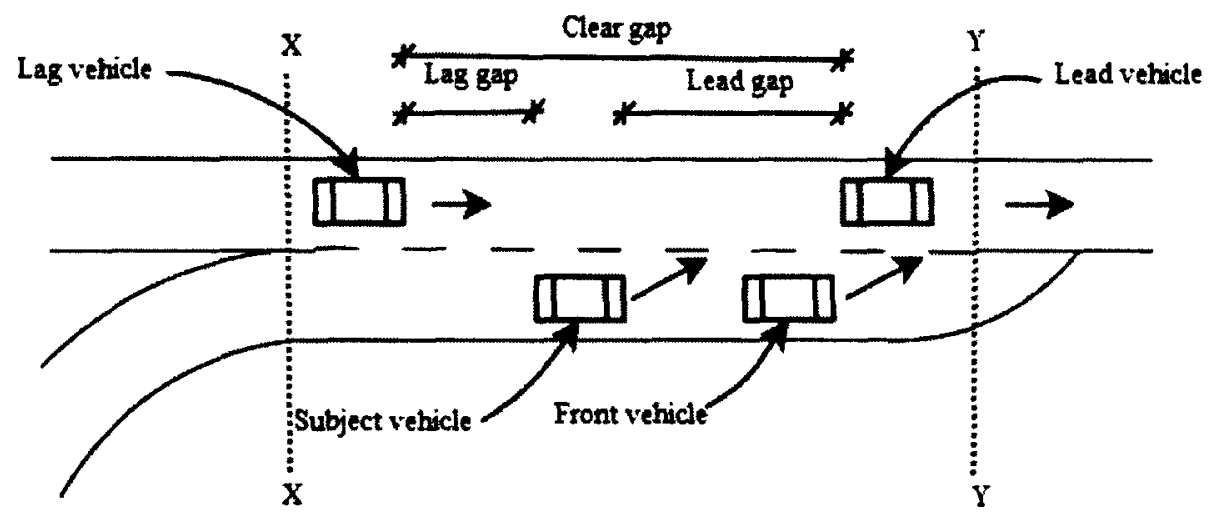

Figure 2.4: Illustration of lag gap, lead gap, lead vehicle and lag vehicle;

[Adapted from: Models of freeway lane changing and gap acceptance behaviour. (Ahmed 1996)]

\section{Critical Gap}

Critical gap is the minimum gap which is required for the driver to manoeuvre for lane change. It is also referred as minimum acceptable gap for merging. The size of the critical gap is stochastic in nature, varies across drivers and also within the driver. It depends upon the style of driving, geometric design of roadway, available gap, drivers' characteristics, delay, and other factors.

\section{Accepted gap}

In this research, accepted gap refers to the gap that was actually accepted by the SCL driver in the field for merging into the freeway right lane. 


\section{Acceptable gap}

In this research, the acceptable gap refers to any gap that is predicted for a specific SCL driver for comfortable merging into the freeway right lane based on the observations of gap size accepted by SCL drivers in the field and their speed characteristics.

\section{Lane Change}

Lane change is defined as the vehicle movement from one lane to another lane. Depending upon the execution of lane change, it can be classified into two types: mandatory lane change and discretionary lane change. In the case of mandatory lane change (MLC), the driver is obliged to perform lane change in order to follow a particular path. For example, drivers must change lane to the adjacent freeway lane when they are moving on the acceleration lane Discretionary lane change depends upon drivers' willingness. It is generally executed when driving condition is not favorable due to front vehicle's lower speed or presence of heavy vehicle in front of the merging driver.

\subsubsection{Previous Research Related to Merging Behaviour of Driver}

Drew (1968) performed regression analysis for modelling the gap acceptance behaviour of driver where length of the acceleration lane and merging angle were considered as independent variables and the critical gap was considered as depending variable. It was observed that the critical gap increases as the merging angle increases and vice-versa. 
Gipps (1986) developed a lane changing decision framework that could be used in the microscopic traffic simulation. This model covers urban driving behaviours where lane changing is affected by various conditions such as presence of heavy vehicle, traffic signal or any other obstruction. It was identified that three factors namely necessity, desirability, and safety influence the lane changing decision. In this framework, variability of drivers' behaviour was not captured.

Kita (1993) developed a discrete choice model to understand the drivers' behaviour when they merge from ramp to freeway. The researchers found that the gap acceptance behaviour depends on the gap size, relative speed between target lane vehicle and merge vehicle. It was also observed that probability of forced merging increases as the remaining distance of acceleration lane decreases.

Yang et al. (1996) developed a probabilistic lane changing model that could be applicable for only freeways. Both mandatory lane change (MLC) and discretionary lane change (DLC) situations were examined using this model framework. In the model, two conditions were examined for a discretionary lane change: whether the speed of lead vehicle is less than a desired speed, and whether existing speed of the surrounding lanes is large enough to increase speed. The gap acceptance model was also developed in this research, and the critical gap size was found smaller under MLC than under DLC condition.

Ahmed et al. (1996) developed a general lane changing model that is applicable for both mandatory and discretionary lane change situations. The framework was consisted in four steps: decision to lane change, selection of a target lane, choice of a 
target gap, and perform lane change. A binary logit model was used to model the framework. For parameter estimation, only one case was considered: merging into a freeway from ramp. The maximum likelihood method was used for estimating the model parameters. The limitation of the model is that drivers forced or courtesy merging behaviour was not considered.

Ahmed (1999) developed a microscopic lane changing model for both mandatory (MLC) and discretionary lane change (DLC) situations. In this research, different lane changing situations were modeled separately in different framework. The framework for lane changing manoeuvre was consisted in four steps as same as Ahmed et al. (1996). A binary logit model was used to respond to DLC or MLC, choice of a target lane, and choice of a gap. Parameters of the MLC and DLC models were estimated by the maximum likelihood estimation method. It was found that drivers behave more aggressively at MLC in comparison to DLC situation. In this research, force merging model was also developed that could capture the forced lane changing behaviour and courtesy yielding.

Kita (1999) developed a merging model where two-directional interactions between through vehicle and merging vehicle were considered. Two cases were considered while driver merges onto the freeway: either merge onto the mainstream or stay on the acceleration lane. Two options were also considered for through vehicle: either co-operative with the merging vehicle in order to give chance to merge into the mainline or move without showing any courtesy to the merging vehicle. The probability of merging for merge vehicle and probability of give way for through vehicle were estimated using the maximum likelihood method. 
Hunter et al. (2001) examined the speed-distance relationship based on the collected data from six ramps in Texas. Length of speed change lane (SCL) on selected ramps varied from 55 meter to 241 meter. Vehicle's speed was calculated from the distance travelled by vehicle and travel time. It was observed that $85^{\text {th }}$ percent of ramp drivers are driving $70 \%$ to $80 \%$ of freeway design speed and ramp geometry has a significant influence on the acceleration and deceleration rate of the merge vehicle.

Hwang et al. (2005) used discrete choice theory for reflecting the drivers' merging behaviour. The factors that affect drivers' gap acceptance behaviour were modeled by utility function. Real data were used for the estimation of variables. It was observed that lag gap is more important parameter for merging than lead gap, and drivers accept smaller gap size in the case of traffic congestion.

Lee (2006) developed a gap acceptance model that captured normal, forced, and co-operative lane changing behaviour in congested traffic situation. The model was formulated using binary choice theory. Maximum likelihood estimation method was used for parameter estimation. It was found that mainline vehicle's speed, interaction between merge and freeway vehicle have significant influence on the merging process in congested traffic situation. Finally, model was validated with the existing gap acceptance model using microscopic simulator, MITSIM. The proposed model was found more effective than the existing gap acceptance model.

Yi et al. (2007) investigated an arrival pattern of vehicles along the acceleration lane of three ramp sites in Kansas City where through and merge traffic volume were moderate to high. Three arrival patterns were observed from the study sites namely free merge $(F M)$, challenge merge $(C M)$ and platoon merge $(P M)$. Authors stated that $F M$ is 
observed at any arbitrary location of acceleration lane, $P M$ follows a smooth natural path mainly centered of certain area of merge lane, and $C M$ occurs mainly in high volume of through traffic where vehicles travel longer distance on the acceleration lane. It was concluded that the merge length for urban freeway is highly correlated to $C M$, $P M$, and average speed of the freeway right lane traffic.

Kim et al. (2008) proposed a gap acceptance model for merging from the SCL to freeway considering stochastic driving behaviour. A microscopic traffic simulation model was coded in Visual Basic and only 10 different types of driver (Henry et al. 1997) were considered. For the analysis purpose, the acceleration lane was divided into eight segments and eight different critical trailing gaps were assigned for each driver on those segments. In the simulation, critical gap was updated depending on the position of vehicle along the acceleration lane. In this research, the drivers' acceleration behaviour during the merging process was not captured. The proposed gap acceptance model checks three conditions for merging: whether the trailing gap is larger than the critical trailing gap, whether the leading gap is larger than the critical leading gap, and whether the relative speed is within the acceptable speed limit. The output of the simulation model was also validated with the field data and it was found that output of the proposed model and existing field condition was statistically strongly comparable.

Li et al. (2007) investigated the drivers' merging behaviour on the acceleration lane. Based on the field data, it was observed that most of the vehicles merge at the middle length of acceleration lane. Mathematical equations were derived in this research to estimate the probability of vehicle's merging distance on the acceleration lane where the variability of drivers' merging behaviour was not captured. Traffic volume, speed, 
acceleration rate and critical gap of merge vehicle, length of acceleration lane were considered as input parameters in the derived equations. The derived equation can model the observed field condition with a strong coefficient of determination. It was also found that traffic volume has significant influence on the vehicle's driving distance before merging.

Ahammed et al. (2006) observed variability of drivers' gore speed, merge speed, acceleration rate, and merging distance based on the collected speed data from 23 entrance SCLs on 15 interchanges. It was observed from the field data that $85^{\text {th }}$ percentile value of merge speed ranged from $90.6 \mathrm{~km} / \mathrm{h}$ to $115.1 \mathrm{~km} / \mathrm{h}$ even though posted the speed limit on freeway was $100 \mathrm{~km} / \mathrm{h}$. It was recommended that the overall acceleration rate can be assumed from the $85^{\text {th }}$ percentile value of acceleration rate which ranged from $0.235 \mathrm{~m} / \mathrm{s}^{2}$ to $1.110 \mathrm{~m} / \mathrm{s}^{2}$.

Kondyli et al. (2009) investigated the drivers' merging behaviour based on the responses given by three focus groups. Based on the discussion with focus groups about their intended action while merging onto a freeway from a ramp, it was revealed that:

- Driver behaves more aggressively on the taper SCL than on parallel SCL type.

- In case of forced merging, the freeway lag driver prefers to change lane instead of decelerating the vehicle.

- Driver's forced merging behaviour depends entirely upon the availability of gap. 
Daamen et al. (2010) performed a data analysis to understand the drivers' merging behaviour on the acceleration lane. It was observed that most of the vehicles merge at the beginning of acceleration lane under free flow condition and more vehicles tend to merge at the end of acceleration lane during congested traffic condition. It was also found from dataset that accepted gap size for merging starts from $0.75 \mathrm{sec}$ to $1 \mathrm{sec}$. They also mentioned that using a certain critical gap in gap acceptance theory does not reflect the observed merging behaviour. Therefore, a new gap acceptance theory is suggested in their research where a set of reachable gaps for merging has assumed instead of a critical gap so that the merging vehicle can find an acceptable gap without overtaking several through vehicles and without stopping vehicle at the end of acceleration lane.

Brewer et al. (2011) evaluated the drivers' merging behaviour on the acceleration lane based on the analysis of nine-entrance ramp data. It was found that at least half of the acceleration lane is used for the merging process under lightly congested traffic volume. A conclusion was drawn in this research that the entrance SCL lengths with taper as recommended in AASHTO (2004) are found adequate for complete merging process under low congested traffic situation.

\subsection{Summary}

- The current design guides consider a deterministic approach for the SCL length design where a single value is assumed for each relevant component variable. But the research shows that those variables are stochastic in nature and a 
probabilistic approach is needed to describe the variability of those variables. Reliability-based probabilistic approach can capture the stochastic behaviour of the variables and use as a replacement of the current deterministic approach.

- Traffic volume is found by most of the researchers as an important factor during the freeway merging process but is not considered in the current SCL length design.

- Gap searching behaviour on the acceleration lane is found important phenomena in many literatures which is not considered in the current SCL design practice.

The current research focuses on probabilistic design approach where both acceleration and gap searching behaviour during the merging from SCL to freeway is considered. 


\section{DATA COLLECTION AND PRELIMINARY ANALYSIS}

The present study is a continuation of previous studies that were started at Carleton University in 2004. Sarhan (2004) performed a research on safety performance of freeways using collision data of 57 merge and 39 diverge areas along Highway 417 located in the City of Ottawa. Ahammed (2005) collected speed data on 23 acceleration SCLs of the same highway and evaluated drivers' behaviour at the merge areas. Salehi (2010) conducted a research on the same study area considering 15 SCLs and worked with the same data gathered by Ahammed (2005). Salehi (2010) checked the adequacy of SCL length using reliability-based approach and considered only the drivers' acceleration distance to evaluate the SCL length. The current research expands on these previous studies by considering both acceleration and gap searching distances in order to model the drivers' merging behaviour on the SCL length more accurately. The data collected by Ahammed (2005) were received in the form of several Excel sheets and were used in the development of a simulation model in the present study. The details of the model will be discussed in Chapter 4 .

This Chapter provides a brief overview of the data collection procedure, parameter selection and statistical characteristics of the parameters. Section 3.1 provides an overview of the selection procedure of the study sites and a brief description of the geometric features of the selected sites. Section 3.2 summarizes the data collection process, and Section 3.3 discusses the parameters selection procedure and statistical characteristics of the selected parameters. 


\subsection{Site Selection}

Highway 417 is a high speed freeway with a posted speed limit of $100 \mathrm{~km} / \mathrm{h}$. It is a part of the Trans Canada Highway and one of the major freeways in Ontario. It is the main highway passing through the City of Ottawa where a large volume of traffic commutes every day. It is running through the east-west direction and continues as Highway 17 in the west side and as Highway 40 through Quebec in the east side. It is connected with Highway 416 and Highway 174 within the City of Ottawa. It has two to four lanes in each direction within the city, and it passes through downtown the City of Ottawa as well as some of the suburban areas. The downtown area is the central part of the city which is highly populated, and therefore the design of interchanges is restricted by the limited right of way. On the other hand, the suburban areas are less populated with lower traffic densities. Therefore, the section contains entrance ramps with varying characteristics in terms of ramp spacing, length of SCL, and traffic volume on the SCL and main freeway lanes. Figure 3.1 shows a map of the study area.

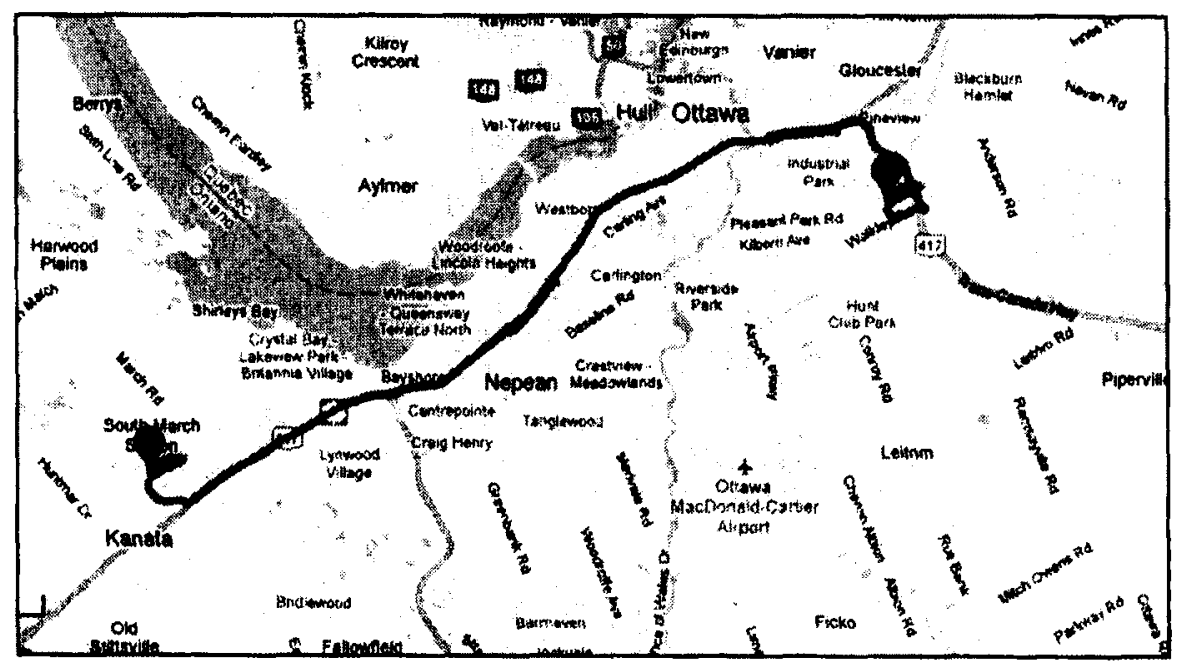

Figure 3.1: Map of the study area [Source: Google Maps]. 
The selected study area covers 27 interchanges where 66 entrance SCLs and 27 exit SCLs are located. Only acceleration SCLs are considered in this study. Ahammed (2005) used laser speed guns and a video camera for the collection of drivers' speed data at the highway's entrance SCLs. Only forty sites were selected for the data collection based on the availability of suitable space for positioning equipment and visibility of the full SCL length. The equipment was positioned on overpasses, roofs or upper floors of buildings or mall parking adjacent to the freeway. In some sites, the building management did not give permission to place the necessary equipment. Therefore, the number of candidate sites were reduced to 27 acceleration SCLs. Out of these 27 SCLs, two sites were abandoned because of a very low traffic volume and two other sites were excluded due to safety reasons. Finally, 23 SCLs were found appropriate for the data collection. Among theses 23 SCLs, 9 SCLs were located in the westbound direction and the remaining SCLs were located in the eastbound direction. Table 3.1 provides a detailed description of the 23 acceleration SCL sites: 
Table 3.1: Description of Data Collection Sites [Source: Ahammed 2005]

\begin{tabular}{|c|c|c|c|c|}
\hline IC no & Hwy Dir & Ramp/SCL name & Data category & SCL Type \\
\hline 110 & WB & Walkley W-W & Merge Speed only & Limited Type \\
\hline 112 & EB & Innes E-E & Merge Speed only & Limited Type \\
\hline 115 & WB & St. Laurent N-W & Full Profile & Extended Type \\
\hline 117 & WB & Vanier N-W & Full Profile & Extended Type \\
\hline 117 & EB & Vanier N-E & Merge Speed only & Limited Type \\
\hline 118 & EB & Nicholas NS-E & Merge Speed only & Extended Type \\
\hline 122 & WB & Parkdale NS-W & Full Profile & Limited Type \\
\hline 126 & EB & Maitland NS-E & Full Profile & Limited Type \\
\hline 127 & WB & Woodroffe NS-W & Full Profile & Limited Type \\
\hline 127 & $\mathrm{~EB}$ & Woodroffe N-E & Merge Speed only & Limited Type \\
\hline 127 & EB & Woodroffe S-E & Full Profile & Extended Type \\
\hline 129 & EB & Greenbank S-E & Full Profile & Extended Type \\
\hline 130 & EB & Richmond S-E & Full Profile & Limited Type \\
\hline 134 & WB & Moodie N-W & Full Profile & Limited Type \\
\hline 138 & WB & Eagleson N-W & Full Profile & Extended Type \\
\hline 138 & EB & Eagleson S-E & Full Profile & Limited Type \\
\hline 139 & $\mathrm{~EB}$ & Castlefrank NS-E & Full Profile & Extended Type \\
\hline 140 & WB & Terryfox N-W & Full Profile & Limited Type \\
\hline 140 & WB & Terryfox S-W & Merge Speed only & Limited Type \\
\hline 140 & EB & Terryfox N-E & Merge Speed only & Limited Type \\
\hline 140 & EB & Terryfox S-E & Merge Speed only & Limited Type \\
\hline 144 & EB & Carp N-E & Merge Speed only & Limited Type \\
\hline 144 & $\mathrm{~EB}$ & Carp S-E & Full Profile & Limited Type \\
\hline
\end{tabular}


As shown in Table 3.1, fifteen SCLs are designated as "Full profile" and the remaining eight SCLs are represented as "Merge speed Only". "Full profile" refers to those locations where speed data were collected from the proximity of gore area to the merge point. In some sites, the gore area was not visible from the observation point and therefore, the profile of SCL vehicles speeds was not fully captured from gore to merge. These locations are designated as "Merge Speed Only". In the present study, vehicles' speed near the gore area i.e. at the end of controlling curve of the entrance ramp is an important parameter to understand the drivers' overall merging behaviour from the beginning to the end of SCL as explained later. "Merge Speed Only" sites are not suitable for the purpose of present study, as the speed of SCL vehicle near the gore area were not captured.

In Table 3.1, sixteen SCLs are also designated as "Limited type" and seven SCLs are designated as "Extended type". During the data collection by Ahammed (2005), the length of limited type SCL was measured from the entrance gore area where the pavement edges of the freeway right lane and ramp are $1.25 \mathrm{~m}$ apart to the end of the taper. For the extended type SCL, the length was measured from the point where pavement edges of ramp and freeway lane are $1.25 \mathrm{~m}$ apart to the same point of exit gore. Limited type SCLs vary from $188 \mathrm{~m}$ to $468 \mathrm{~m}$ and extended type SCLs vary from $673 \mathrm{~m}$ to $1366 \mathrm{~m}$. For the limited type, SCL length ends with a taper and drivers on the SCL are forced to merge onto the freeway right lane. As the length in extended type SCL is longer in comparison to the length of limited type, SCL drivers get more time, space to accelerate, and may accept longer gap for merging comfortably. Further, the freeway right lane vehicles use the extended type SCL to take exit, an interaction may 
occur between the exit and the merge vehicle. Therefore, the extended type SCLs are excluded from the current research. Finally, the current study considers only eight limited type acceleration SCLs with "Full Profile" to capture the merging behaviour from beginning to the end. Table 3.2 shows the geometric configurations of these eight acceleration SCLs.

Table 3.2: Geometric Features of Selected Eight SCLs [Source: Ahammed 2005]

\begin{tabular}{|l|c|c|c|c|c|c|}
\hline \multicolumn{1}{|c|}{$\begin{array}{c}\text { Ramp/ } \\
\text { SCL Name }\end{array}$} & $\begin{array}{c}\text { Ramp } \\
\text { Type }\end{array}$ & $\begin{array}{c}\text { SCL } \\
\text { Config. }\end{array}$ & $\begin{array}{c}\text { SCL } \\
\text { Length(m) }\end{array}$ & $\begin{array}{c}\text { No. of } \\
\text { Freeway lane }\end{array}$ & $\begin{array}{c}\text { Ramp } \\
\text { Radius (m) }\end{array}$ & $\begin{array}{c}\text { Ramp } \\
\text { Grade }\end{array}$ \\
\hline Parkdale (NS-W) & Direct & Taper & 188 & 4 & 884 & Up \\
\hline Maitland (NS-E) & Loop & Parallel & 468 & 3 & 74 & Down \\
\hline Terry fox (N-W) & Outer & Parallel & 419 & 2 & 155 & Down \\
\hline Carp (S-E) & Outer & Parallel & 430 & 2 & 200 & Down \\
\hline Woodroffe (NS-W) & Loop & Parallel & 346 & 3 & 113 & Down \\
\hline Richmond (S-E) & Outer & Parallel & 321 & 4 & 295 & Down \\
\hline Moodie (N-W) & Outer & Parallel & 323 & 2 & 238 & Down \\
\hline Eagleson (S-E) & Outer & Parallel & 327 & 2 & 350 & Down \\
\hline
\end{tabular}

Length of the selected SCLs varies from $188 \mathrm{~m}$ to $468 \mathrm{~m}$. Four SCLs have lengths between $300 \mathrm{~m}$ to $400 \mathrm{~m}$, three SCL lengths are above $400 \mathrm{~m}$, and one SCL length is less than $200 \mathrm{~m}$. The number of freeway lanes at the selected sites varies from two to four. Out of eight SCLs, four sites have two freeway lanes, two have three freeway lanes, and remaining two have four freeway lanes. Out of eight, five ramps are outer connection type and two are loop type. Seven ramps are located on a downgrade 
and one ramp is located on an upgrade. Finally, only one SCL is a taper type and the remaining seven SCLs are of the parallel type.

\subsection{Data Collection Procedure}

It has been mentioned in the previous section that Ahammed (2005) collected speed data from each SCL using two laser speed guns. During data collection, vehicles were targeted from the proximity of the gore area to the merging point. In addition to speed, the distance travelled by the SCL vehicles from the target point to the merge point and time required to travel this distance were recorded using the laser speed gun. Ahammed (2005) calculated the acceleration rate using speed and time data based on the laws of kinematics. For the freeway right lane, the profile of freeway vehicles' speeds was captured from the proximity of physical gore to the end of SCL length. A digital video camera was also set adjacent to the laser speed guns to record traffic movements on the SCL and freeway through lanes. The author of this thesis received the video recordings in a $\mathrm{CD}$ format, and the merging distance, speed, and acceleration data in several Excel files.

In the current study, the actual gap sizes accepted by the SCL vehicles were estimated from the video recordings. The gap size was extracted from the video recordings when the left side front wheel of the merge vehicle hit the white lane marking between the SCL and freeway right lane. At this instant, the clear gap (sec) between the rear bumper of the freeway vehicle immediately in front of the merge vehicle (lead vehicle) and the front bumper of the freeway vehicle immediately behind 
the merge vehicle (lag vehicle) was recorded. Figure 3.2 shows a schematic diagram of the measured gap on SCL.

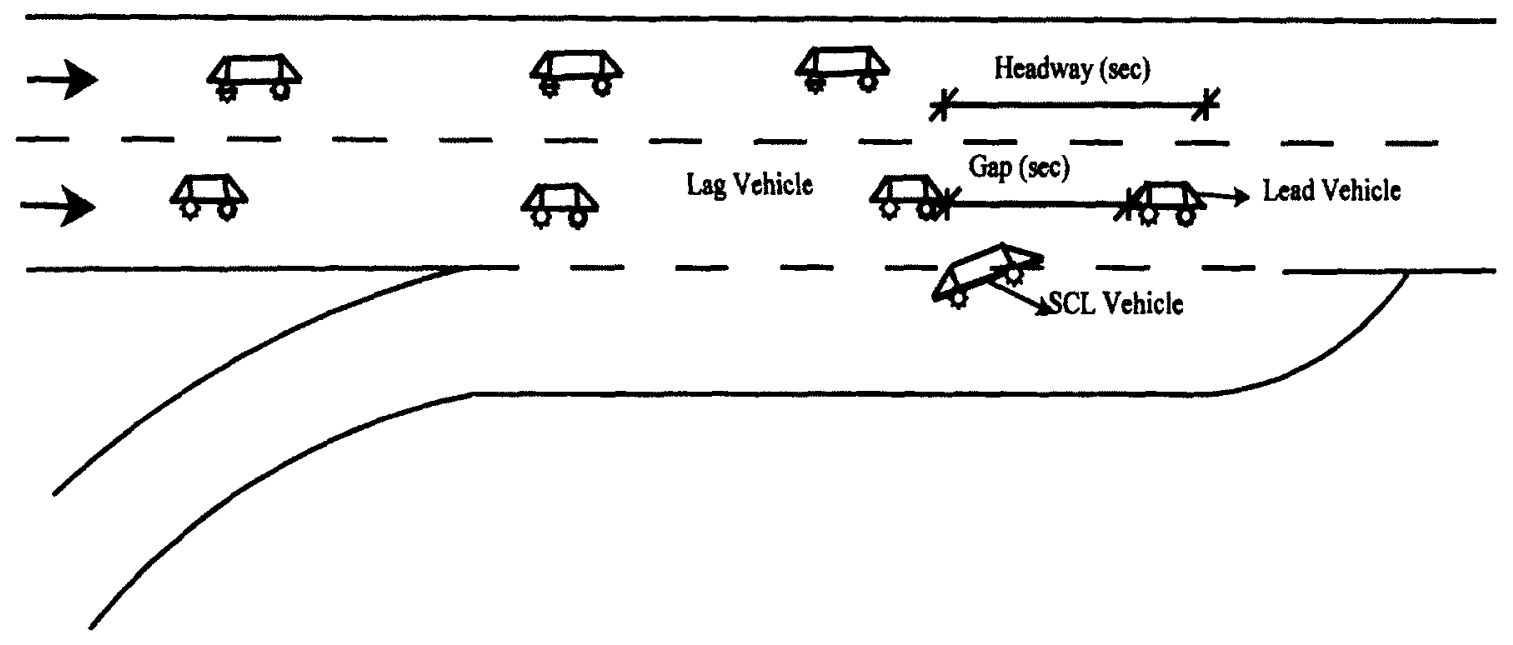

Figure 3.2: The data collection procedure

The following procedures were followed for collecting the actual gap size accepted by the SCL vehicles:

- Time $t_{l}$ was recorded and position of lead vehicle's rear bumper was marked when the merge vehicle's front wheel hit the white lane marking between SCL and freeway right lane.

- Time $t_{2}$ was recorded when the lag vehicle's front bumper passed the same position as marked in the first step.

- During the gap data collection, the accommodating manoeuvres of lag freeway vehicle to allow SCL vehicle to merge onto the freeway right lane were not considered.

- The time difference between time $t_{1}$ and $t_{2}$ was recorded as the accepted gap (sec). 
Initially, the data of accepted gap were collected for both passenger cars and heavy vehicles. However, as the number of heavy vehicles was very low, ranging from $2 \%$ to $4 \%$ at each site, the gap data of passenger cars and heavy vehicles were combined and used in the analysis.

The accepted gaps for passenger cars and heavy vehicles were then screened to remove very large values that have resulted from low traffic volume on the freeway right lane. In this research, accepted gap size equal to or less than 6 seconds were only considered as large gap values would not accurately reflect the drivers' gap acceptance behaviour. Bham and Benekohal et al. (2000) observed that drivers are to be interacting when they are separated by $250 \mathrm{ft}$ or less. Kim et al. (2007) performed a research on the gap acceptance behaviour during lane change from acceleration lane to freeway. In their research, it was believed that the merging drivers do not interact with the through traffic when the available gap is more than 6 second. Therefore, based on the literature and own judgment, gap less than or equal to six seconds were utilized in the current study.

\subsection{Statistical Characteristics of Parameters}

In the present study, microscopic simulation is used in order to model the interaction between merging vehicles and through traffic vehicle movements on the SCL and freeway right lane. In this section, the parameters involved in the model during the merging process from the SCL to freeway are identified. In the simulation model, the 
merging process is idealized as: the SCL vehicle enters into the beginning of SCL length with a specific speed, vehicle accelerates, simultaneously scans the available gap in the freeway right lane, and finally merges onto the freeway when acceptable speed is reached and acceptable gap is found. In order to generate a SCL vehicle in the simulation, the parameters considered for describing the merging scenario of SCL vehicle are accepted gap at different location of SCL, initial speed, merge speed, and acceleration rate. For freeway right lane, the related parameters are traffic volume, vehicle's speed, and vehicle length. It should be noted here that the initial speed of SCL vehicle represents the speed at the end of controlling curve of entrance ramp.

The key statistical characteristics of above mentioned parameters are identified from the data of eight study sites. For the eight study sites, 788 vehicle speed profiles were received in the form of several Excel sheets from Ahammed (2005). At each study site, the number of vehicles varies from 77 to 110 . The following sections describe the key statistical characteristics of the parameters:

\subsubsection{Gore Speed $\left(V_{G}\right)$}

As mentioned earlier, the profile of SCL vehicles speeds was captured by Ahammed (2005) from the proximity of gore area to the merge point. As speed data collected by Ahammed (2005) is used in the present study, initial speed at the start of SCL length will also be termed as the gore speed regardless of whether the SCLs begin at the gore area or not. The SCL vehicles' gore speed represents all the geometric features on upstream of the SCL. It was observed from the eight SCLs that the mean gore speed 
varied from 62.13 to $100.05 \mathrm{~km} / \mathrm{h}$ and the $85^{\text {th }}$ percentile gore speed varied from 67.1 to $108.0 \mathrm{~km} / \mathrm{h}$ irrespective of the vehicles' type. The data were also categorized by Ahammed (2005) based on vehicle types. For passenger cars, the mean gore speed varied from 62.29 to $101 \mathrm{~km} / \mathrm{h}$. The $85^{\text {th }}$ percentile gore speed varied from 67.12 to $109.15 \mathrm{~km} / \mathrm{h}$, and the standard deviation ranged from 5.71 to $10.49 \mathrm{~km} / \mathrm{h}$. For heavy vehicles, the mean gore speed varied from 58.08 to $95.98 \mathrm{~km} / \mathrm{h}$, the $85^{\text {th }}$ percentile gore speed varied from 61.62 to $102.23 \mathrm{~km} / \mathrm{h}$, and the standard deviation ranged from 4.32 to $10.75 \mathrm{~km} / \mathrm{h}$. A comparison of the mean, $85^{\text {th }}$ percentile, and standard deviation of gore speed among passenger cars (PC), heavy vehicles (HV) and all vehicles combined are shown in Figures 3.3, Figure 3.4, and Figure 3.5.

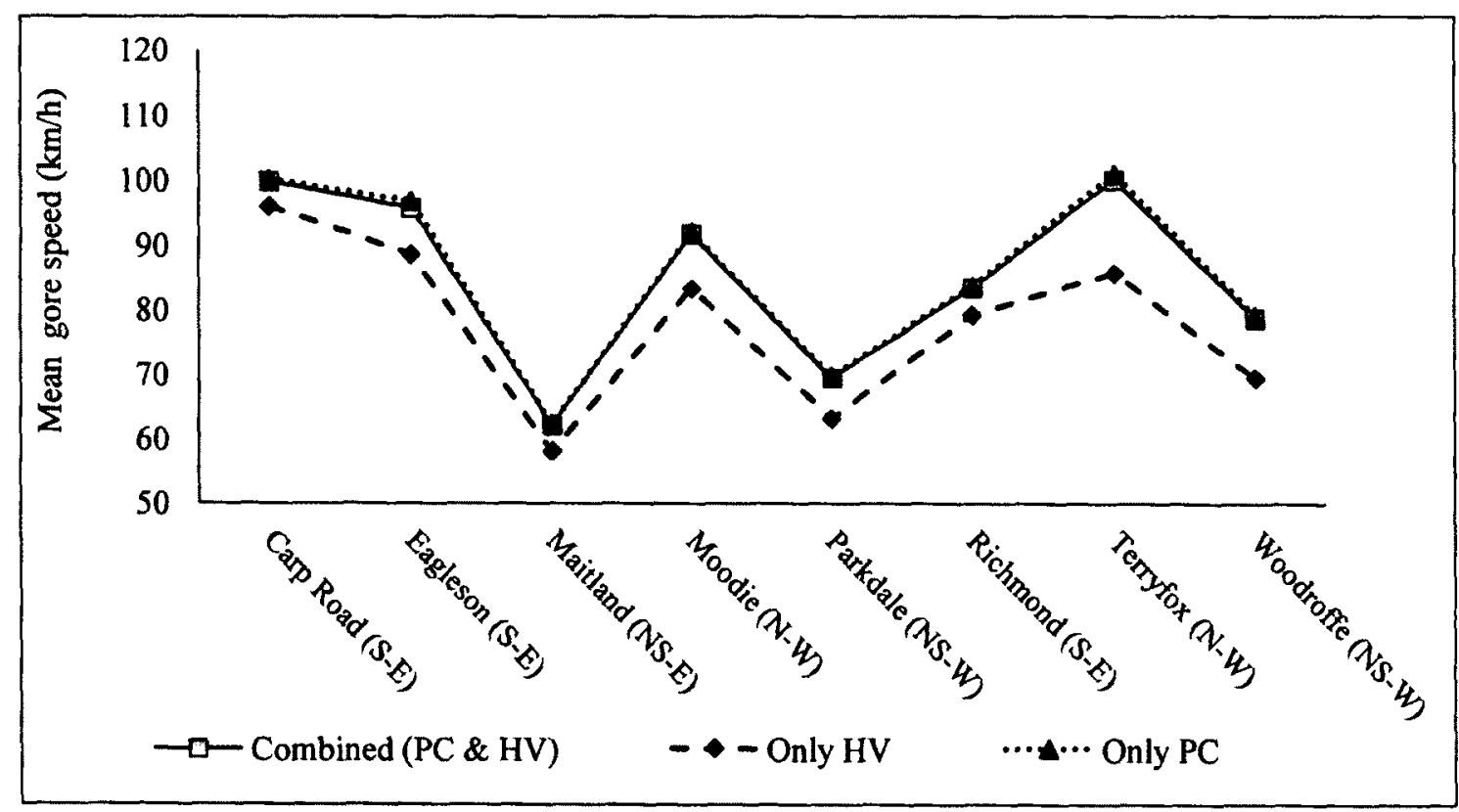

Figure 3.3: Comparison of mean gore speed among all SCLs. 


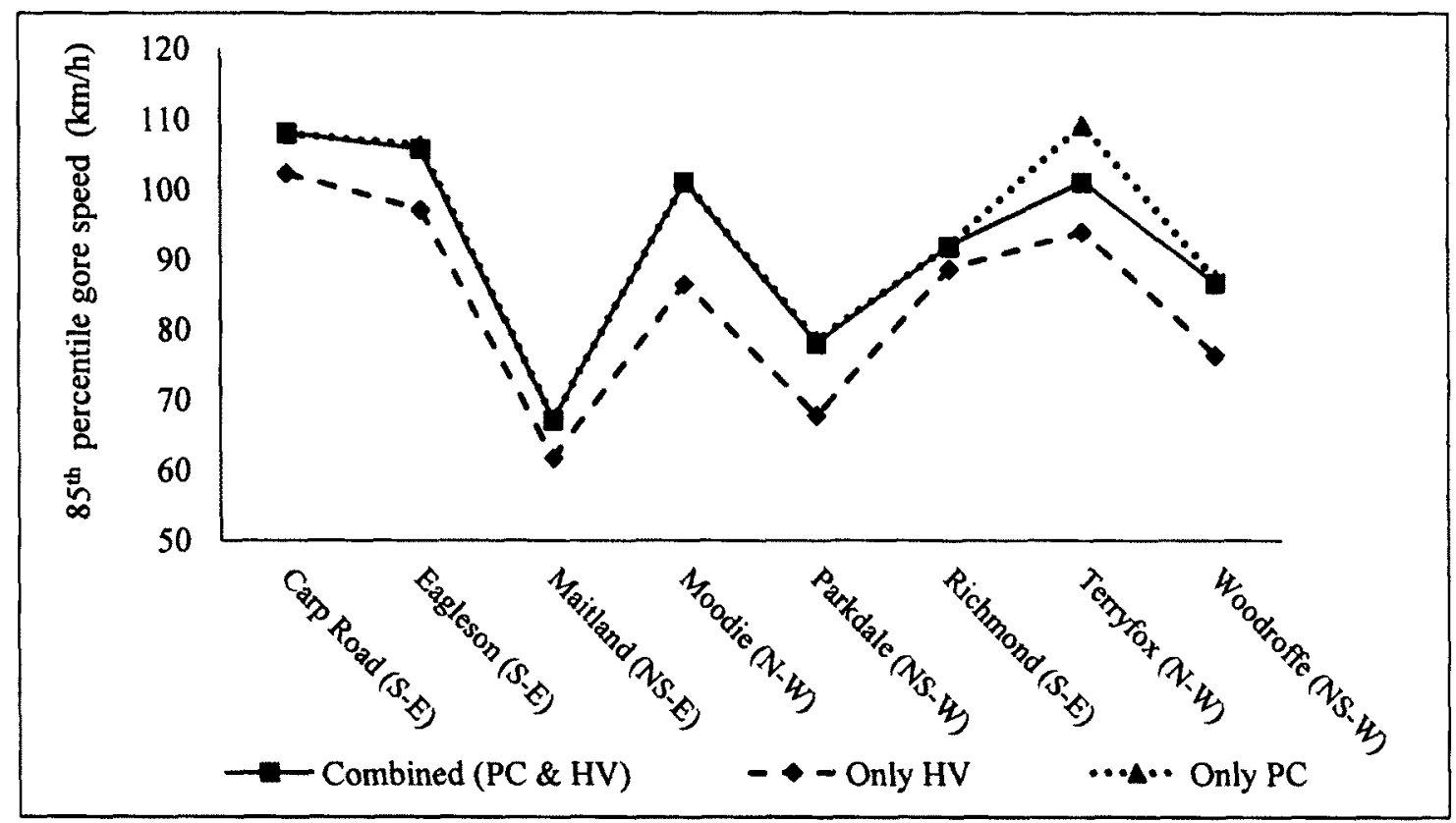

Figure 3.4: Comparison of $85^{\text {th }}$ percentile gore speed among all SCLs.

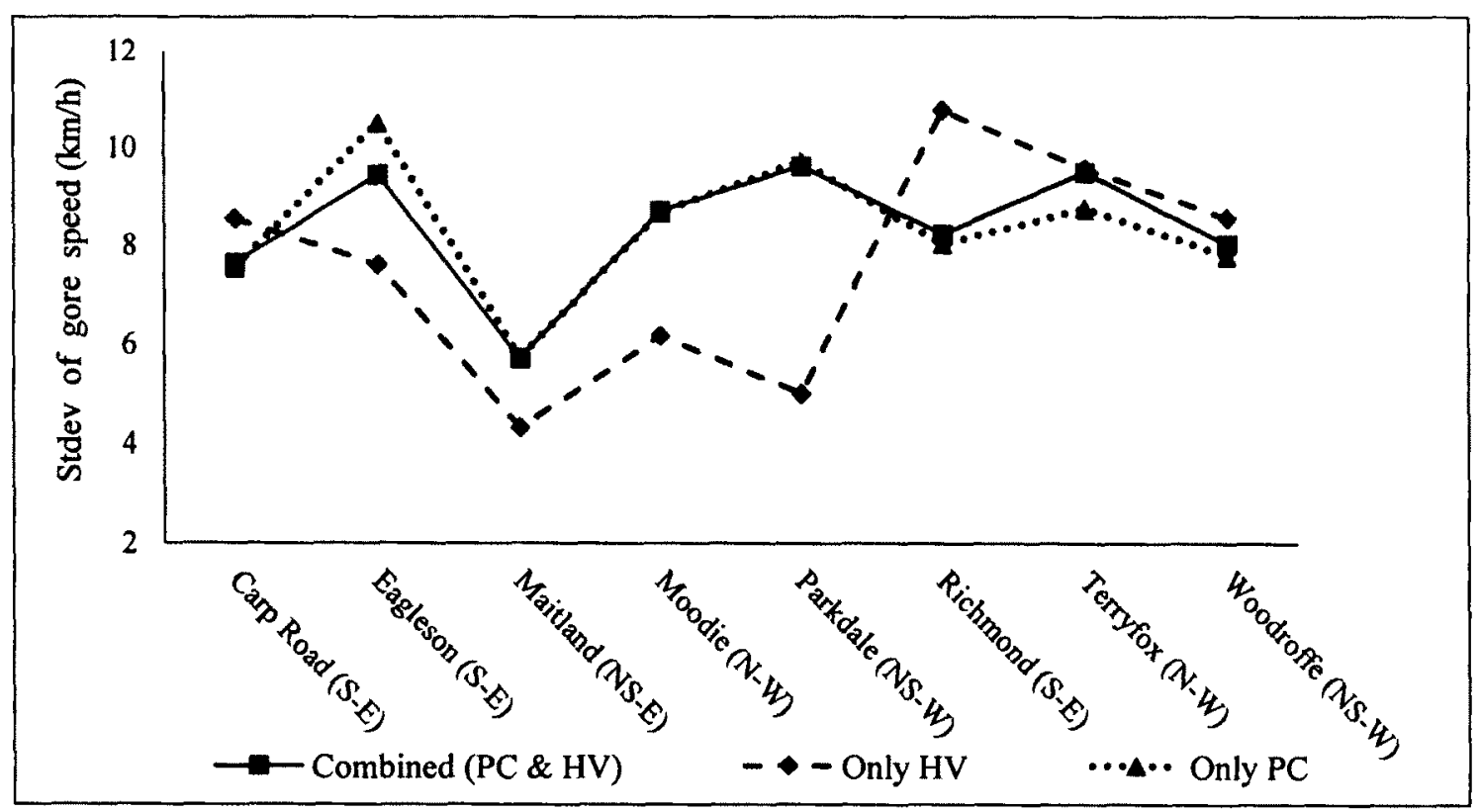

Figure 3.5: Comparison of standard deviation of gore speed among all SCLs. 


\subsubsection{Merge Speed $\left(V_{M}\right)$}

It was found from the eight SCLs that the mean, $85^{\text {th }}$ percentile and standard deviation of merge speed for all vehicle types combined ranged from 86.57 to $105.95 \mathrm{~km} / \mathrm{h}$, 90 to $114.76 \mathrm{~km} / \mathrm{h}$ and 7.00 to $10.00 \mathrm{~km} / \mathrm{h}$, respectively. Both the mean and $85^{\text {th }}$ percentile merge speeds of five SCLs exceed the operating speed considered in AASHTO (2011) design table for the recommendation of SCL length. However, the mean and $85^{\text {th }}$ percentile merge speeds of eight SCLs are within the operating speed range considered in TAC (1999).

For passenger cars, the mean merge speed ranged from 80.12 to $106.30 \mathrm{~km} / \mathrm{h}$, the $85^{\text {th }}$ percentile merge speed ranged from 90.51 to $114.80 \mathrm{~km} / \mathrm{h}$, and the standard deviation ranged from 6.87 to $10.09 \mathrm{~km} / \mathrm{h}$. For heavy vehicles, the mean merge speed ranged from 70.75 to $101.5 \mathrm{~km} / \mathrm{h}$, the $85^{\text {th }}$ percentile merge speed ranged from 74.61 to $106.40 \mathrm{~km} / \mathrm{h}$, and the standard deviation ranged from 4.95 to $13.01 \mathrm{~km} / \mathrm{h}$. Figures 3.6 , 3.7, and 3.8 show the comparison of the mean merge speed, $85^{\text {th }}$ percentile merge speed, and standard deviation of merge speed among all SCLs for passenger cars (PC), heavy vehicles (HV), and all vehicles combined. 


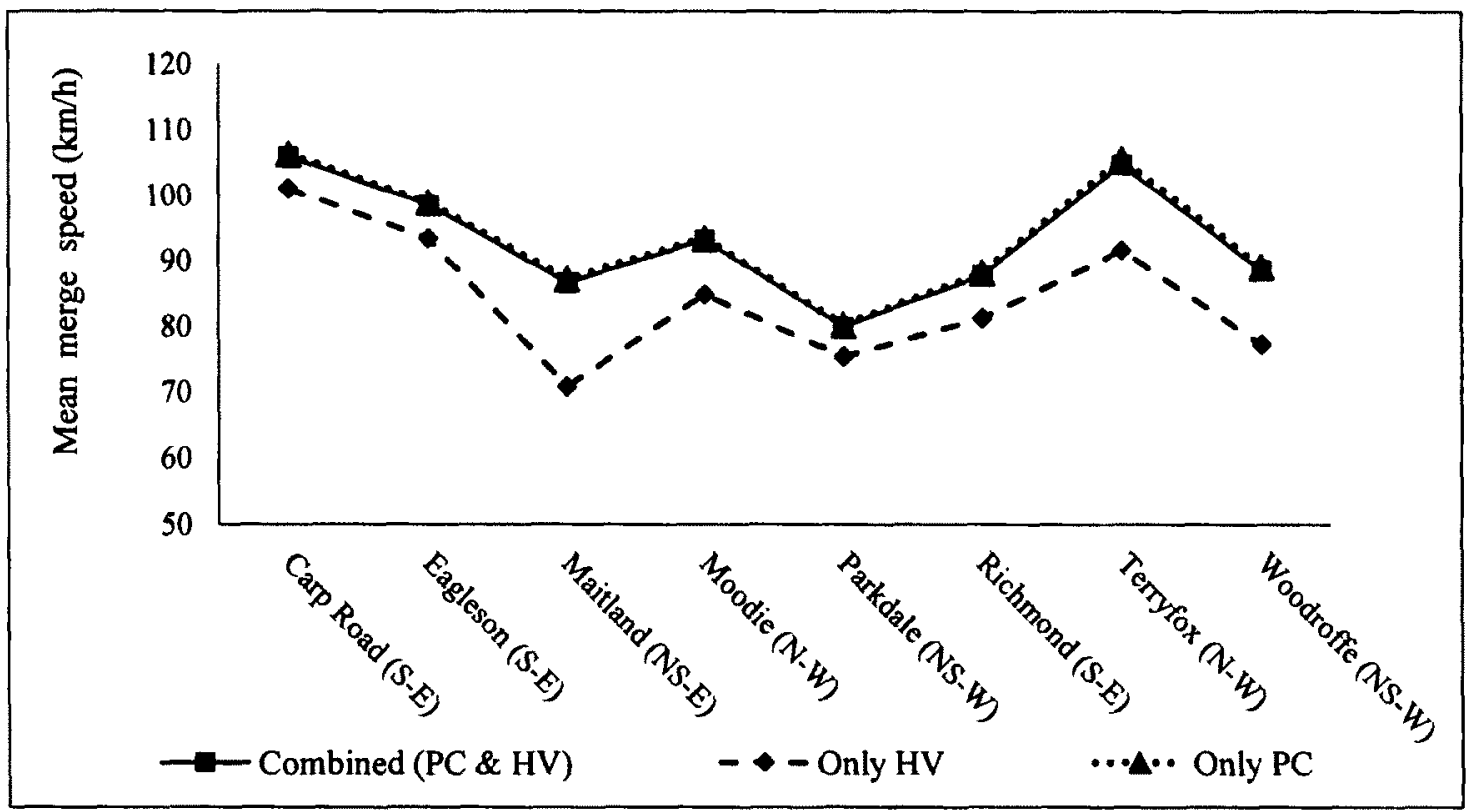

Figure 3.6: Comparison of mean merge speed among all SCLs.

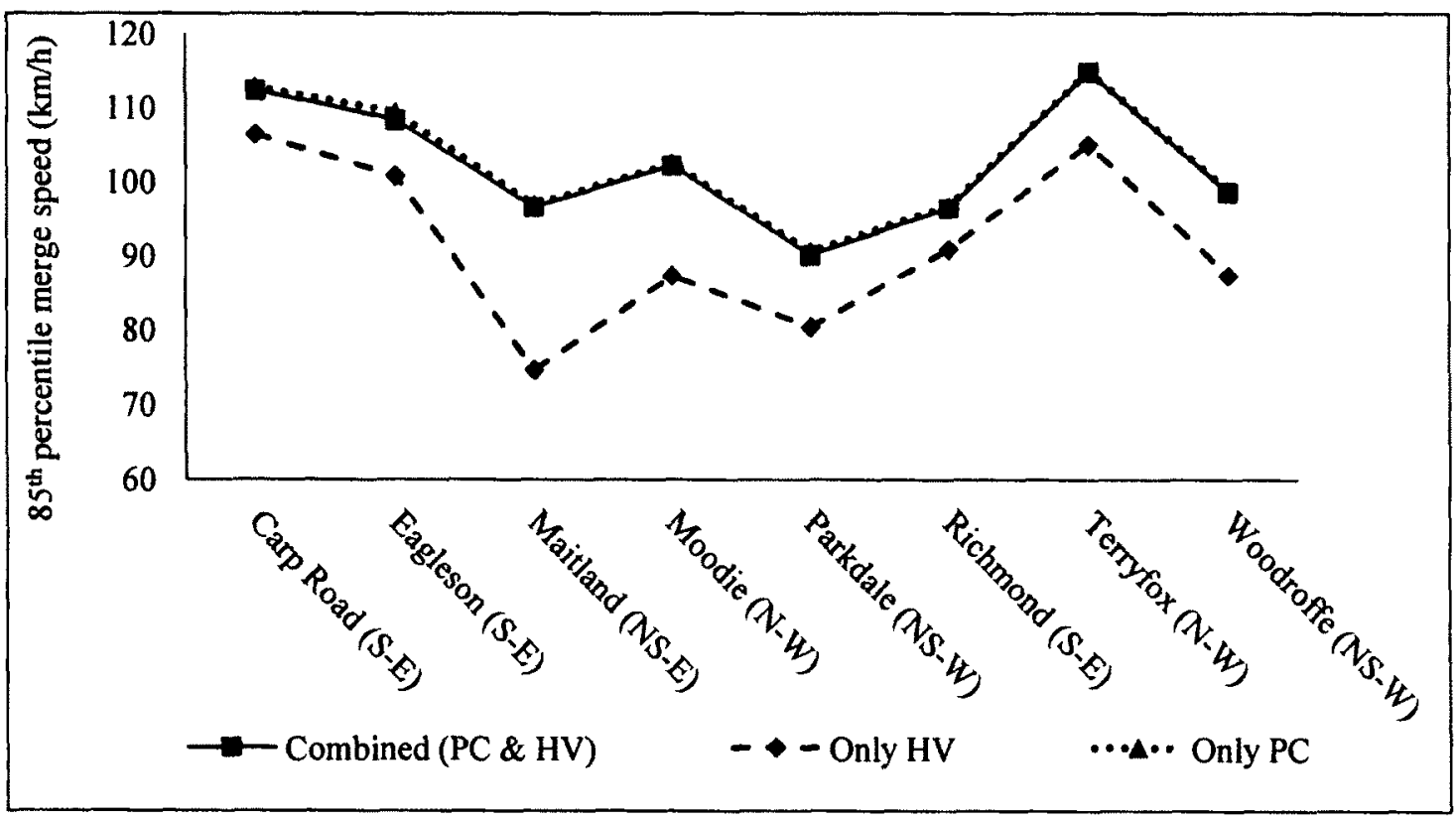

Figure 3.7: Comparison of $85^{\text {th }}$ percentile merge speed among all SCLs. 


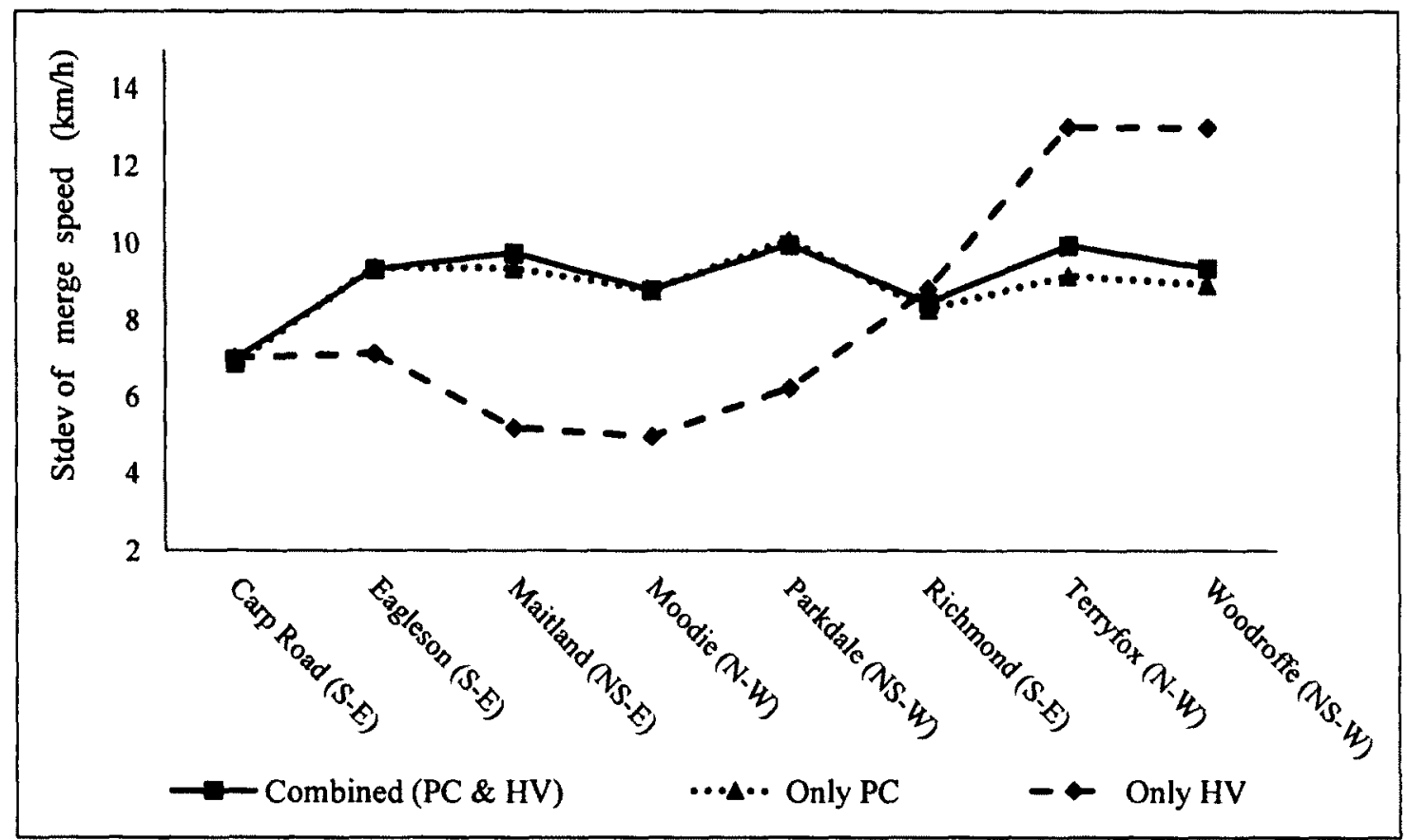

Figure 3.8: Comparison of standard deviation of merge speed among all SCLs.

\subsubsection{Overall Acceleration Rate (a)}

Ahammed (2005) calculated the maximum, mean, and overall acceleration rate for each vehicle using the collected speed, time and distance data where the maximum and mean acceleration rate refer to the maximum and mean value of all successive acceleration rates and the overall acceleration rate refers to the acceleration rate which was calculated using the speed at the beginning of SCL length, speed at the merge point, and time elapsed for changing speed from initial to merge speed. After comparing the calculated three acceleration rates, Ahammed decided that overall acceleration rate is a good approximation of vehicle acceleration on the SCL. Salehi (2010) also considered the overall acceleration rate to evaluate the SCL length. 
The mean, $85^{\text {th }}$ percentile, and standard deviation of overall acceleration rate for all vehicles combined ranged from 0.100 to $0.843 \mathrm{~m} / \mathrm{s}^{2}, 0.316$ to $1.120 \mathrm{~m} / \mathrm{s}^{2}$, and 0.199 to $0.291 \mathrm{~m} / \mathrm{s}^{2}$, respectively. The variation of the mean, $85^{\text {th }}$ percentile, and standard deviation of overall acceleration rate for all vehicles combined, passenger cars (PC), and heavy vehicles (HV) are shown in Figures 3.9, 3.10, and 3.11.

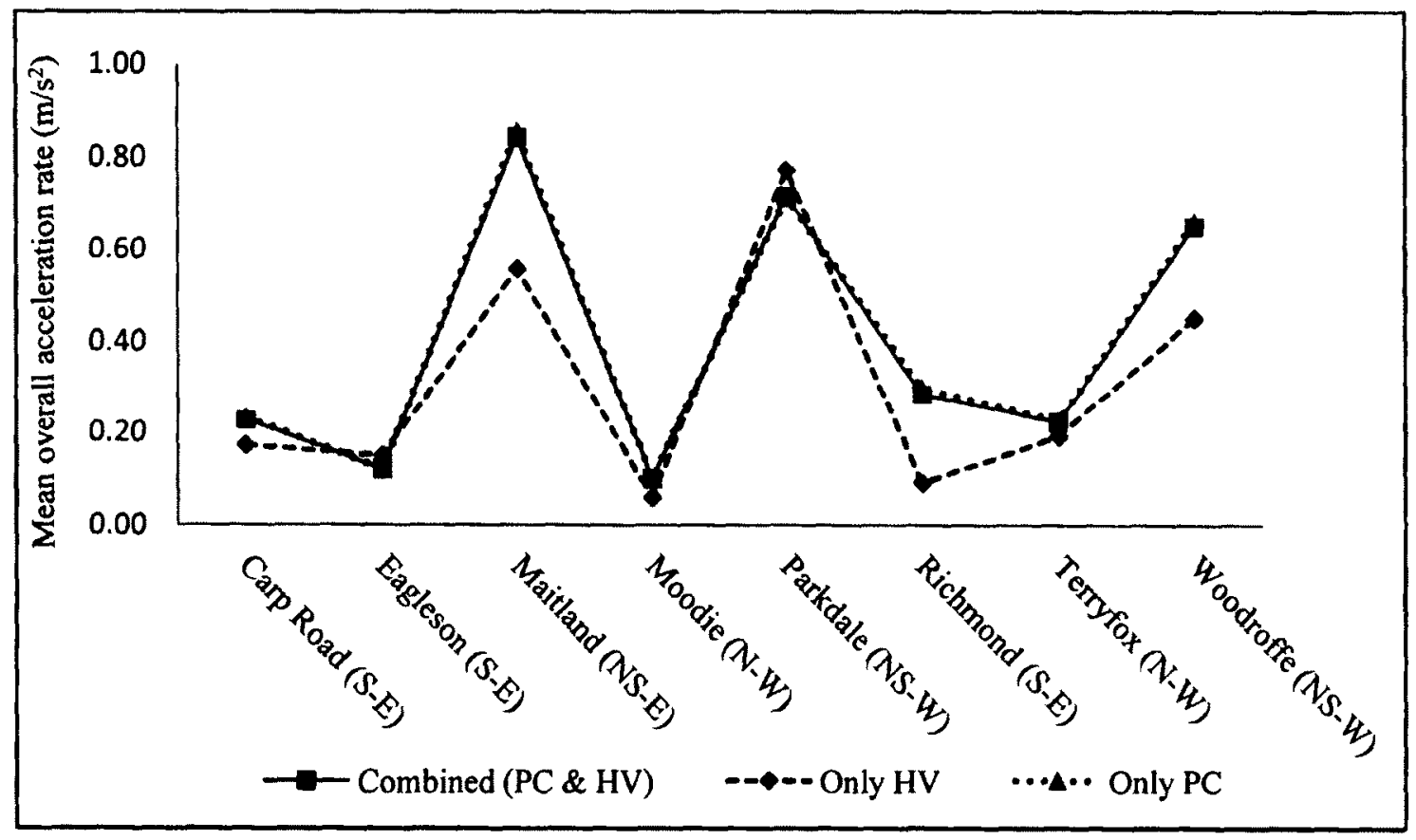

Figure 3.9: Comparison of mean overall acceleration rate among all SCLs. 


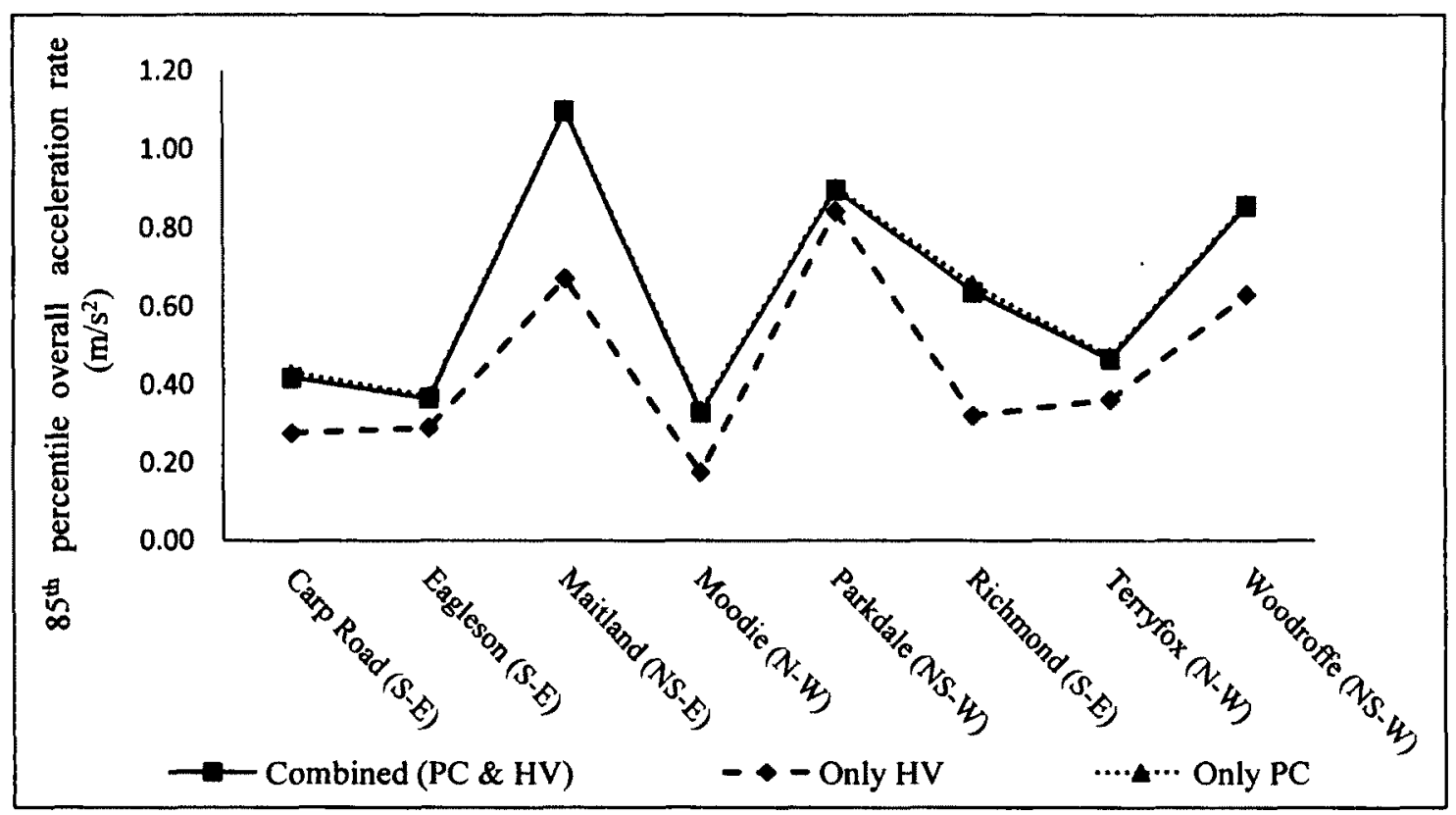

Figure 3.10: Comparison of $85^{\text {th }}$ percentile overall acceleration rate among all SCLs.

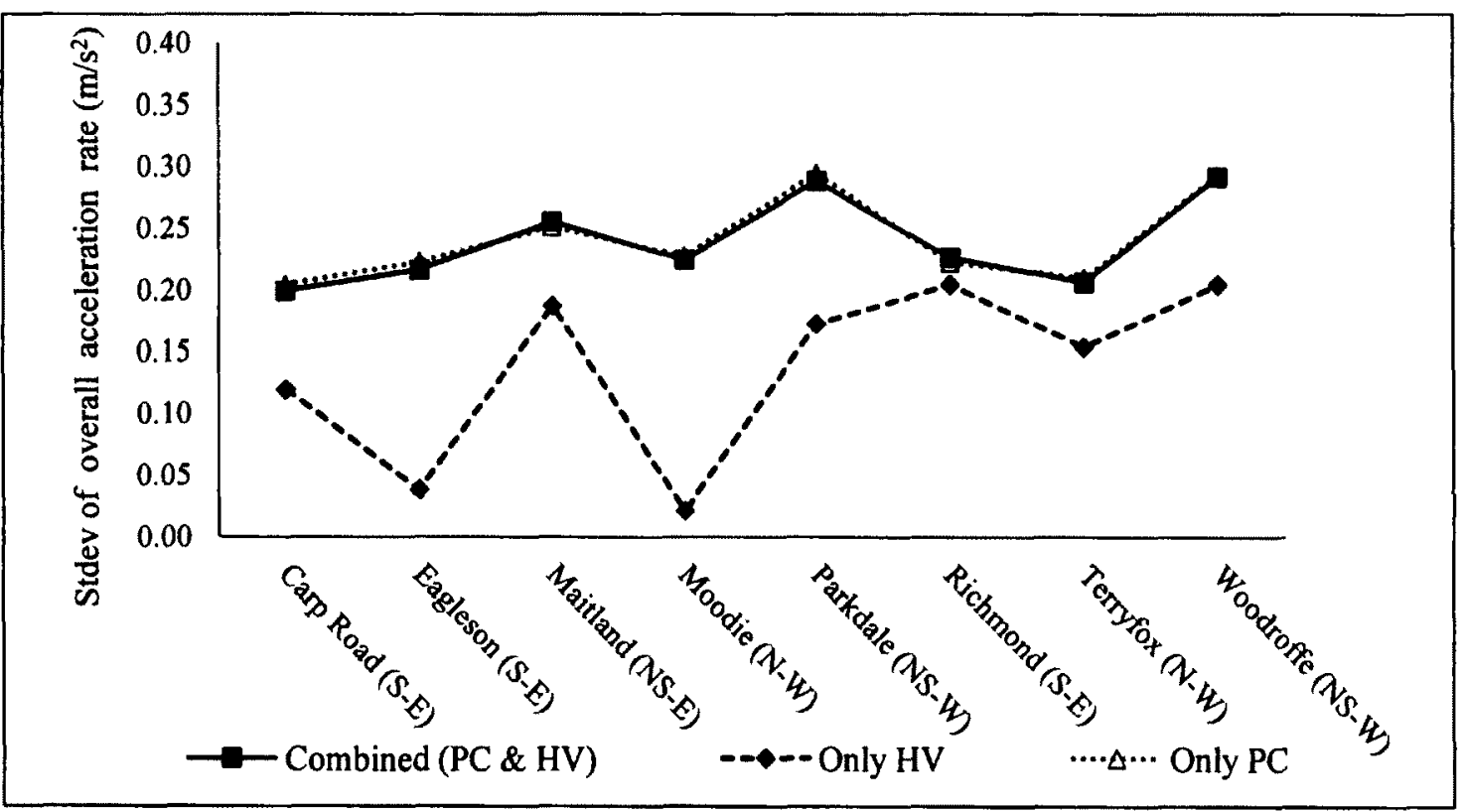

Figure 3.11: Standard deviation of overall acceleration rate among eight SCLs. 


\subsubsection{Freeway Right Lane Vehicle Speed $\left(V_{R L}\right)$}

The mean speed in the freeway right lane ranged from 96.64 to $109.29 \mathrm{~km} / \mathrm{h}$. The $85^{\text {th }}$ percentile freeway speed ranged from 106.39 to $117.54 \mathrm{~km} / \mathrm{h}$, and the standard deviation ranged from 7.51 to $11.75 \mathrm{~km} / \mathrm{h}$. The variation of the mean, standard deviation, and $85^{\text {th }}$ percentile freeway right lane speed for all vehicles combined, passenger cars (PC), and heavy vehicles (HV) are shown in Figures 3.12, 3.13, and 3.14.

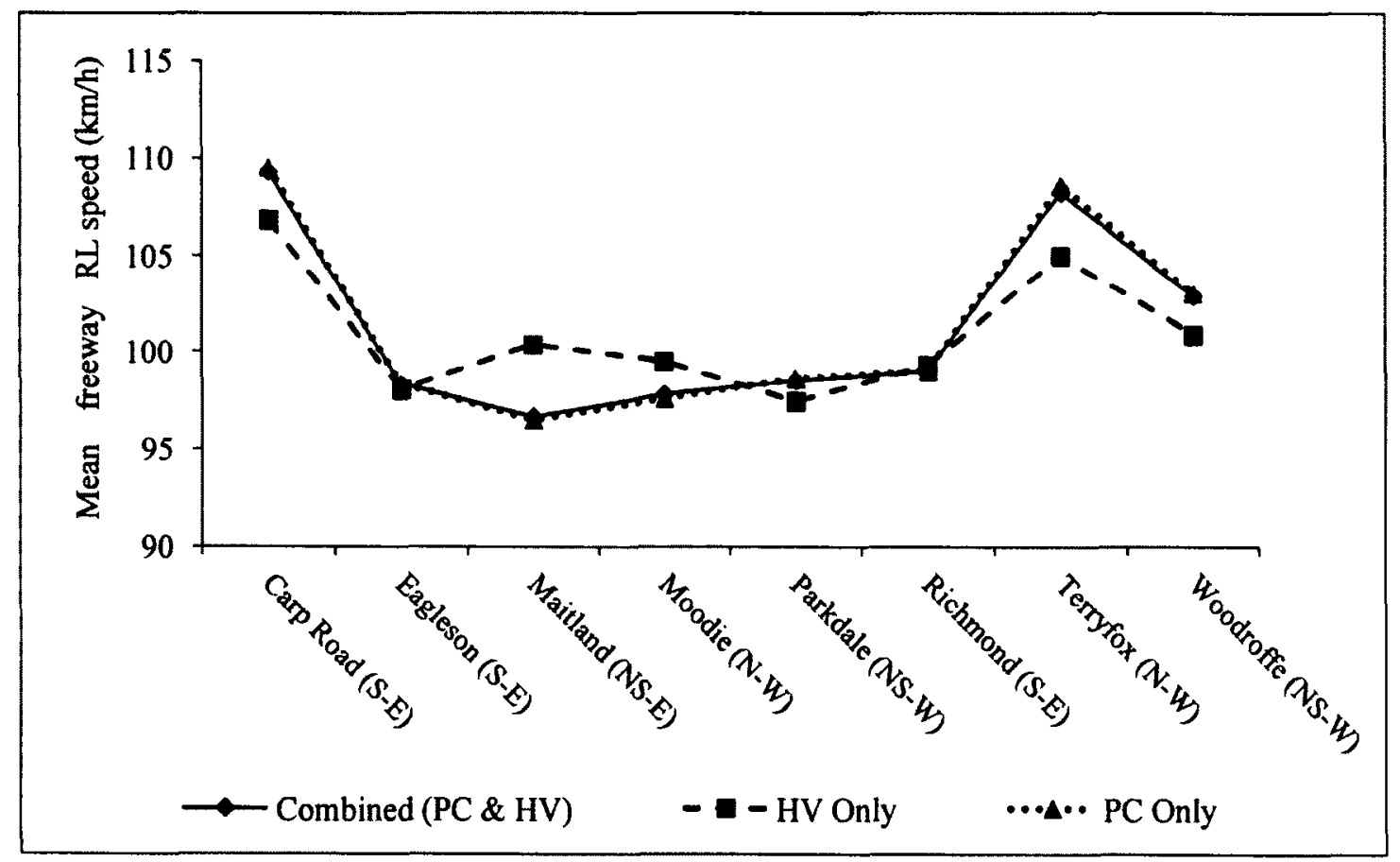

Figure 3.12: Comparison of freeway RL speed among eight SCLs 


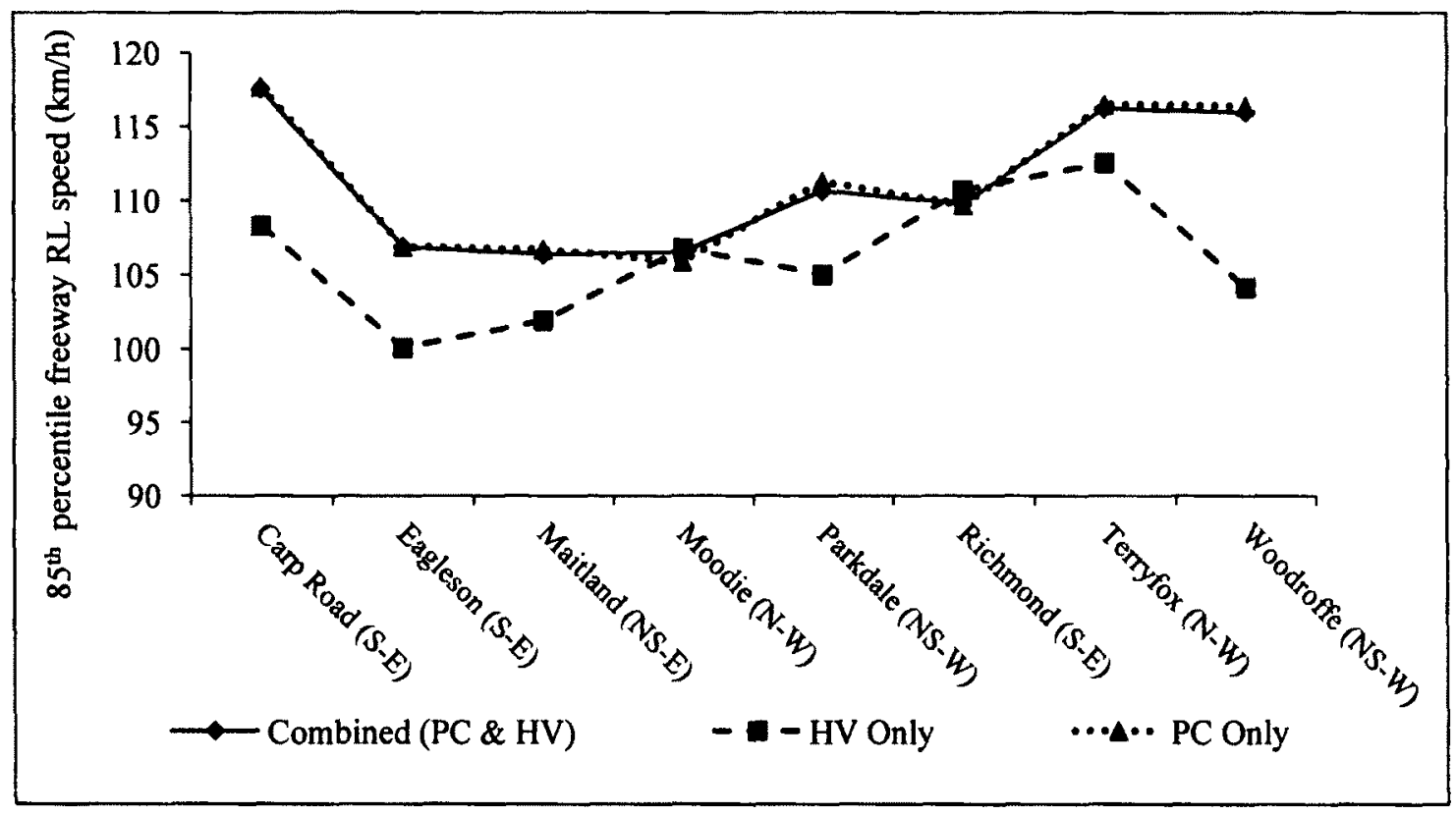

Figure 3.13: Comparison of $85^{\text {th }}$ percentile freeway speed among all SCLs.

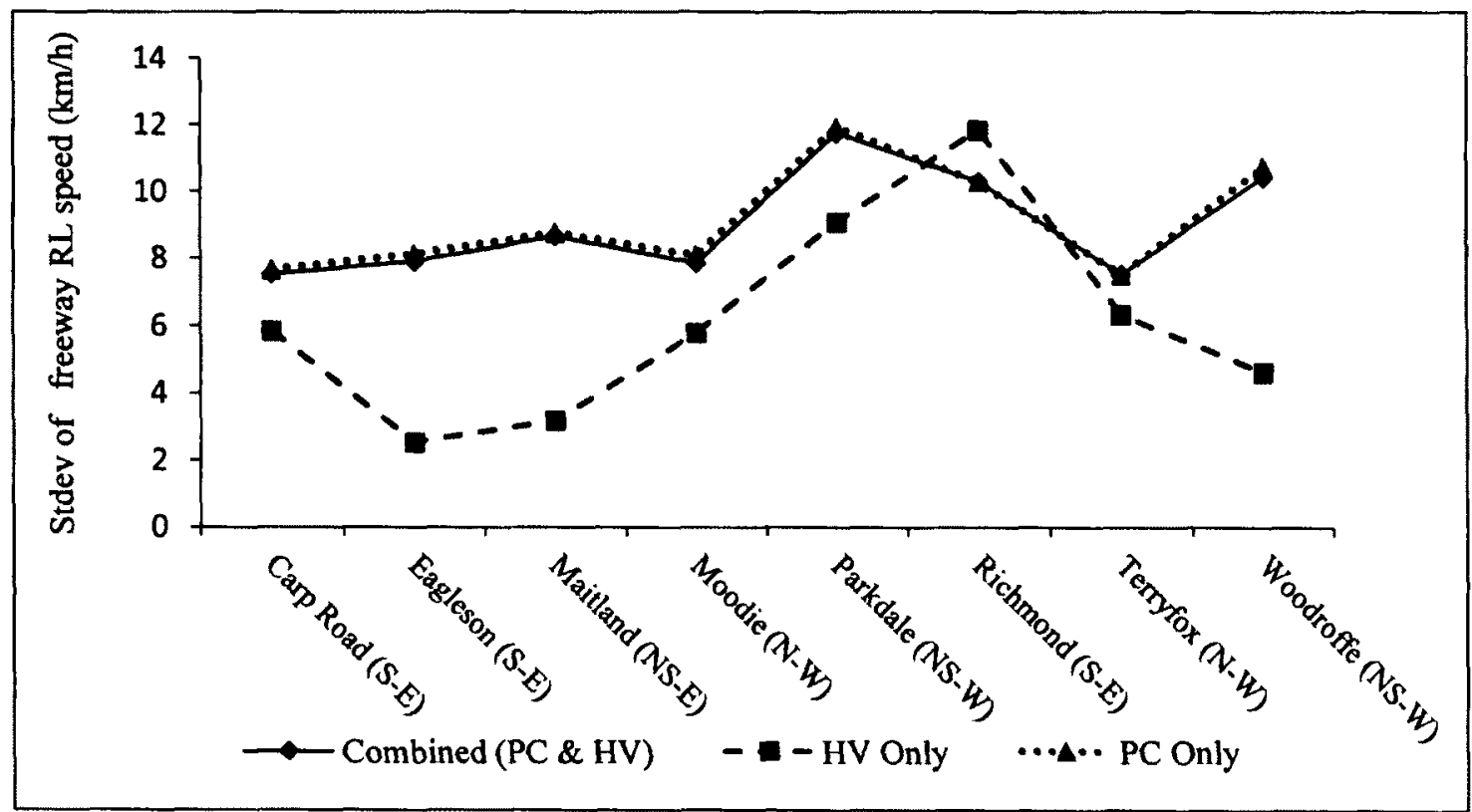

Figure 3.14: Comparison of standard deviation of freeway RL speed among SCLs 


\subsubsection{Statistical Distribution of Parameters}

The first step towards the development of the simulation model (detailed description given in Chapter 4) is the identification of the statistical distribution of parameters. The distribution of each parameter was checked using the data of each study site. The statistical tests were carried out to check whether the dataset of each parameter (the gore speed, merge speed, acceleration rate, and freeway speed) was drawn from a normal distribution or not. Normality tests, Kolmogorov-Smirnov and Shapiro-Wilk were conducted at $5 \%$ level of significance using SPSS 19.0 software. Tables 3.3, 3.4, 3.5, and 3.6 show the normality test results for gore speed $\left(V_{G}\right)$, merge speed $\left(V_{M}\right)$, freeway speed $\left(V_{R L}\right)$, and acceleration rate $(a)$ at each study site.

Table 3.3: Normality Test for Gore Speed $\left(V_{G}\right)$

\begin{tabular}{|c|c|c|c|c|}
\hline \multirow{2}{*}{ Gore speed } & \multicolumn{2}{|c|}{ Kolmogorov-Smirnov } & \multicolumn{2}{|c|}{ Shapiro-Wilk } \\
\hline & Statistic & p-value & Statistic & $p$-value \\
\hline Carp (S-E) & .536 & .936 & .988 & .602 \\
\hline Eagleson (S-E) & .696 & .717 & .981 & .140 \\
\hline Maitland(NS-E) & .974 & .275 & .976 & .053 \\
\hline Moodie(N-W) & .697 & .716 & .986 & .570 \\
\hline Parkdale(NS-W) & .495 & .967 & .991 & .776 \\
\hline Richmond(S-E) & .717 & .683 & .991 & .681 \\
\hline Terryfox $(\mathrm{N}-\mathrm{W})$ & .501 & .963 & .990 & .705 \\
\hline Woodroffe (NS-W) & .540 & .932 & .990 & .686 \\
\hline \multicolumn{5}{|c|}{$\begin{array}{l}\text { Null Hypothesis: The sample data are not significantly different from norma } \\
\text { distribution. } \\
\text { Alternative Hypothesis: The sample data are significantly different from norma } \\
\text { distribution. } \\
\text { Null Hypothesis should be rejected if } p \text {-value is less than level of significance of } 5 \% \text {. }\end{array}$} \\
\hline
\end{tabular}


Table 3.4: Normality Test for Merge Speed $\left(V_{M}\right)$

\begin{tabular}{|c|c|c|c|c|}
\hline \multirow{2}{*}{ Merge speed } & \multicolumn{2}{|c|}{ Kolmogorov-Smirnov } & \multicolumn{2}{|c|}{ Shapiro-Wilk } \\
\hline & Statistic & p-value. & Statistic & $p$-value \\
\hline Carp (S-E) & .644 & .802 & .983 & .262 \\
\hline Eagleson (S-E) & .578 & .892 & .989 & .546 \\
\hline Maitland(NS-E) & .354 & .998 & .994 & .909 \\
\hline Moodie $(\mathrm{N}-\mathrm{W})$ & .707 & .700 & .986 & .567 \\
\hline Parkdale (NS-W) & .769 & .595 & .983 & .247 \\
\hline Richmond(S-E) & .752 & .624 & .988 & .428 \\
\hline Terryfox $(\mathrm{N}-\mathrm{W})$ & .449 & .988 & .991 & .792 \\
\hline Woodroffe (NS-W) & .573 & .897 & .991 & .794 \\
\hline \multicolumn{5}{|c|}{$\begin{array}{l}\text { Null Hypothesis: The sample data are not significantly different from normal } \\
\text { distribution. } \\
\text { Alternative Hypothesis: The sample data are significantly different from normal } \\
\text { distribution. } \\
\text { Null Hypothesis should be rejected if } p \text {-value is less than level of significance of } 5 \% \text {. }\end{array}$} \\
\hline
\end{tabular}

Table 3.5: Normality Test for Freeway speed $\left(V_{R L}\right)$

\begin{tabular}{|c|c|c|c|c|}
\hline \multirow{2}{*}{ Freeway speed } & \multicolumn{2}{|c|}{ Kolmogorov-Smirnov } & \multicolumn{2}{|c|}{ Shapiro-Wilk } \\
\hline & Statistic & $p$-value & Statistic & p-value \\
\hline Carp (S-E) & .714 & .688 & .984 & .271 \\
\hline Eagleson (S-E) & .463 & .983 & .989 & .817 \\
\hline Maitland(NS-E) & .529 & .943 & .987 & .694 \\
\hline Moodie (N-W) & .617 & .814 & .983 & .504 \\
\hline Parkdale (NS-W) & .542 & .931 & .985 & .286 \\
\hline Richmond(S-E) & .579 & .891 & .986 & .262 \\
\hline Terryfox $(\mathrm{N}-\mathrm{W})$ & .547 & .927 & .987 & .461 \\
\hline Woodroffe (NS-W) & .773 & .589 & .981 & .500 \\
\hline \multicolumn{5}{|c|}{$\begin{array}{l}\text { Null Hypothesis: The sample data are not significantly different from normal } \\
\text { distribution. } \\
\text { Alternative Hypothesis: The sample data are significantly different from normal } \\
\text { distribution. } \\
\text { Null Hypothesis should be rejected if } p \text {-value is less than level of significance of } 5 \% \text {. }\end{array}$} \\
\hline
\end{tabular}


Table 3.6: Normality Test for Acceleration rate (a)

\begin{tabular}{|c|c|c|c|c|}
\hline \multirow{2}{*}{ Acceleration rate } & \multicolumn{2}{|c|}{ Kolmogorov-Smirnov } & \multicolumn{2}{|c|}{ Shapiro-Wilk } \\
\hline & Statistic & $p$-value & Statistic & $p$-value \\
\hline $\operatorname{Carp}(S-E)$ & .646 & .799 & .985 & .371 \\
\hline Eagleson (S-E) & .733 & .656 & .991 & .682 \\
\hline Maitland(NS-E) & .752 & .624 & .983 & .194 \\
\hline Moodie(N-W) & 1.262 & .043 & .989 & .001 \\
\hline Parkdale (NS-W) & .896 & .399 & .959 & .005 \\
\hline Richmond(S-E) & .528 & .943 & .994 & .878 \\
\hline Terryfox (N-W) & .656 & .783 & .989 & .592 \\
\hline Woodroffe (NS-W) & 1.986 & .028 & .955 & .003 \\
\hline \multicolumn{5}{|c|}{$\begin{array}{l}\text { Null Hypothesis: The sample data are not significantly different from normal } \\
\text { distribution. } \\
\text { Alternative Hypothesis: The sample data are significantly different from normal } \\
\text { distribution. } \\
\text { Null Hypothesis should be rejected if } p \text {-value is less than level of significance of } 5 \% \text {. }\end{array}$} \\
\hline
\end{tabular}

It is observed from Tables $3.3,3.4,3.5$, and 3.6 that the $p$ value in almost all cases was greater than 5\%. Therefore, the null hypothesis was not rejected in most of the cases for a level of significance of $5 \%$. Therefore, it can be said that the sample data for gore speed, merge speed, acceleration rate, and freeway speed in most of the study sites are not significantly different from the normal distribution.

\subsubsection{Correlation of Parameters}

This section examines the correlations among the merge speed, gore speed and acceleration rate. Correlation is a useful statistical measure that describes the extent of association between two parameters by a single number. Correlation coefficient between each two parameters was calculated using the combined data of the eight SCLs and for 
each study site. Table 3.7 shows the correlation coefficients among the merge speed, gore speed and acceleration rate by combining all data at the eight study sites. The correlation coefficients among the parameters at each study site are presented in Appendix A.

Table 3.7 Summary of Correlation Coefficients among Parameters

\begin{tabular}{cccc}
\hline & $V_{M}$ & $V_{G}$ & $a$ \\
\hline$V_{M}$ & 1 & 0.830 & -0.242 \\
\hline$V_{G}$ & 0.830 & 1 & -0.580 \\
\hline$A$ & -0.242 & -0.580 & 1 \\
\hline
\end{tabular}

The negative correlation coefficient between $V_{G}$ and $a$ indicates that when SCL drivers enter the gore area with a low speed, they adopt a high acceleration rate to attain an acceptable merge speed for merging comfortably onto the freeway. The observed correlation coefficient between $V_{M}$ and $V_{G}$ is 0.830 , which is positive and strong. This suggests that drivers who enter the gore area with a high speed will also merge onto the freeway with high speed. In the case of $a$ and $V_{M}$, the hypothesis is that a high acceleration rate will result in a high merge speed. However, as shown in the Table 3.7, the observed correlation coefficient between $a$ and $V_{M}$ is negative and weak. Based on the correlation coefficients among the three parameters, it was hypothesized by Hassan et al. (2012) that drivers who reach the gore area with relatively low speed adopt a high acceleration rate on SCL but merge with a relatively low speed compared to those who enter at a high gore speed and adopt a relatively low acceleration rate on the SCL. 


\subsubsection{Traffic Volume}

As mentioned earlier, Ahammed (2005) recorded the traffic movement on the freeway right lane and SCL using a video camera during the collection of speed data for a period of 30 to 45 minutes at each site. The number of passenger cars, buses, trucks and recreational vehicles were counted for the whole duration at each site using this video recording. In order to calculate the equivalent hourly traffic volume $(\mathrm{pc} / \mathrm{h} / \mathrm{ln})$, Ahammed (2005) converted buses, trucks and recreational vehicles to passenger car equivalent using a conversion factor of 1.5 for buses, trucks, and a conversion factor of 1.2 for recreational vehicles as recommended in the Highway Capacity Manual (HCM 2000) for level terrain. Figure 3.15 shows the equivalent hourly traffic volume on each SCL and freeway right lane at the eight study sites considered in the present study.

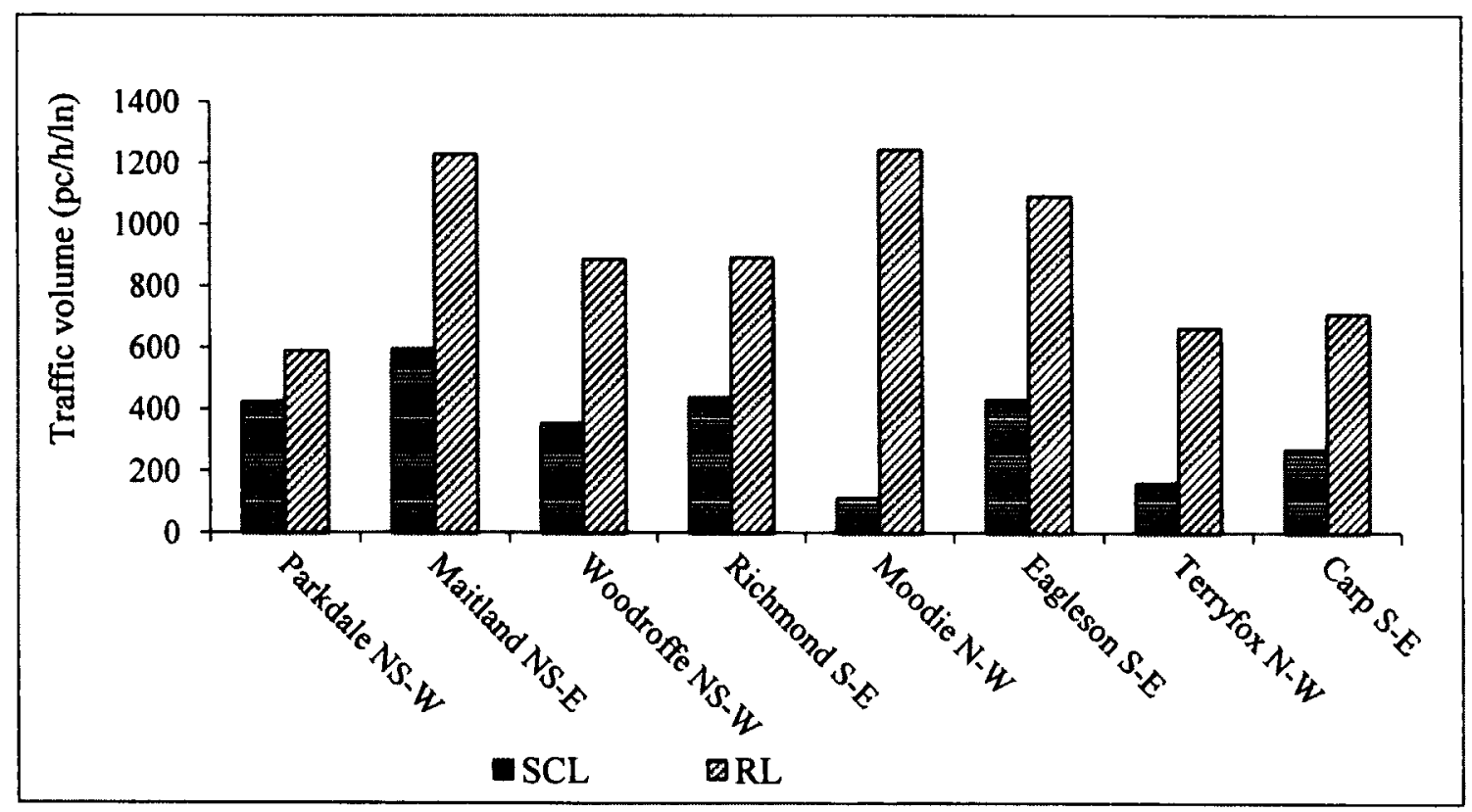

Figure 3.15: Hourly traffic volume (pc/h/ln) on SCL and on freeway right lane 
As shown in Figure 3.15, the equivalent hourly traffic volume on the selected SCL sites ranged from $111(\mathrm{pc} / \mathrm{h} / \mathrm{lane})$ to $594(\mathrm{pc} / \mathrm{h} / \mathrm{ln})$, and the equivalent hourly traffic volume on the freeway right lane ranged from $588(\mathrm{pc} / \mathrm{h} / \mathrm{ln})$ to $1244(\mathrm{pc} / \mathrm{h} / \mathrm{ln})$.

The percentage of passenger cars on the eight SCLs ranged from $93.9 \%$ to $98 \%$ and $79.8 \%$ to $94.9 \%$ on the freeway right lane. Figures 3.16 and 3.17 show the percentage of passenger cars and heavy vehicles in the traffic stream at the eight sites on SCL and on freeway right lane, respectively.

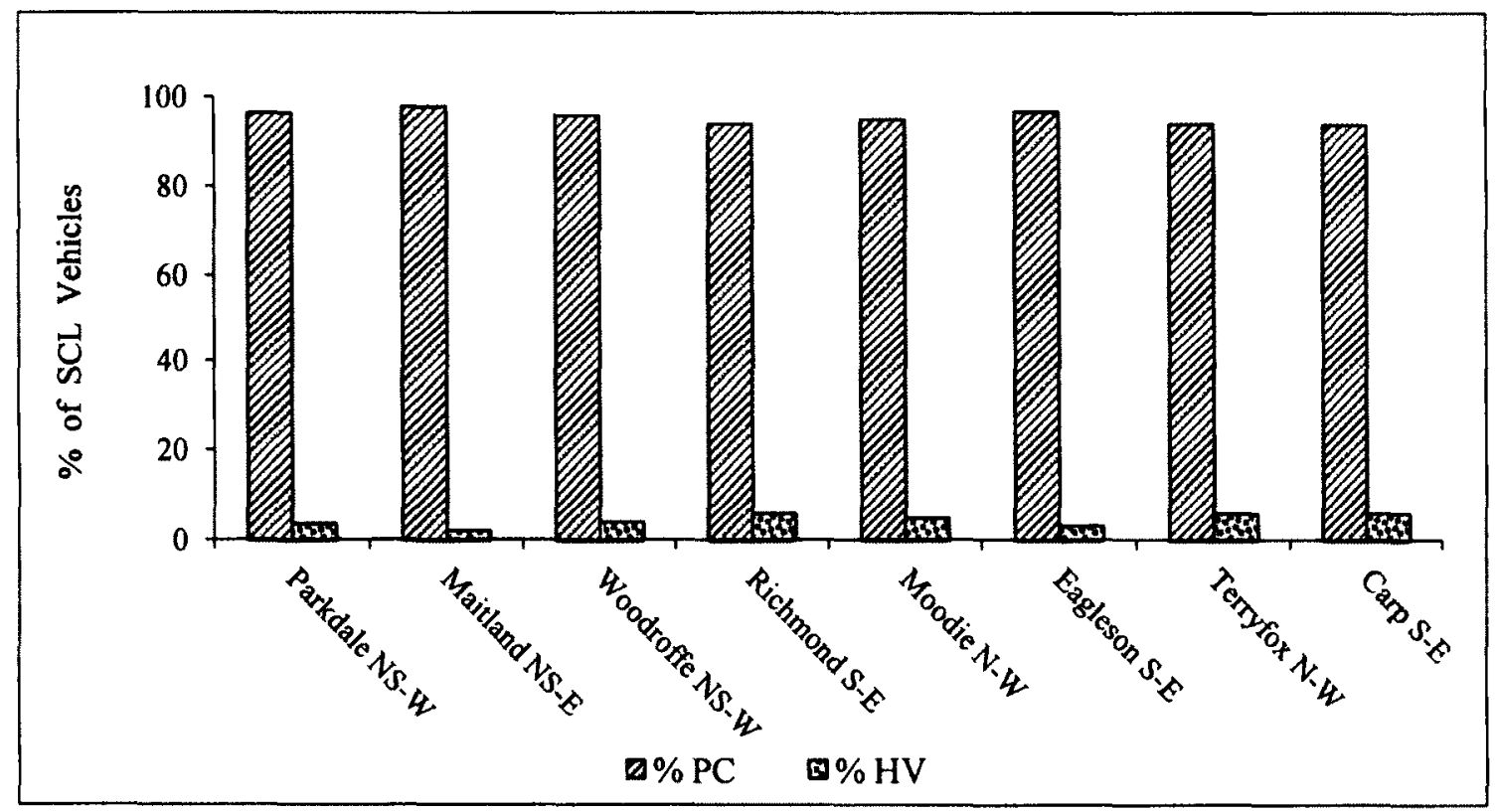

Figure 3.16: Percentage of passenger cars and heavy vehicles on the SCL. 


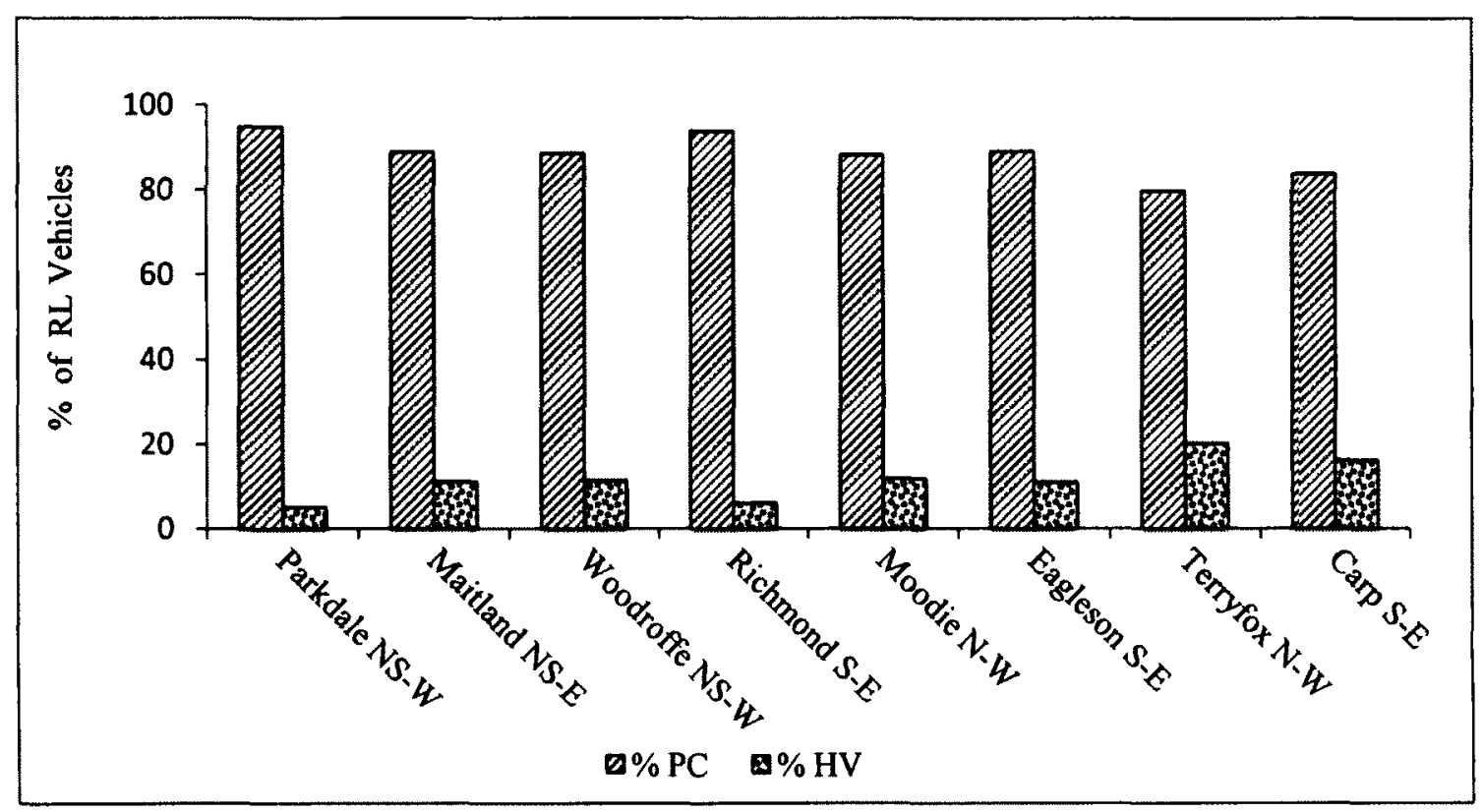

Figure 3.17: Percentage of passenger cars and heavy vehicles on the freeway right lane.

\subsubsection{Accepted Gap}

As mentioned earlier, it was found literature that drivers tend to accept smaller gap when they get close to the end of the SCL (Kita et al. 1993). In order to quantitatively examine the trend, each of the eight SCLs was divided into a number of segments. The number of segments for each SCL length was determined statistically using Sturges' method (Yang 1997). The following equation was used to determine the optimum number of segments based upon the sample size:

$K=1+3.32 \log n$

Where

$K=$ number of segments.

$n=$ sample size. 
It can be observed from Table 3.8 that the number of segments corresponding to each of SCL sites ranged from 8.5 to 9.7. Therefore, each SCL was divided into nine segments.

Figure 3.18 shows a schematic of the nine segments for each SCL.

Table 3.8: The Number of Segments for Each SCL Length

\begin{tabular}{|l|c|}
\hline \multicolumn{1}{|c|}{ SCL Length } & No of Segments \\
\hline Parkdale (NS-W) & 8.5 \\
\hline Maitland (NS-E) & 9.9 \\
\hline Terry fox (N-W) & 9.7 \\
\hline Carp (S-E) & 9.5 \\
\hline Woodroffe (NS-W) & 9.4 \\
\hline Richmond (S-E) & 9.3 \\
\hline Moodie (N-W) & 9.3 \\
\hline Eagleson (S-E) & 9.3 \\
\hline
\end{tabular}

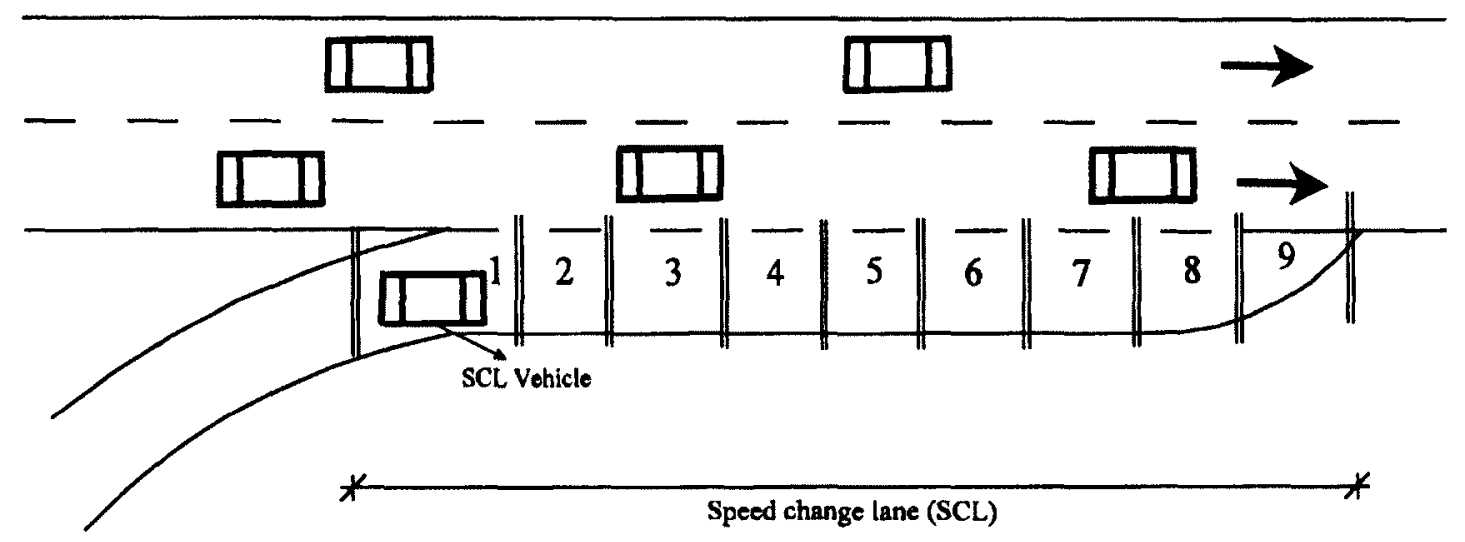

Figure 3.18: The number of segments for each SCL 
The data received from Ahammed (2005) contained a vehicle identification number, merge point, gore speed, merge speed and acceleration rate but did not include gap acceptance data. Therefore, the author of this thesis collected accepted gap for all vehicles on the eight SCLs from the video recordings. The gap data collection procedure has already been described in Section 3.2. The accepted gap data (less than or equal to 6 s) were complied for each segment of each SCL. The values of mean accepted gap at each of the nine segments of each SCL are shown in Figure 3.19. It is observed that the mean accepted gap (sec) decreases when the merging vehicle gets closer to the end of the acceleration lane. No merging activity was observed at Segment 1 in any of the study sites.

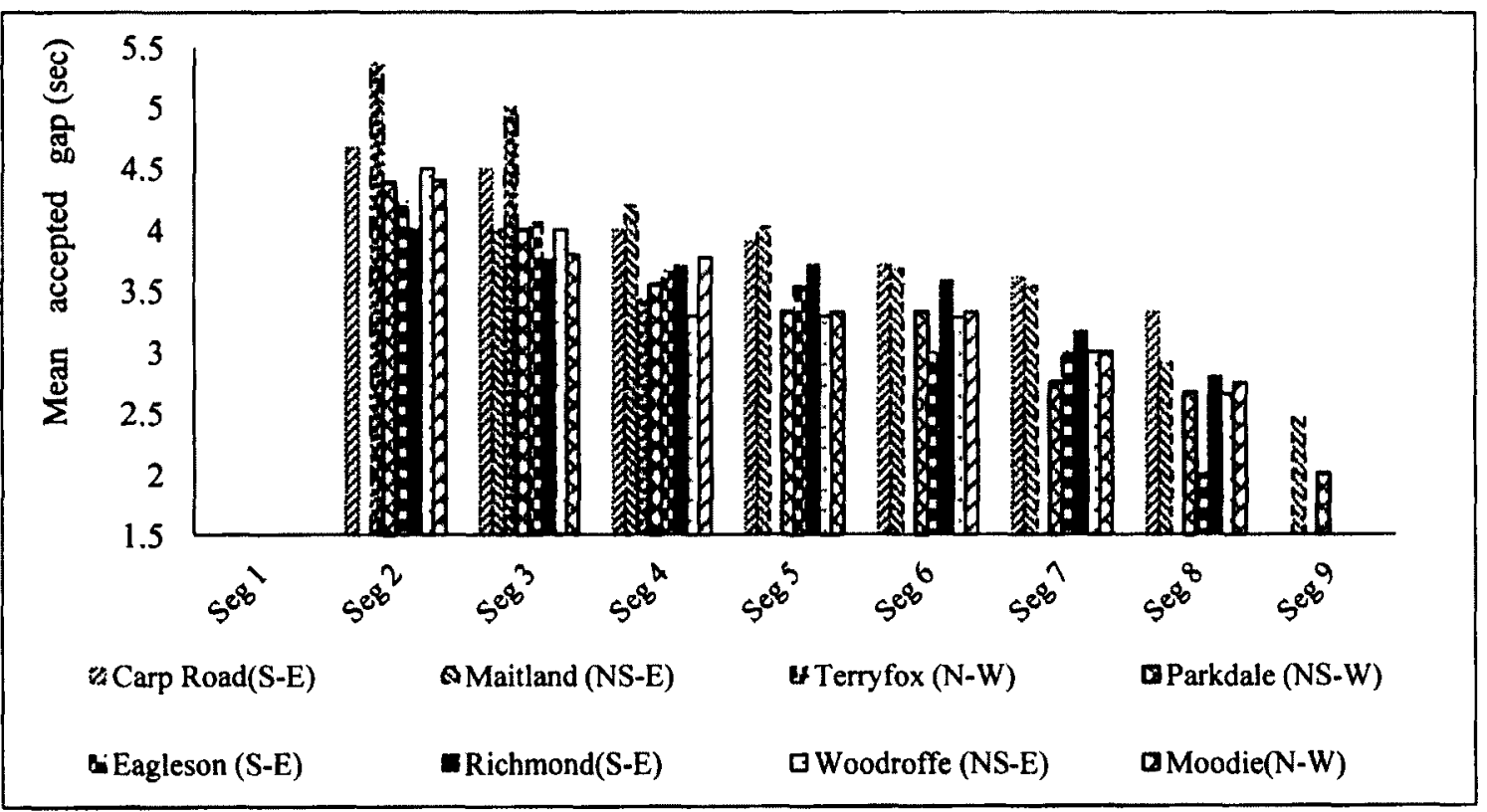

Figure 3.19: Mean accepted gap at different segments of eight SCLs 


\subsubsection{Segments of SCL Length}

The purpose of this section is to analyze and observe the accepted gap data based on the sectional lengths of each SCL. A set of statistical tests were performed to verify whether the gap data samples from the eight study sites were proportionally comparable or not according to their sectional lengths. To examine this assumption, following steps were done: the distributions of accepted gap data for eight SCLs were checked by doing the normality tests, Kolmogrov-Smirnov and Shapiro-Wilk, at 5\% level of significance. As no merging activity was observed at Segment 1 for each segment of each SCL, this segment was not considered for the normality test. Table 3.9 shows the normality test results for each segment of all SCLs 
Table 3.9: The Normality Test Results for Each Segment of Eight SCLs

\begin{tabular}{|c|c|c|c|c|c|}
\hline & \multicolumn{2}{|c|}{ Kolmogorov-Smirnov } & \multicolumn{2}{|c|}{ Shapiro-Wilk } \\
\hline & & Statistics & Sig & Statistics & Sig \\
\hline \multirow{7}{*}{ Carp Road (S-E) } & $\operatorname{Sec} 2$ & .385 & $<.001$ & .750 & $<.001$ \\
\hline & $\operatorname{Sec} 3$ & .307 & $<.001$ & .729 & .024 \\
\hline & $\operatorname{Sec} 4$ & .227 & .036 & .892 & .041 \\
\hline & $\operatorname{Sec} 5$ & .317 & .003 & .748 & .002 \\
\hline & $\operatorname{Sec} 6$ & .223 & .046 & .922 & .233 \\
\hline & $\operatorname{Sec} 7$ & .247 & .029 & .856 & .034 \\
\hline & $\operatorname{Sec} 8$ & .385 & $<.001$ & .750 & $<.001$ \\
\hline \multirow{6}{*}{ Maitland (NS-E) } & $\operatorname{Sec} 3$ & .175 & $<.001$ & .750 & $<.001$ \\
\hline & $\operatorname{Sec} 4$ & .327 & .003 & .770 & .006 \\
\hline & $\operatorname{Sec} 5$ & .222 & .178 & .906 & .258 \\
\hline & $\operatorname{Sec} 6$ & .186 & .031 & .886 & .011 \\
\hline & $\operatorname{Sec} 7$ & .268 & $<.001$ & .786 & $<.001$ \\
\hline & $\operatorname{Sec} 8$ & .202 & .223 & .853 & .167 \\
\hline \multirow{3}{*}{ Terryfox (N-W) } & $\operatorname{Sec} 2$ & .75 & $<.001$ & .786 & $<.001$ \\
\hline & $\operatorname{Sec} 3$ & .391 & $<.001$ & .683 & .001 \\
\hline & $\operatorname{Sec} 4$ & .308 & .044 & .750 & .013 \\
\hline \multirow{7}{*}{ Parkdale(NS-W) } & $\operatorname{Sec} 2$ & .256 & $<.001$ & .875 & .003 \\
\hline & $\operatorname{Sec} 3$ & .155 & .232 & .928 & .317 \\
\hline & $\operatorname{Sec} 4$ & .200 & .256 & .909 & .237 \\
\hline & $\operatorname{Sec} 5$ & .385 & $<.001$ & .750 & $<.001$ \\
\hline & $\operatorname{Sec} 6$ & .385 & $<.001$ & .750 & $<.001$ \\
\hline & $\operatorname{Sec} 7$ & .395 & $<.001$ & .777 & $<.001$ \\
\hline & $\operatorname{Sec} 8$ & .385 & $<.001$ & .695 & $<.001$ \\
\hline
\end{tabular}




\begin{tabular}{|c|c|c|c|c|c|}
\hline \multirow{6}{*}{$\operatorname{Moodie}(\mathrm{N}-\mathrm{W})$} & $\operatorname{Sec} 2$ & .275 & .020 & .898 & .174 \\
\hline & $\operatorname{Sec} 3$ & .180 & .453 & .888 & .063 \\
\hline & $\operatorname{Sec} 4$ & .186 & .460 & .917 & .229 \\
\hline & Sec 5 & .192 & .523 & .917 & .364 \\
\hline & $\operatorname{Sec} 6$ & .385 & $<.001$ & .750 & $<.001$ \\
\hline & $\operatorname{Sec} 7$ & .175 & $<.001$ & .750 & $<.001$ \\
\hline \multirow{7}{*}{ Richmond (S-E) } & $\operatorname{Sec} 2$ & .307 & $<.001$ & .729 & .024 \\
\hline & $\operatorname{Sec} 3$ & .441 & $<.001$ & .630 & $<.001$ \\
\hline & $\operatorname{Sec} 4$ & .200 & .453 & .932 & .466 \\
\hline & Sec 5 & .177 & .163 & .905 & .085 \\
\hline & Sec 6 & .193 & .032 & .896 & .041 \\
\hline & $\operatorname{Sec} 7$ & .401 & .003 & .770 & .031 \\
\hline & Sec 8 & .245 & .0914 & .820 & .085 \\
\hline \multirow{7}{*}{ Woodroffe (NS-W) } & $\operatorname{Sec} 2$ & .260 & $<.001$ & .776 & .005 \\
\hline & Sec 3 & .151 & $<.001$ & .993 & .972 \\
\hline & $\operatorname{Sec} 4$ & .327 & .003 & .770 & .006 \\
\hline & $\operatorname{Sec} 5$ & .222 & .178 & .906 & .258 \\
\hline & $\operatorname{Sec} 6$ & .186 & .031 & .886 & .011 \\
\hline & Sec 7 & .268 & $<.001$ & .786 & $<.001$ \\
\hline & Sec 8 & .202 & .253 & .853 & .167 \\
\hline \multirow{7}{*}{ Eagleson (S-E) } & $\operatorname{Sec} 2$ & .244 & $<.001$ & .890 & .001 \\
\hline & $\operatorname{Sec} 3$ & .229 & $<.001$ & .889 & .002 \\
\hline & $\operatorname{Sec} 4$ & .159 & .004 & .894 & $<.001$ \\
\hline & $\operatorname{Sec} 5$ & .160 & .023 & .899 & .004 \\
\hline & $\operatorname{Sec} 6$ & .296 & $<.001$ & .745 & $<.001$ \\
\hline & $\operatorname{Sec} 7$ & .3 & .011 & .744 & .003 \\
\hline & $\operatorname{Sec} 8$ & .296 & $<.001$ & .645 & $<.001$ \\
\hline
\end{tabular}


Table 3.9 shows that the $p$ value for most of the segments was greater than $5 \%$. The null hypothesis was rejected in most of the cases for a level of significance of $5 \%$. Therefore, it can be said that the gap data samples do not follow the normal distribution. Then, the distribution of the accepted gap data on each segment was compared across the eight sites using the non-parametric Kruskal-Wallis test. The hypotheses of the test are:

(a) Null Hypothesis, $H_{o}$ : The population distributions of accepted gap data for a specific segment are identical for the eight SCL sites.

(b) Alternative Hypothesis, $H_{a}$ : At least two sites have different probability distributions of accepted gap data on the specific segment.

$H_{o}$ should be accepted if $p$-value is greater than the level of significance.

The test results for comparison of the gap distributions (segment by segment) are summarized in the following Table 3.10 .

Table 3.10: Test Summary for Comparison of Accepted Gap Distributions across Eight SCLs (segment by segment)

\begin{tabular}{ccc}
\hline Segment & Chi-square value $(\chi 2)$ & Level of significance $(p$ value $)$ \\
\hline 2 & 2.151 & .828 \\
\hline 3 & 8.506 & .290 \\
\hline 4 & 4.867 & .676 \\
\hline 5 & 5.894 & .435 \\
\hline 6 & 8.692 & .192 \\
\hline 7 & 6.045 & .418 \\
\hline 8 & 1.914 & .927 \\
\hline 9 & 7.830 & .098 \\
\hline
\end{tabular}


Table 3.10 shows that the null hypothesis was not rejected for all nine segments at $5 \%$ level of significance. Therefore, it was concluded that the distributions of accepted gaps on each segment were proportionally comparable for the eight SCL sites. Subsequently, the data for the eight sites were combined segment by segment to form non-specific data sample that is divided into eight segments

It was checked whether the eight samples corresponding to the eight segments were statistically comparable or not. The Kruskal-Wallis test was again conducted to examine whether the gap data samples between Segment 2 and 3 are statistically comparable or not. Test statistics showed that there is no statistical evidence found to indicate a difference between the gap data in Segment 2 and 3. Therefore, the data samples of Segment 2 and 3 were combined and subsequently labeled as Segment 2 3, This sample in Segment 2 3 was then compared with that of the Segment 4 by performing the same test again. The test statistics showed that the $p$ value is less than $5 \%$. Therefore, the null hypothesis was rejected in this case for a level of significance of $5 \%$. It can be said that the data samples in Segment $2 \sim 3$ and Segment 4 were statistically different. The gap data in Segment 4 was then compared with that of Segment 5 by performing the same test again and this process was continued up to ninth segments. Table 3.11 shows the test summary for pair wise comparison of gap data sample. 
Table 3.11: Test Summary for Pair wise Comparison of Gap Data Samples

\begin{tabular}{lcc}
\hline Segment & Chi-square value $(\chi 2)$ & Level of significance $(p$ value $)$ \\
\hline $2 \& 3$ & 1.535 & 0.215 \\
\hline $2 \sim 3 \& 4$ & 15.86 & $<.001$ \\
\hline $4 \& 5$ & 0.996 & 0.318 \\
\hline $4 \sim 5 \& 6$ & 5.619 & 0.018 \\
\hline $6 \& 7$ & 2.408 & 0.121 \\
\hline $6 \sim 7 \& 8$ & 2.523 & 0.012 \\
\hline $8 \& 9$ & 2.537 & 0.111 \\
\hline
\end{tabular}

Finally, the results was to amalgamate the original segments into four larger segments as follows: (a) the second and third segments into a new Segment 1, (b) the fourth and fifth segments into a new Segment 2, (c) the sixth and seventh segments into a new segment 3 , (d) the last two segments into a segment 4 .

\subsubsection{Collision Data}

Collision data were received from Sarhan (2004) who collected the collision records on Highway 417 from the City of Ottawa. The data include five years collision records from 1998-2002 on Highway 417 within the City of Ottawa. The data fields covered location, date, time, and day of the week, collision type, and severity (fatal injury, nonfatal injury and property damage only (PDO). Fatal injury collisions were those where at least one person died within one month of the occurrence of the collision. Non-fatal injury collisions corresponded to those collisions where no people died but at least one people was bodily injured. Finally, property damage only (PDO) collisions referred to those collisions with no bodily injury and the cost of property damage exceeded $\$ 1000$. 
Sarhan (2004) processed the data and examined two collision measures for each site: total collisions (TCol) and equivalent property damage only (EPDO). The EPDO measure was calculated by summing up all three types of collisions after giving them weight factors. Sarhan (2004) discarded EPDO as it could not be used successfully in collision prediction modelling. Tcol was calculated as the arithmetic sum of three types of collision. The total number of collisions on sections including the SCL was termed as TCol and the number of collisions on acceleration lanes was termed as TColAcc. Total Collision on acceleration lane (TColAcc) was used in the current research. Figure 3.20 shows the distribution of collision frequency of TColAcc on each of the eight sites considered in this study.

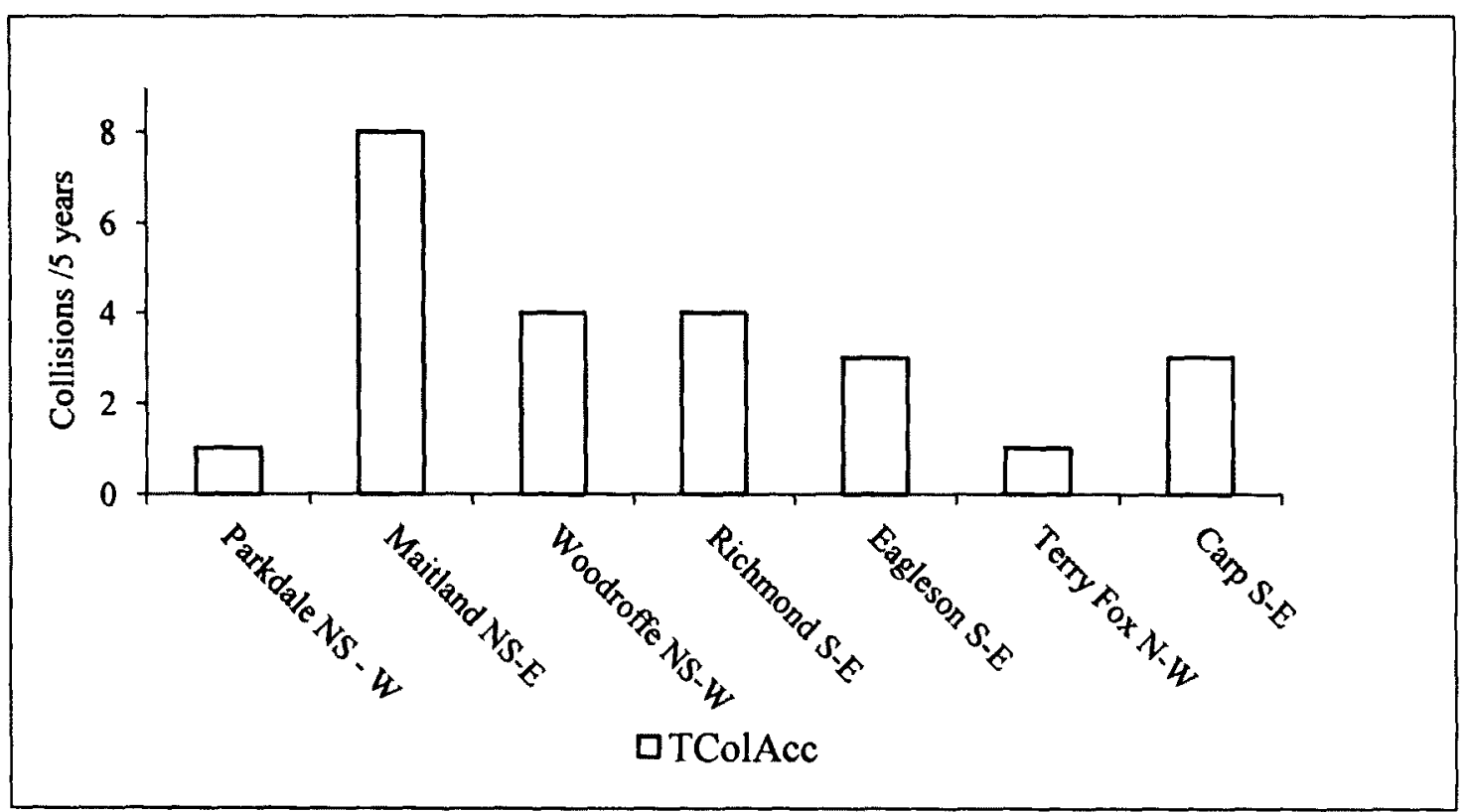

Figure 3.20: Collision frequency on the acceleration lane only 


\section{METHODOLOGY}

In the current study, a probabilistic model is proposed to understand the effect of SCL length on the freeway merging process. The conceptual framework and methodology used for modelling the merging process on SCL are presented in this chapter. Section 4.1 provides a brief discussion of the proposed model. Section 4.2 presents general discussion of the modelling technique. Section 4.3 presents the methodology which is used to evaluate the non-compliance of SCL vehicle for a specific SCL. Finally, Section 4.4 presents the interpretation of model output.

\subsection{Introduction}

In the current design guides, SCL lengths are recommended implicitly based on the SCL vehicles' acceleration performance. The current design guides consider initial speed, operating speed and acceleration rate for the determination of SCL length, where the initial speed and operating speed refer to the speed at the end of entrance ramp curve and merge speed of the vehicle, respectively. Polus et al. (1985) reported that most of the merging drivers on the acceleration lane do not seem to use the merging distance for acceleration purpose only, rather the gap searching and acceptance issue is more focused during the merging process. AASHTO (2011) states that: " $A$ speed-change lane should have sufficient length to enable a driver to make the appropriate change in speed between the highway and the turning roadway in a safe and comfortable manner. 
Moreover, in the case of an acceleration lane there should be additional length to permit adjustments in speeds of both through and entering vehicles so that the driver of the vehicle can position himself opposite a gap in the through-traffic stream and manoeuvre into it before reaching the end of the acceleration lane."

Although, the guide mentions that gap acceptance is a fact in the design of SCL length, it has not been completely examined quantitatively in any of the previous research for determination of the SCL length. In reality, the overall merging process from SCL to freeway is dependent on the drivers' acceleration and gap acceptance behaviour. SCL drivers' acceleration and gap acceptance behaviour are associated with vehicles' speed at the beginning of SCL, acceptable merge speed, acceleration rate, available gap in the freeway right lane, and freeway vehicles' speed. All of these parameters are related to human factors and vehicle characteristics which are stochastic in nature. Ben-Akiva et al. (1985) proposed a new way to consider the probabilistic approach in highway geometric design where distribution of possible design values have been considered instead of a single value for each parameter. This probabilistic approach poses different possibilities of output so that designers can select an appropriate design value considering safety, economy, and other factors. In the present study, a probabilistic model is proposed considering the SCL drivers' acceleration and gap searching behaviour during the merging process onto the freeway. It has been mentioned in Chapter 3 that the current research is a continuation of previous research. Salehi (2010) conducted a research on the same study area considering 15 limited type SCLs and developed a probabilistic method based on the reliability theory for calculating the SCL length. The output of his model is a distribution of drivers' 
acceleration distance on the SCL. In his research, the distance travelled by the drivers on SCL is considered for acceleration purposes only.

In the present study, both acceleration and gap searching behaviour of drivers are considered during the merging process. A simulation technique is used to model the overall merging process from gore area to the end of SCL length. The model checks whether all of the SCL vehicles coming onto the acceleration lane could merge comfortably after accelerating and searching gap. The output of model provides the anticipated failed merging associated with a specific SCL length. However, a theoretically failed merge will actually be a forced or uncomfortable merge. In addition, although forced merging would increase the probability of collisions, not every forced merge would result the probability of collisions, not every forced merge would result in a collision. Therefore, in this research a successful merge will be referred to as comfortable merge while failed merge will be referred to as forced or uncomfortable merge. The final output of the model will be termed as probability of non-compliance (PNC) of each vehicle associated with a SCL length which will reflect the probability of forced merge.

\subsection{Simulation Technique}

Computer simulation techniques have been widely used in the field of transportation engineering in order to understand the traffic interactions. Such techniques can aid in assessing the influence of different parameters on the system. The prediction of the performance of a complex system through a logical and mathematical solution is often 
achieved by the simulation models. In the current study, computer simulation techniques, namely Monte Carlo and microscopic simulation, are applied to simulate the merging process of vehicles from the SCL to freeway right lane.

\subsubsection{Monte Carlo Simulation}

In the Monte Carlo simulation technique, random numbers are generated for each input parameter. The input parameters should follow a pre-defined distribution. Several rounds of sampling ensure that each random parameter represents the real distribution. A matrix is then formed considering a set of all random parameters where each column represents an input parameter and each row represents random scenario of parameter. The generated random numbers in each row are used to estimate the model's outcome of design element based on a physical relationship. The accuracy of the simulation depends on the number of trials (Reuven et al. 1981). In the present study, Monte Carlo simulation is used to consider the variability of the vehicle parameters. In this technique, large number of vehicles is generated on the SCL to capture the outcome of the whole population.

\subsubsection{Microscopic Simulation}

Microscopic traffic simulation is a stochastic modelling technique where the movement of individual vehicles are taken into consideration on a second or sub-second basis. In 
this technique, a series of logical algorithms and rules are applied to model the vehicles' movement and interactions.

\subsection{Modelling of Merging Scenario}

In the simulation model, vehicles' acceleration and merging from the SCL to freeway can be idealized into a four-step process as follows:

Step 1: Initially the vehicle enters onto the SCL with a specific initial speed which is the speed at the end of entrance ramp curve.

Step 2: SCL vehicle controls speed to attain an acceptable merge speed through acceleration.

Step 3: SCL driver scans vehicles on the adjacent freeway lane in search of a gap.

Step 4: SCL vehicle merges onto the freeway right lane when both merge speed and gap are acceptable.

In order to simulate the above merging process, the input parameters considered in the model are SCL vehicles' initial speed, merge speed, acceleration rate, acceptable gap size at different locations of SCL, freeway right lane traffic volume, freeway traffic composition (percentage of passenger cars and heavy vehicles), freeway vehicle's length, freeway vehicles' speed, and correlations among merge speed, initial speed, and acceleration rate. Characteristics of these parameters were extracted from the field data. 
Details of the input parameters and assumptions considered in the model are described in the following paragraphs:

- Ahammed (2005) collected speed data of each SCL vehicle from the proximity of gore area to the merge point. In his research, the initial speed was termed as gore speed and the speed at the merge point was termed as merge speed. In the proposed model of the present study, the initial speed of the SCL driver is termed as gore speed as Ahammed (2005).

- Salehi (2010) conducted a research on the same data collected by Ahammed (2005) and observed that the SCL vehicles accelerate from gore speed to an acceptable merge speed using a constant acceleration rate. According to Salehi, this is most likely due to the limited length of the SCL. Based on this observation, it is assumed in the simulation model that each SCL vehicle maintains a constant acceleration rate during the movement on SCL until it reaches an acceptable merge speed.

- Once a SCL vehicle reaches the acceptable merge speed, the vehicle ceases acceleration and maintains this constant speed until it merges onto the freeway right lane or reaches the end of SCL.

- Based on the field data at eight study sites, it was found that SCL vehicles' gore speed, merge speed, acceleration rate, and freeway vehicles' right lane speed follow the normal distribution.

- For a specific freeway right lane traffic volume, a headway is assigned to each freeway vehicle that is measured from the front of the lead vehicle to the front of 
the lag vehicle. On the other hand, the available gap between each two successive freeway vehicles is calculated as the clear distance between the rear of the lead vehicle to the front of the lag vehicle. Therefore, vehicle's length is used to calculate the available gap in the freeway right lane. Figure 4.1 shows the relationship between headway and available gap.

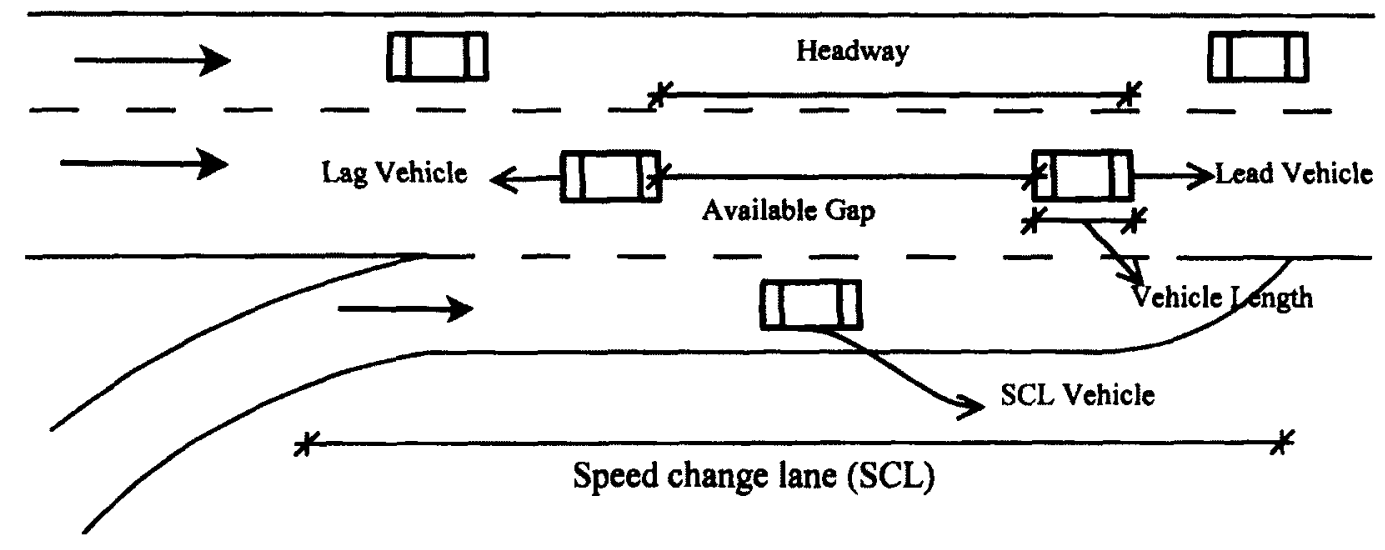

Figure 4.1: The relationship between headway and available gap.

- Freeway right lane vehicles maintain a constant speed throughout the movement while maintaining a minimum gap with the lead vehicle.

- Freeway right lane vehicles do not perform any accommodating manoeuvres to allow SCL to merge onto the freeway.

- Only one SCL vehicle is considered at a time, and no friction between SCL vehicles is considered. 
- From field data, it is observed that drivers tend to accept smaller gap sizes, as they get closer to the end of SCL. Therefore, the length is divided into four segments each having uniform drivers' gap acceptance characteristics. The reason for dividing the SCL length into four segments has already been discussed in Chapter 3. It is assumed that the SCL driver accepts a different gap size in the freeway right lane at each of the four segments of SCL. Therefore, four different acceptable gap sizes corresponding to the four segments are assigned to each SCL vehicle. In the current study, the acceptable gap size refers to a target gap that can be accepted by the SCL driver in order to merge comfortably onto the freeway right lane.

- A SCL vehicle can merge onto the freeway only if it has attained the acceptable merge speed and can find an acceptable gap.

\subsubsection{Framework of Model}

In the simulation model of the current study, only two lanes are considered, the speed change lane (SCL) and the freeway right lane. MATLAB 7.8 software was used for simulating the merging process. At the beginning of simulation model, a SCL length is specified and divided into equal four segments. The acceptable gaps for the four segments, gore speed, merge speed, and acceleration rate are assigned to each SCL vehicle as discussed in Section 4.3.3. Then, twenty number of freeway vehicles are generated and positioned on the freeway right lane behind the start point of SCL length. This twenty number of freeway vehicles are considered due to reduction of the 
computation time and to maximize the efficiency of the program. The freeway vehicles' headway and speed are assigned randomly based on the corresponding distributions as discussed in section 4.3.3. The simulation is then run for 10 seconds so that some freeway vehicles can form a platoon adjacent to the SCL. Subsequently, one SCL vehicle is released on the SCL. The SCL vehicle enters onto the SCL length with the assigned initial speed and starts to accelerate from the beginning of SCL length at the assigned constant acceleration rate until it reaches the assigned acceptable merge speed. When the acceptable merge speed is attained, the SCL vehicle seizes acceleration and starts to search gap onto the freeway right lane. In the model, the position of the SCL and freeway vehicles is updated at a time step of $0.1 \mathrm{sec}$. The SCL vehicle's speed is also updated at the same time step. Through the simulation, once a SCL vehicle reaches at the end of the SCL, twenty number of freeway vehicles are again generated. After forming freeway vehicle's platoon at the adjacent right lane, next SCL vehicle is generated on the start point of SCL length and subsequently, this SCL vehicle starts to check the acceptable merge speed and acceptable gap for merging. This process continues until the last SCL vehicle reaches at the end of SCL length. The output of model provides the probability of non-compliance (PNC) for merging of each SCL vehicle. The PNC of each SCL vehicle is evaluated based on two conditions: (i) whether the SCL vehicle would attain an acceptable merge speed, and (ii) whether the SCL vehicle would find an acceptable gap in the freeway right lane for comfortable merging. These two conditions are checked in each of the four segments of SCL. Figure 4.2 shows flow-chart of the simulation logic. 
In order to accomplish the above sequences, the proposed model is divided into three sub-models: (i) generation of freeway vehicles, (ii) generation of SCL vehicles, and (iii) evaluation of the non-compliance. Details descriptions of each sub-model are discussed in the rest of the sections. 


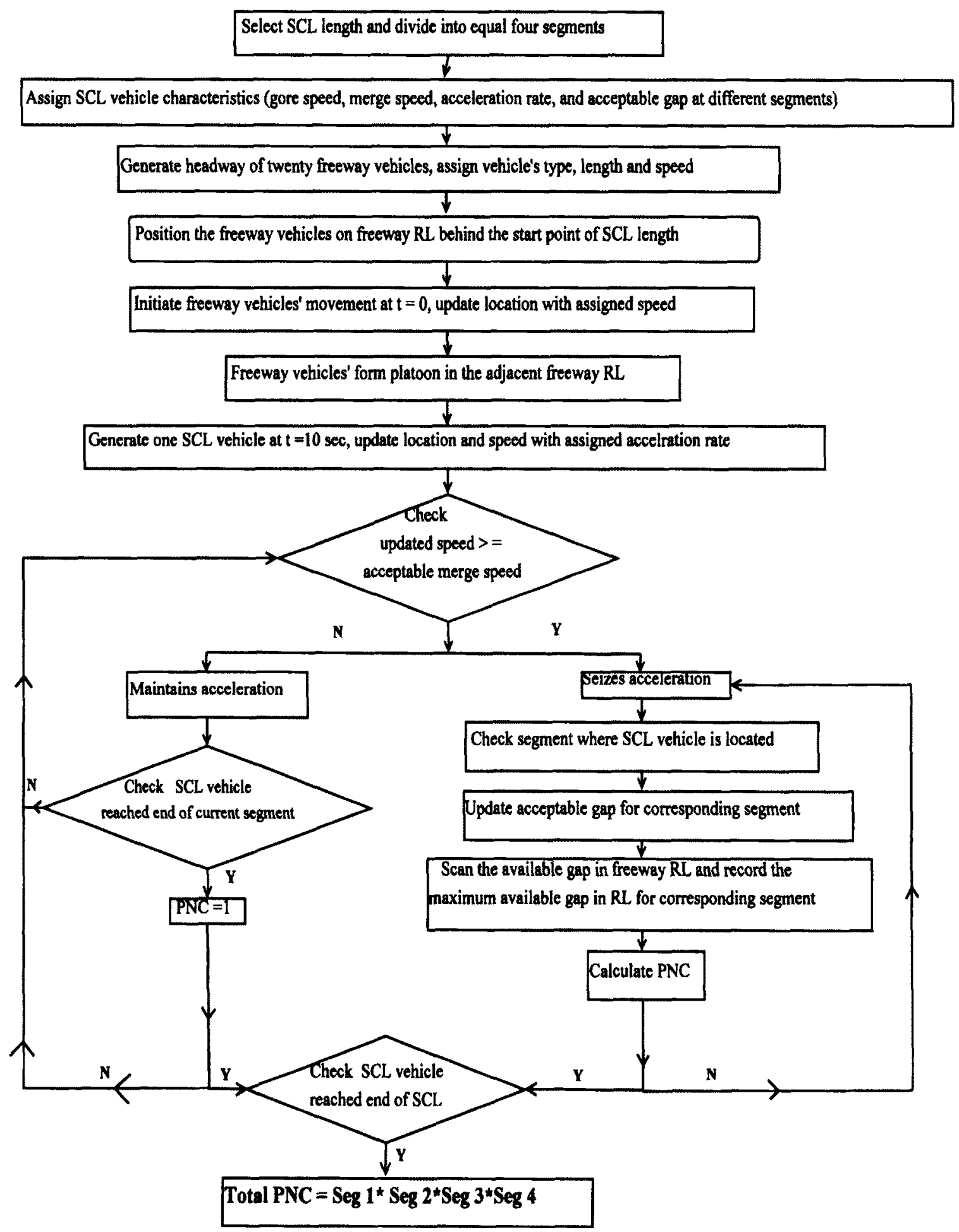

Figure 4.2: Flow chart of the simulation logic 


\subsubsection{Generation of SCL Vehicle}

\subsection{2 (a) SCL Vehicles' Characteristics}

In the model, individual driving characteristics are assigned to each vehicle using the Monte Carlo simulation technique. The SCL vehicle parameters in the simulation can be classified into two main categories: speed and acceleration parameters and gap acceptance parameters. Information collected from the field data are used to stochastically assign speed, acceleration and gap acceptance parameters. The process consists of several steps as follows:

- At first, uncorrelated random numbers are generated for each parameter (merge speed, gore speed and acceleration rate) in the range of 0 to 1 .

- From the field data, it was found that the merge speed, gore speed and acceleration rate are correlated. The correlation coefficients among parameters change from one SCL site to the other and for all sites combined. The correlation matrix of parameters is used to convert the set of uncorrelated random numbers to correlated random numbers using the Cholesky decomposition method (Kaiser and Ditchman 1962). The following example shows how correlated random numbers are generated using the Cholesky decomposition. In this example, the correlation matrix [C] for all sites combined is used.

$$
C=\left[\begin{array}{ccc}
1 & 0.830 & -0.242 \\
0.830 & 1 & -0.580 \\
-0.242 & -0.580 & 1
\end{array}\right]
$$


The Cholesky decomposition is applied to the correlation matrix to find the upper triangular matrix $\mathrm{A}$ such that $\mathrm{C}=A A^{T}$. For the example given below:

$$
A=\left[\begin{array}{ccc}
1 & 0.830 & -0.242 \\
0 & 0.558 & -0.679 \\
0 & 0 & 0.692
\end{array}\right]
$$

Now, consider three uncorrelated random numbers represented by the vector, $X$. It is possible to transform these three uncorrelated numbers into correlated numbers ( $X_{o}$ ) by multiplying $X$ by $A$.

$$
\begin{aligned}
& X=\left[\begin{array}{lll}
0.1269 & 0.4749 & 0.4536
\end{array}\right] \\
& X_{o}=X * A=\left[\begin{array}{lll}
0.1269 & 0.4749 & 0.4536
\end{array}\right] *\left[\begin{array}{ccc}
1 & 0.830 & -0.242 \\
0 & 0.558 & 0.679 \\
0 & 0 & 0.692
\end{array}\right] \\
&=\left[\begin{array}{lll}
0.1269 & 0.3702 & -0.0395
\end{array}\right]
\end{aligned}
$$

The generated correlated random numbers are used along with the mean, standard deviation, and distribution for each parameter to generate random values of gore speed, merge speed, and acceleration rate. Based on the observed distributions of field data, normal distribution is considered for each parameter. In the model, inverse of normal probability density function is used to generate the values of parameters using the set of random correlated numbers. The normal inverse function can be expressed in terms of normal cumulative distribution function (Ang et al. 1975). Mathematically,

$$
x=F^{-1}(p \mid \mu, \sigma)
$$




$$
\begin{aligned}
& \text { Where } \\
& \begin{array}{l}
p=F(x \mid \mu, \sigma) \\
=\frac{1}{\sigma \sqrt{2 \pi}} \int_{-\infty}^{x} e^{\frac{-(x-\mu)^{2}}{2 \sigma^{2}}} d x
\end{array}
\end{aligned}
$$

Where,

$\mu=$ the mean of parameter.

$\sigma=$ the standard deviation of parameter.

$x=$ generated random parameter

- The assigned gore speed represents the initial speed and the merge speed represents the acceptable speed to merge comfortably onto the freeway.

- The generated parameters are then checked to remove any abnormalities or extreme values.

- All negative speeds or acceleration rates are considered abnormalities.

- As for extreme speed values, it was decided to control the speed difference between the assigned values of merge speed and gore speed and acceleration rate. Any value of speed difference or acceleration rate deviating from the mean value by more than two times the standard deviation is considered an extreme value.

- Next step, the acceptable gaps in each of the four segments on SCL are assigned to each vehicle. The process consists of several steps as follows:

It has been mentioned in Chapter 3 that data regarding each SCL vehicle's merging point, merge speed, gore speed, acceleration rate, and accepted gap sizes were extracted from the eight SCLs. As each SCL was divided into four segments, data were isolated for each segment according to the 
merging point. Then, all of the data from eight SCLs were combined segment wise, i.e. all data of segment one of the eight SCLs were combined and the same procedure was followed for the other three segments. Using the field data, it was tried to develop a model for each segment in order to predict the acceptable gap size. Linear regression analysis was used to develop the model for each segment where accepted gap was entered as dependent variable, and merge speed, gore speed, and acceleration rate were entered as independent variables. Finally, four linear equations were developed for each of the four segments to predict the acceptable gap size. The details description of the developed models will be presented in Chapter 5. As linear equation is developed based on the sample data from population, the value of acceptable gap size using the linear regression equation is a prediction of the mean of acceptable gap $\left(\mu_{A c c, G a p}\right)$ for a given value of independent variable. The standard deviation $(\sigma)$ of acceptable gap at any value of independent variable is equal to the standard error of the regression model. It is assumed in regression model, the standard deviation is same for all of the values of independent variable. Let us consider a linear regression equation $\mu_{G}=\alpha_{0}+\alpha_{1} x$. Figure 4.3 illustrates the linear regression assumption. 
For any given value of $x$, the dependent variable $y$ follow a normal distribution

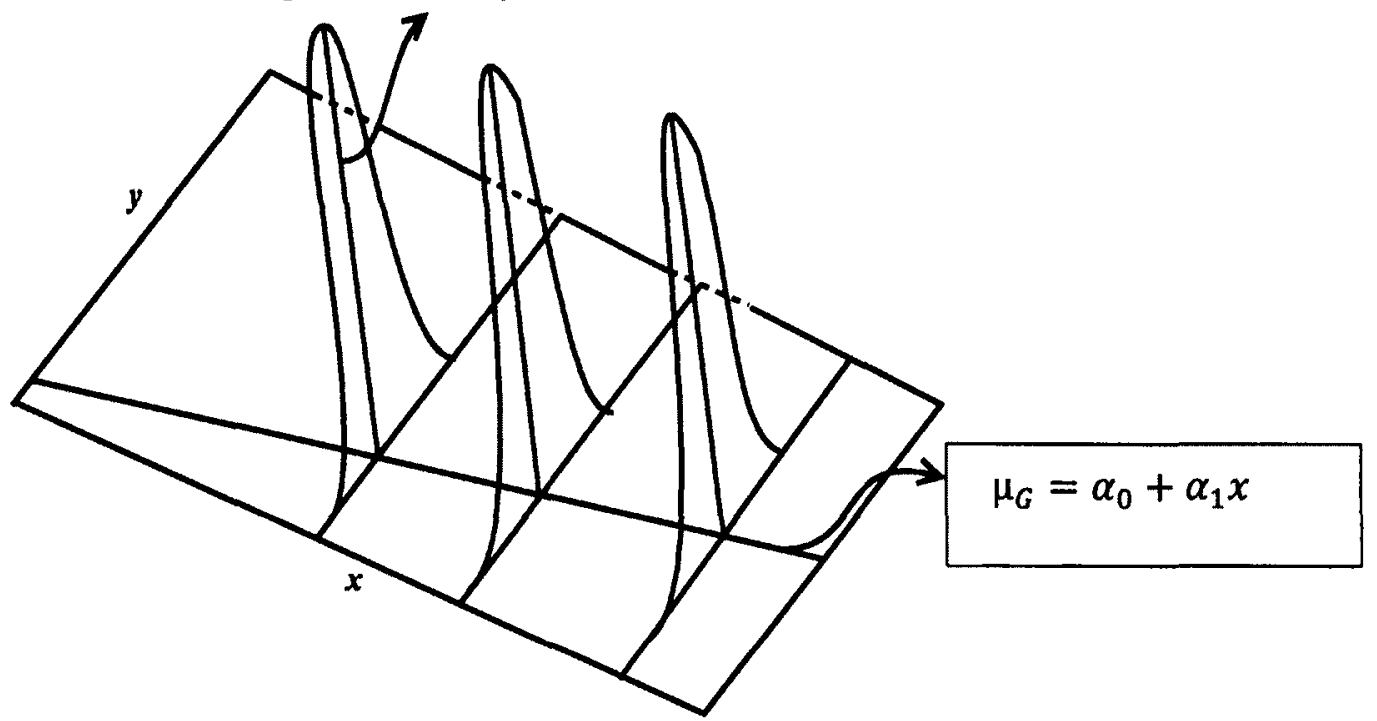

Figure 4.3: Illustration of linear regression assumption

\subsection{2 (b) SCL Vehicles' Location}

When a SCL vehicle is released at the beginning of SCL length, the vehicle's speed gets updated at each time step. Using this updated speed, SCL vehicle's position is also updated. The speed is updated using the following equation as follows:

$u_{i}=u_{i-1}+a * \Delta t$

Where

$u_{i}=$ updated speed, $(\mathrm{m} / \mathrm{sec})$.

$u_{i-1}=$ speed at the beginning of step, $(\mathrm{m} / \mathrm{sec})$.

$a=$ acceleration rate, $\left(\mathrm{m} / \mathrm{s}^{2}\right)$.

$\Delta t=$ time step, $(\mathrm{sec})$

The vehicle's position is updated using the following equation: 
$x_{i}=x_{i-1}+u_{i-1} * \Delta t+\frac{1}{2} * a * \Delta t^{2}$

Where

$x_{i-1}=$ position at the beginning of step, (m).

$x_{i}=$ updated position, $(\mathrm{m})$.

$u_{i-1}=$ speed at the beginning of step, $(\mathrm{m} / \mathrm{s})$.

$a=$ acceleration rate, $\left(\mathrm{m} / \mathrm{s}^{2}\right)$.

$\Delta t=$ time step, $(\mathrm{sec})$.

\subsubsection{Generation of Freeway Vehicle}

During simulation, freeway speed, headway, vehicle type, and vehicle length are assigned to each freeway vehicle. Details of the above parameters are described below:

\subsection{3 (a) Headway}

In accordance with the general trend of free-flow vehicle movement, the probability of arrival of any number of freeway right lane vehicles within a time period is assumed to follow a Poisson's distribution (Garber et al. 2009). For such a distribution and a specific traffic volume, a set of randomly assigned numbers in the range $[0,1]$ can be converted to time headway values as follows: 
$h=-\frac{1}{\lambda} \ln \left(R_{N}\right)$

Where

$R_{N}=$ set of random numbers in the range [ $\left[\begin{array}{ll}0 & 1\end{array}\right]$.

$h=$ headway, $(\mathrm{sec})$.

$\lambda=$ hourly traffic volume, $(\mathrm{veh} / \mathrm{h} / \mathrm{ln})$.

The headway between each two freeway right lane successive vehicles in the model is randomly assigned based on the freeway traffic volume. However, in setting the random headway values, minimum headway is considered in order to avoid extremely short headway. Zhang et al. (2007) used advanced loop event data analyzer (ALDEA) for collecting accurate headway data from an interstate highway during different times of the day. From their research, the observed minimum headway varied from 0.375 seconds to 0.453 seconds. In the current study, the minimum headway in the freeway right lane was observed to be 0.5 seconds at Maitland (NS-W) which is not very different from that of the literature. In the proposed model, the minimum headway between two consecutive vehicles is considered as $0.5 \mathrm{sec}$. In the simulation, the generated headway less than $0.5 \mathrm{sec}$ is observed for $5 \%$ to $10 \%$ of freeway right lane traffic. Therefore, the effect of this assumption on the distribution of headways was found to be negligible for the range of traffic volumes used in the attempted model runs. 


\subsection{3 (b) Types of Freeway vehicles}

The lengths of the freeway right lane vehicles are needed to convert the time headway between each two vehicles (measured from the front bumper of the lead vehicle to the front bumper of the lag vehicle) to time gap (measured from the rear bumper of the lead vehicle to the front bumper of the lag vehicle). Because heavy vehicles on the freeway usually utilize the freeway right lane, it was necessary for the model to consider both types of vehicles: passenger cars (PC) and heavy vehicles (HV). The distribution of PC lengths was surveyed from the 2012 GM cars catalogue for small size, mid-size, full size, luxury, SUV, and sports cars (www.gm.ca) as an example of PC in the traffic stream. Based on this survey, the lengths of PC are assumed to follow a uniform distribution in the range of $4.399 \mathrm{~m}$ to $5.207 \mathrm{~m}$ as shown in Figure 4.4. On the other hand, a constant length of $12.5 \mathrm{~m}$, which corresponds almost to the $98^{\text {th }}$ percentile truck length (U.S. Census Bureau, 2004), was set for all HV. Thus, to assign the freeway right lane vehicle's length in the model, the vehicle type is first assigned randomly based on the percentages of PC and HV. Then, if the vehicle is a HV, the length is set as $12.5 \mathrm{~m}$.

On the other hand, if the vehicle is a PC, the length is assigned randomly from the uniform distribution. 

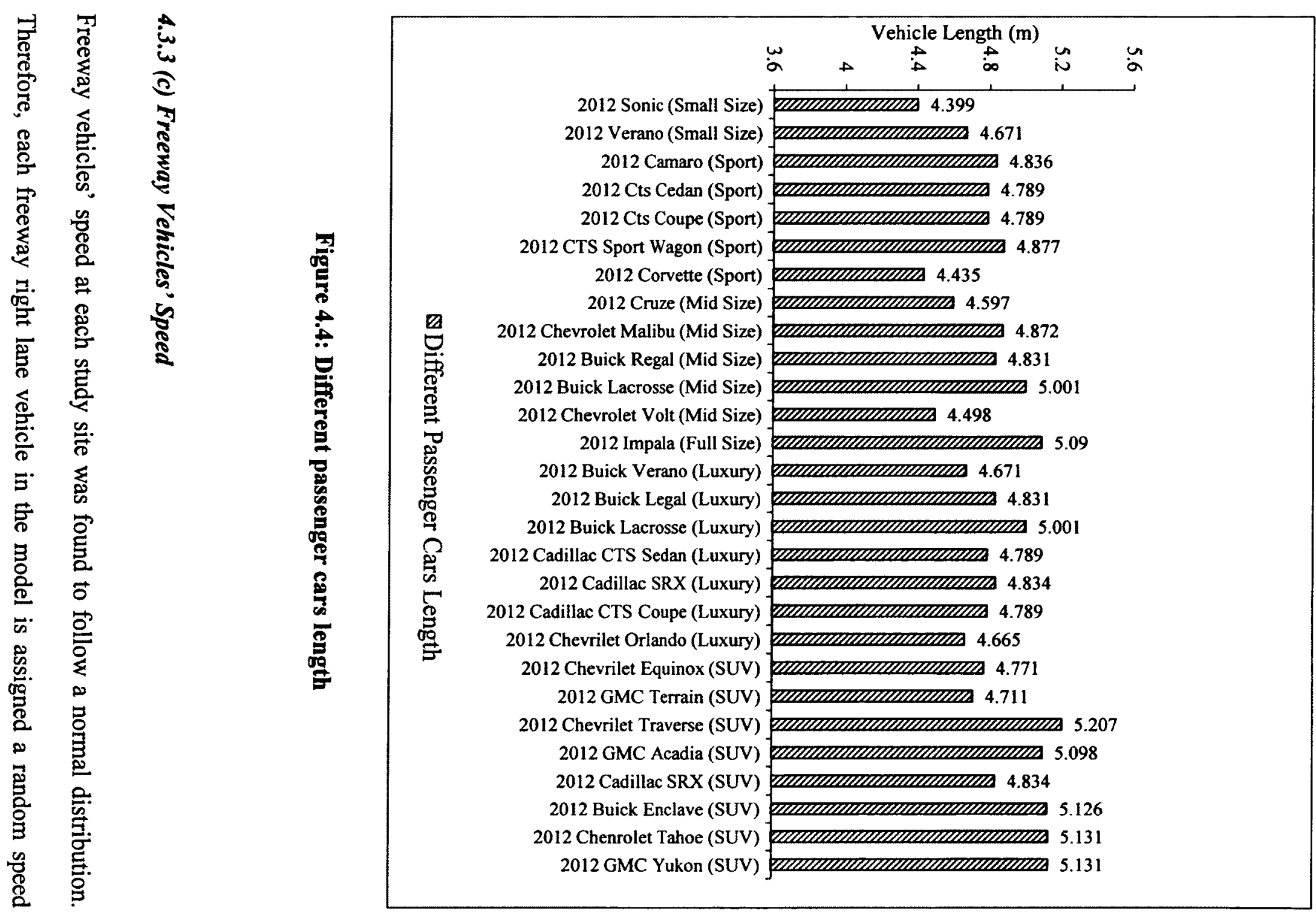
based on the normal distribution, mean and standard deviation. Each vehicle is assumed to maintain this assigned speed with no acceleration or deceleration.

\subsection{3 (d) Freeway Vehicles' Location}

At the beginning of simulation run, freeway vehicles are placed behind the start point of SCL length at distances based on the assigned initial headway. Then, freeway vehicles maintain their assigned speed through their movement on the freeway right lane. The position of freeway vehicle is calculated at a time step of $0.1 \mathrm{sec}$ by using equation 4.5.

$x_{i}=x_{i-1}+u * \Delta t$

Where

$x_{i}=$ updated position, $(\mathrm{m})$.

$x_{i-1}=$ position at the beginning of step, (m).

$u=$ freeway vehicle's speed, $(\mathrm{m} / \mathrm{s})$

$\Delta t=$ time step, $(\mathrm{sec})$.

\subsection{3 (e) Available Gap in Freeway Right lane}

As different speeds are assigned to the freeway vehicles, the available gap between two successive vehicles is changed at each time step. In order to measure the available gap size, the model records the positions of immediately lead (front bumper) and lag vehicle 
(front bumper) with respect to the beginning point of SCL length. This point is referred to as SCL origin as all the calculations are done with respect to this point. The following equation is used to calculate the available gap (distance) in the freeway right lane:

Gap $($ distance $)=($ distance $($ lead vehicle - lag vehicle $)-$ vehicle length (lead vehicle $))$

In order to compare the available gap with the assigned acceptable gap, the available gap (distance) is then converted into time gap using the following equation:

$\operatorname{Gap}($ time $)=\frac{\text { Gap }(\text { distance })}{\text { Speed }(\text { lag vehicle })}$

\subsubsection{Non-Compliance Evaluation}

The method used for determination of the PNC is described in the following section. Two conditions are checked in each segment of SCL length to estimate the PNC.

Condition 1: Acceleration to Acceptable Merge Speed

In the simulation, when a SCL vehicle is moving on the acceleration lane, the vehicle accelerates continuously to attain an acceptable merge speed. The speed is updated using the assigned acceleration rate and the updated speed is compared with the acceptable merge speed. If the vehicle reaches the end of specific segment with a speed lower than the acceptable merge speed, the vehicle would not able to merge onto the freeway right lane. Thus, probability of uncomfortable merging for that particular vehicle on this segment is equal to 1 . On the other hand, if the vehicle reaches the acceptable merge speed while on a specific segment, the first criterion would be 
satisfied and the probability of uncomfortable merging on this segment will be controlled by the second criterion.

\section{Condition 2: Finding an Acceptable Gap}

Once the acceptable merge speed is reached, the available gap in the freeway right lane is tracked at each time step. When the SCL vehicle reaches the acceptable merge speed while on a specific segment, the maximum available gap on the freeway right lane is recorded for that segment and for all following segments. To use this information in estimating the vehicle's uncomfortable merging, two approaches were considered. The first approach was to assign a value for the acceptable gap for each vehicle. In this case, the SCL vehicle would have one of two options: to merge if available gap $\geq$ acceptable gap or not to merge if available gap < acceptable gap. Such an approach would make all vehicles ending with a probability of uncomfortable merging value of zero (if acceptable gap $\geq$ available gap for any segment) or a value of probability of uncomfortable merging of one (If acceptable gap < available gap for all segments). Therefore, this approach was found not to be able to produce a proper distribution of the output.

The second approach was to take an advantage of the fact that the expected value using a regression analysis model can be considered to follow a normal distribution with the mean equal to the fitted value and the standard deviation equal to standard error of estimate. Thus, the acceptable gap of any specific vehicle is then assumed to belong to a distribution with a mean equal to the acceptable gap as estimated using the linear regression model and a standard deviation equal to the corresponding standard error of estimate. Subsequently, the probability of uncomfortable merging for a specific vehicle 
on a specific segment can be calculated using the normal cumulative distribution function based on the maximum available gap on this segment and the predicted values of mean acceptable gap and standard error of estimate on the segment. Therefore, this approach will produce a probability of uncomfortable merging value of each vehicle on each segment in the range (0-1). provided that the vehicle has reached the acceptable merge speed. Figure 4.5 shows the schematic diagram for estimation of the probability of uncomfortable merging.

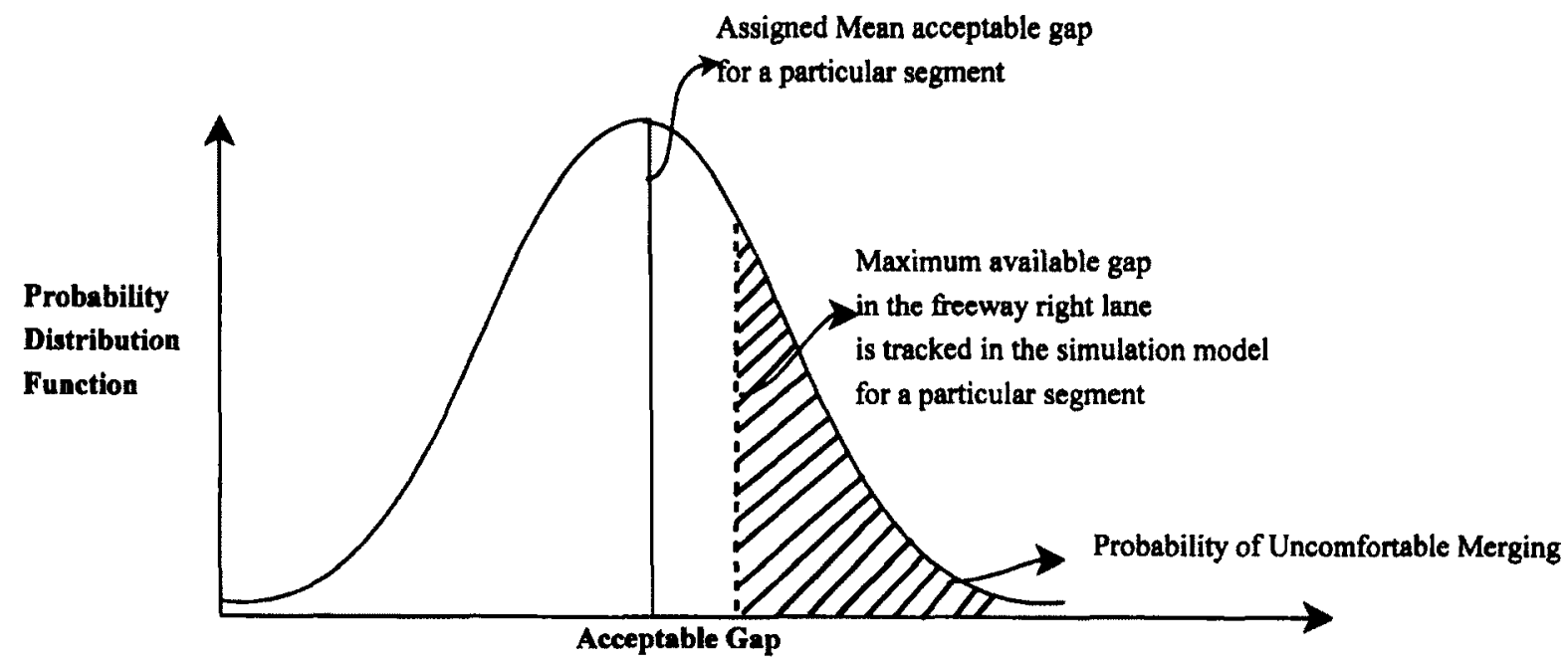

Figure 4.5: The concept of calculating probability of uncomfortable merging.

Mathematically,

Probability of uncomfortable merging $=1-p$ 
Where

$p=F\left(x \mid \mu_{1}\right)=\frac{1}{\sigma \sqrt{2 \pi}} \int_{-\infty}^{x} e^{-\left(x-\mu_{x}\right)^{2}} / 2 \sigma^{2} d x$

$\mu_{x}=$ mean of the acceptable gap.

$\sigma=$ standard deviation of the acceptable gap.

$x=$ maximum available gap in the freeway right lane.

The following example shows how probability of uncomfortable merging is calculated for each segment. Let us consider, SCL length is divided into segments 1,2 , 3, and 4. SCL vehicle attains an acceptable merge speed at segment 2 and starts to scan the available gap in the freeway right lane. At the end of segments 2,3 , and 4 , the maximum available gaps on the freeway right lane for corresponding segments are recorded; say $x_{2}, x_{3}$, and $x_{4}$. Let us consider, the value of mean and standard deviation of acceptable gaps which are assigned based on the regression equations for segment 2 , 3, and 4, are $\mu_{x_{2}}, \mu_{x_{3}}, \mu_{x_{4}}$ and $\sigma_{x_{2}}, \sigma_{x_{3}}, \sigma_{x_{4}}$, respectively. Therefore, the probability of uncomfortable merging for segment $1,2,3$, and 4 are

Probability of uncomfortable merging $($ segl $)=I$

Probability of uncomfortable merging $($ seg 2$)=1-\frac{1}{\sigma \sqrt{2 \pi}} \int_{-\infty}^{x_{2}} e^{\frac{-\left(x_{2}-\mu_{x_{2}}\right)^{2}}{2 \sigma_{x_{2}}{ }^{2}}} d x_{2}$ Probability of uncomfortable merging $($ seg 3$)=1-\frac{1}{\sigma \sqrt{2 \pi}} \int_{-\infty}^{x_{3}} e^{\frac{-\left(x_{3}-\mu_{x_{3}}\right)^{2}}{2 \sigma_{x_{3}}{ }^{2}}} d x_{3}$ Probability of uncomfortable merging $($ seg 4$)=1-\frac{1}{\sigma \sqrt{2 \pi}} \int_{-\infty}^{x_{4}} e^{\frac{-\left(x_{4}-\mu_{x_{4}}\right)^{2}}{2 \sigma_{x_{4}}{ }^{2}}} d x_{4}$ 
Where

$x=$ the recorded maximum available gap on the freeway for a particular SCL's segment, $(\mathrm{sec})$.

$\mu_{x}=$ mean acceptable gap assigned to the SCL vehicle in each segment, (sec).

$\sigma=$ the standard deviation which is the standard error of the regression model (sec).

Finally, the PNC values for the four segments are considered statistically independent events. When the SCL vehicle reaches the end of SCL length, the probability of the best chance of comfortable merging across the four segments of SCL is considered as the overall PNC for that particular SCL vehicle. In the simulation model, the probability of uncomfortable merging is calculated on the four segments. Therefore, minimum probability of uncomfortable merging on the four segments of SCL refers to the SCL drivers' best option for merging comfortably into the freeway.

Overall PNC of a specific SCL vehicle = minimum value of uncomfortable merging across the four segments of SCL.

\subsection{Interpretation of Output}

The merging process from the SCL to freeway is captured in the proposed model. As the field data is considered in constructing the model, the model should be able to replicate the actual merging behavior as precisely as possible. The output of the model is the PNC which is estimated based on the driver's acceleration and gap acceptance behaviour. If the estimated PNC for a specific vehicle is equal or close to zero, it is obvious that this 
vehicle can merge comfortably. PNC equal to 1 indicates that SCL vehicle cannot merge without forced merging. When PNC is greater than 0 and less than $1(0<\mathrm{PNC}>1)$, there is a chance of SCL driver to merge uncomfortably onto the freeway right lane.

In reality, all the vehicles on the SCL are compelled to merge from SCL to freeway. If vehicle's PNC value greater than zero, it is hypothesized that driver would compensate this situation by adopting a higher acceleration rate or accepting a shorter gap or the freeway right lane would accommodate the SCL vehicle. All these situations increase the chances of driving error which might result in collisions. So it is anticipated that the greater PNC, the higher the collision frequency for a specific SCL length. 


\section{REGRESSION ANALYSIS AND SIMULATION}

\section{PARAMETERS}

The parameters related to drivers' merging behavior have been identified in the modelling framework as explained in Chapter 4. All the parameters considered in the simulation model are based on the field data. For more general parameter assignment, regression analysis was carried out using SPSS 19.0 software to predict the input parameters in the simulation model. This chapter presents the modelling attempts that were undertaken to predict the input parameters such as the mean and standard deviation of acceleration rate, merge speed, gore speed, speed difference between merge speed and gore speed based on the $85^{\text {th }}$ percentile gore speed. Assuming that the design speed of the ramp controlling curve is equal to the $85^{\text {th }}$ percentile speed at the beginning of SCL (which will be referred to also as $V_{G, 85}$ ). The regression analysis was also carried out to examine the relationship between the accepted gaps for merging at different segments of the SCL length and other vehicle speed characteristics.

\subsection{Model for Mean Gore speed}

It has been mentioned in Chapter 3 and Chapter 4 that the initial speed of each SCL vehicle is the speed at the end of entrance ramp curve and is labeled in this research as gore speed. It was assumed in the proposed model that the design speed of ramp controlling curve is equal to the $85^{\text {th }}$ percentile gore speed $\left(V_{G, 85 t h}\right)$. For this reason, this 
section explores the relationship between mean gore speed, $\left(\mu_{V, G}\right)$ and $V_{G, 85 t h}$. Based on linear regression analysis of the existing field data at eight SCLs, the following relationship was found to estimate $\mu_{V, G}$ as a function of $V_{G, 85 t h}$

$\mu_{V, G}=-0.287+0.922 * V_{G, 85 t h},\left(R^{2}=0.99\right)$

Where

$\mu_{V, G}=$ predicted mean of gore speed, $(\mathrm{m} / \mathrm{s})$.

$V_{G, 85 t h}=85^{\text {th }}$ percentile of gore speed, $(\mathrm{m} / \mathrm{s})$.

Regression analysis was also carried out to predict the standard deviation of gore speed

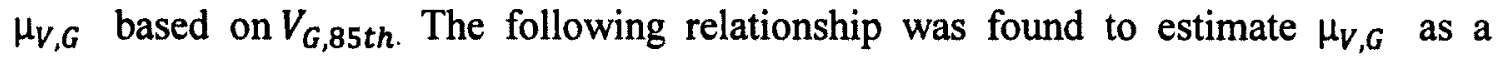
function of $V_{G, 85 t h}$.

$\sigma_{V, G}=0.446+0.069 * V_{G, 85 t h},\left(R^{2}=0.65\right)$

Where

$\sigma_{V, G}=$ standard deviation of gore speed, $(\mathrm{m} / \mathrm{s})$.

$V_{G, 85 t h}=85^{\text {th }}$ percentile of gore speed, $(\mathrm{m} / \mathrm{s})$. 


\subsection{Model for Merge Speed}

Linear regression analysis was carried out to predict the mean merge speed $\left(\mu_{V, M}\right)$ and standard deviation of merge speed $\left(\sigma_{V, M}\right)$ based on the $85^{\text {th }}$ percentile gore speed $\left(V_{G, 85 t h}\right)$. The following relationships were found:

$\mu_{V, M}=12.458+0.516 * V_{G, 85 t h},\left(R^{2}=0.74\right)$

$\sigma_{V, M}=3.675-0.044 * V_{G, 85 t h},\left(R^{2}=0.55\right)$

Where

$\mu_{V, M}=$ predicted mean merge speed, $(\mathrm{m} / \mathrm{s})$.

$\sigma_{V, M}=$ standard deviation of merge speed, $(\mathrm{m} / \mathrm{s})$.

$V_{G, 85 t h}=85^{\text {th }}$ percentile of gore speed, $(\mathrm{m} / \mathrm{s})$.

Equation 5.3 implies that SCL vehicles who enter onto the SCL with high initial speed, can merge with higher speed as well and vice-versa.

\subsection{Model for Acceleration Rate}

Based on linear regression analysis, the following relationships were found to predict the mean acceleration rate $\left(\mu_{a}\right)$ and standard deviation of acceleration rate $\sigma_{a}$ as a function of $V_{G, 85 t h}$. 
$\mu_{a}=2.040-0.063 * V_{G, 85 t h},\left(R^{2}=0.85\right)$

$\sigma_{a}=0.408-0.006 * V_{G, 85 t h},\left(R^{2}=0.61\right)$

Where

$\mu_{a}=$ predicted mean acceleration rate, $\left(\mathrm{m} / \mathrm{s}^{2}\right)$

$\sigma_{a}=$ predicted standard deviation of acceleration rate, $\left(\mathrm{m} / \mathrm{s}^{2}\right)$.

$V_{G, 85 t h}=85^{\text {th }}$ percentile gore speed, $(\mathrm{m} / \mathrm{s})$.

Equation 5.5 shows that the acceleration rate decreases as the $85^{\text {th }}$ percentile gore speed increases which indicates that SCL vehicles compensate for the existing situation by adopting a higher acceleration rate when the initial speed is low and vice-versa.

\subsection{Model for Speed Difference $\left(\mu_{\mu_{V, M}-\mu_{V, G}}\right)$}

The term, speed difference, refers to the difference of speed between the mean merge and mean gore speed. A simple linear regression was done and a strong relationship was found between the mean speed difference, $\mu_{\left(\mu_{V, M}-\mu_{V, G}\right)}$ and $V_{G, 85 t h}$, as shown:

$\mu_{\left(\mu_{V, M}-\mu_{V, G}\right)}=12.745-0.406 * V_{G, 85 t h},\left(R^{2}=0.72\right)$ 
Where

$\mu_{\left(\mu_{V, M}-\mu_{V, G)}\right.}=$ mean speed difference, $(\mathrm{m} / \mathrm{s})$.

$V_{G, 85 t h}=85^{\text {th }}$ percentile of gore speed, $(\mathrm{m} / \mathrm{s})$.

Equation 5.7 shows that the mean speed difference decreases as $V_{G, 85 t h}$ increases and vice versa. This relationship will be used in the simulation model for the truncation of the generated speed difference of merge and gore speed.

A simple linear regression analysis was done to predict the standard deviation of speed difference, $\sigma_{\mu_{V, M}-\mu_{V, G}}$ as a function of $V_{G, 85 t h}$. The model for predicting the $\sigma_{\left(\mu_{V, M}-\mu_{V, G}\right)}$ is as follows:

$\sigma_{\left(\mu_{V, M}-\mu_{V, G}\right)}=3.228-0.114 * V_{G, 85 t h},\left(R^{2}=0.85\right)$

Where

$\sigma_{\left(\mu_{V, M}-\mu_{V, G}\right)}=$ standard deviation of speed difference, $(\mathrm{m} / \mathrm{s})$.

$V_{G, 85 t h}=85^{\text {th }}$ percentile of gore speed, $(\mathrm{m} / \mathrm{s})$.

\subsection{Models for Acceptable Gap}

A simple regression analysis was run for each segment to explore the relationship of accepted gap with the vehicle speed characteristics such as merge speed $\left(V_{M}\right)$, gore 
speed $\left(V_{G}\right)$, and acceleration rate $(a)$. This section describes the modelling attempts that were undertaken to predict the acceptable gap size at each of the four segments of SCL.

In the regression model, acceptable gap was entered as the dependent variable and $V_{M}, V_{G}$, and $a$ were entered as the independent variables. Summary of modelling outputs for the four segments are presented in Table 5.1, 5.2, 5.3, and 5.4.

Table 5.1: Model Summary for Acceptable Gap Size at Segment 1

\begin{tabular}{|c|c|c|c|c|c|c|}
\hline Model & & Coefficient & $\mathrm{t}$-value & $p$ - value & $R^{2}$ & Standard error of estimate \\
\hline \multirow{2}{*}{1} & Constant & 9.992 & 14.493 & $<.001$ & 0.61 & 0.992 \\
\cline { 2 - 5 } & $V_{M}$ & -0.221 & -8.473 & $<.001$ & & \\
\hline \multirow{2}{*}{2} & Constant & 8.125 & 14.880 & $<.001$ & 0.49 & 1.047 \\
\cline { 2 - 5 } & $V_{G}$ & -0.164 & -7.296 & $<.001$ & & \\
\hline \multirow{2}{*}{3} & Constant & 4.041 & 28.747 & $<.001$ & \multirow{2}{*}{0.02} & \multirow{2}{*}{1.229} \\
\cline { 2 - 5 } & $a$ & 0.515 & 1.713 & .089 & & \\
\hline
\end{tabular}


Table 5.2: Model Summary for Acceptable Gap Size at Segment 2

\begin{tabular}{|c|c|c|c|c|c|c|}
\hline Model & & Coefficient & $\mathrm{t}$-value & $p$-value & $R^{2}$ & Standard error of estimate \\
\hline \multirow{2}{*}{1} & Constant & 11.344 & 40.01 & $<.001$ & \multirow{2}{*}{0.87} & 0.678 \\
\cline { 2 - 5 } & $V_{M}$ & -0.290 & -26.91 & $<.001$ & & \\
\hline \multirow{2}{*}{2} & Constant & 7.125 & 17.65 & $<.001$ & \multirow{2}{*}{0.60} & 0.774 \\
\cline { 2 - 5 } & $V_{G}$ & -0.139 & -8.29 & $<.001$ & & \\
\hline \multirow{2}{*}{3} & Constant & 3.723 & 25.741 & $<.001$ & \multirow{2}{*}{0.05} & 0.996 \\
\cline { 2 - 5 } & $a$ & 0.282 & 1.059 & 0.292 & & \\
\hline
\end{tabular}

Table 5.3: Model Summary for Acceptable Gap Size at Segment 3

\begin{tabular}{|l|c|c|c|c|c|c|}
\hline Model & & Coefficient & $\mathrm{t}$-value & $p$-value & $R^{2}$ & Standard error of estimate \\
\hline \multirow{3}{*}{1} & Constant & 10.76 & 17.671 & $<.001$ & \multirow{2}{*}{0.74} & 0.497 \\
\cline { 2 - 5 } & $V_{M}$ & -0.300 & -11.842 & $<.001$ & & \\
\hline \multirow{2}{*}{2} & Constant & 6.492 & 12.807 & $<.001$ & 0.48 & 0.708 \\
\cline { 2 - 5 } & $V_{G}$ & -0.134 & -6.565 & $<.001$ & & \\
\hline \multirow{2}{*}{3} & Constant & 3.165 & 18.246 & $<.001$ & 0.11 & 0.960 \\
\cline { 2 - 5 } & $a$ & 0.254 & 0.539 & 0.592 & & \\
\hline
\end{tabular}


Table 5.4: Model Summary for Acceptable Gap Size at Segment 4

\begin{tabular}{|c|c|c|c|c|c|c|}
\hline Model & & Coefficient & $\mathrm{t}$-value & $p$-value & $R^{2}$ & Standard error of estimate \\
\hline \multirow{2}{*}{1} & Constant & 7.524 & 20.010 & $<.001$ & \multirow{2}{*}{0.63} & 0.328 \\
\cline { 2 - 5 } & $V_{M}$ & -0.220 & -16.910 & $<.001$ & & \\
\hline \multirow{2}{*}{2} & Constant & 5.125 & 17.652 & $<.001$ & 0.38 & 0.174 \\
\cline { 2 - 5 } & $V_{G}$ & -0.139 & -8.291 & $<.001$ & & \\
\hline \multirow{2}{*}{3} & Constant & 2.433 & 6.822 & 0.869 & \multirow{2}{*}{0.00} & 0.587 \\
\cline { 2 - 5 } & $a$ & 0.481 & 0.691 & 0.673 & & \\
\hline
\end{tabular}

It is observed from Tables 5.1, 5.2, 5.3 and 5.4, The best models developed for the four segments of SCL were to relate the accepted gap by a specific vehicle to that vehicle's merge speed as follows:

$$
\begin{aligned}
& \mu_{G A P, \text { Segment } 1}=9.992-0.221 * V_{M},\left(R^{2}=0.61\right), S E E=0.992 \\
& \mu_{G A P, \text { Segment } 2}=11.344-0.290 * V_{M},\left(R^{2}=0.87\right), S E E=0.678 \\
& \mu_{G A P, \text { Segment } 3}=10.760-0.300 * V_{M},\left(R^{2}=0.74\right), S E E=0.497 \\
& \mu_{G A P, \text { Segment } 4}=7.524-0.220 * V_{M},\left(R^{2}=0.63\right), S E E=0.328
\end{aligned}
$$


Where

$\mu_{G A P, S e g m e n t 1}=$ predicted mean acceptable gap (s) at segment 1 .

$\mu_{G A P, \text { Segment2 }}=$ predicted mean acceptable gap (s) at segment 2 .

$\mu_{G A P, S e g m e n t 3}=$ predicted mean acceptable gap (s) at segment 3.

$\mu_{G A P, S e g m e n t 4}=$ predicted mean acceptable gap (s) at segment 4.

$V_{M}=$ merge speed of vehicle, $(\mathrm{m} / \mathrm{s})$.

$S E E=$ standard error of estimate. 


\section{ANALYSIS AND RESULT}

The modelling technique to capture the driver's freeway merging behaviour from SCL to the freeway right lane has already been described in Chapter 5. The outcome of the proposed model is the probability of non-compliance (PNC) which reflects the probability of vehicles' forced or uncomfortable merging behaviour. Section 6.1 discusses the number of SCL vehicles that needed to be generated in the model. Section 6.2 presents the output of the model by applying the simulation model to the eight SCLS on Highway 417. Section 6.3 explores the relationship between reliability measures and collision frequency on the SCL. Section 6.4 presents the application of the proposed model to determine the PNC associated with the SCL lengths recommended by AASHTO (2011) and TAC (1999) design guides. Section 6.6 presents a sensitivity analysis of the input parameters used in the model.

\subsection{Required Number of Model Iterations}

If the number of the SCL vehicles generated in each model run is large enough, the input parameters would have accurately represented the vehicle population and the output would have accurately represented the site conditions. Therefore, the accuracy of the model output depends on the number of SCL vehicles generated in each model run. Subsequently, it was important to determine the optimum number of SCL vehicles in the 
model to obtain a consistent output. Thus, the mean PNC was determined for a specific set of input parameters and using different numbers of generated SCL vehicles.

The input parameters considered in the simulation model for different iterations are presented in the following paragraph, and Table 6.1 shows the output for different iterations.

- Mean gore speed $\left(\mu_{G}\right)=70 \mathrm{~km} / \mathrm{h}$.

- Standard deviation of gore speed $\left(\sigma_{G}\right)=6.66 \mathrm{~km} / \mathrm{h}$.

- Mean merge Speed $\left(\mu_{M}\right)=93 \mathrm{~km} / \mathrm{h}$.

- Standard deviation of merge speed $\left(\sigma_{M}\right)=9.03 \mathrm{~km} / \mathrm{h}$.

- Mean acceleration rate $\left(\mu_{a}\right)=0.857 \mathrm{~m} / \mathrm{s}^{2}$

- Standard deviation of acceleration rate $\left(\sigma_{a}\right)=0.279 \mathrm{~m} / \mathrm{s}^{2}$.

- The correlation coefficients among input parameters were taken based on the combined data of eight SCLs as shown in Table 4.2.

- The freeway right lane traffic volume $=700 \mathrm{veh} / \mathrm{h} / \mathrm{ln}$.

- The mean freeway RL speed $103.10 \mathrm{~km} / \mathrm{h}$.

- The standard deviation of freeway RL speed $=10.35 \mathrm{~km} / \mathrm{h}$.

- $\mathrm{SCL}$ length $=460 \mathrm{~m}$. 
- Percentage of Heavy vehicles $=10 \%$ and percentage of passenger cars $=90 \%$

As shown in Table 6.1, for SCL vehicles of 10,000 or more, the maximum variation was less than $1 \%$. Therefore, the number of 10,000 vehicles was used as the number of SCL vehicles to be generated in any model run.

Table 6.1: Number of SCL Vehicles Generated

\begin{tabular}{ccc}
\hline No of SCL vehicles & Mean PNC & Standard Deviation \\
\hline 1000 & 0.1703 & 0.331 \\
2000 & 0.1657 & 0.336 \\
5000 & 0.1624 & 0.335 \\
10000 & 0.1604 & 0.337 \\
20000 & 0.1595 & 0.327 \\
30000 & 0.1592 & 0.327 \\
40000 & 0.1603 & 0.327 \\
50000 & 0.1590 & 0.327 \\
60000 & 0.1598 & 0.326 \\
80000 & 0.1600 & 0.327 \\
100000 & 0.1605 & 0.327 \\
\hline
\end{tabular}

\subsection{Probability of Non-compliance (PNC) at Study Sites}

The eight SCLs of the present study were considered one by one in the simulation model. The input parameters were assigned based on the information gathered from each study site. The model was run considering $10,000 \mathrm{SCL}$ vehicles at each SCL length. The output of the model provides the PNC value of each SCL vehicle. The PNC of each vehicle is calculated in the range of 0 to 1 . As explained earlier, a PNC value equal to zero indicates that SCL vehicle can merge smoothly onto the freeway. Any PNC value greater than zero indicates that there is a probability of forced or 
uncomfortable merging. The mean and standard deviation of PNC for 10,000 generated SCL vehicles are also calculated in the model. The values of input parameters, the mean and standard deviation of PNC associated with each study site are shown in Table 6.2. The correlation coefficients among the parameters at eight study sites are presented in Appendix A. In the simulation, the minimum and maximum values of each parameter at each study site are used for truncation of the generated input values. 
Table 6.2: Input Parameters and Output of the Model for Eight SCLs

\begin{tabular}{|c|c|c|c|c|c|c|c|c|c|c|c|}
\hline \multirow[t]{2}{*}{$\begin{array}{l}\text { SCL } \\
\text { sites }\end{array}$} & & $\begin{array}{c}\text { Freeway } \\
\text { speed }\end{array}$ & $\begin{array}{l}\text { Gore } \\
\text { Speed }\end{array}$ & $\begin{array}{l}\text { Merge } \\
\text { Speed }\end{array}$ & $\begin{array}{l}\text { Acc } \\
\text { rate }\end{array}$ & $\begin{array}{c}\text { Freeway } \\
\text { RL } \\
\text { Volume }\end{array}$ & $\begin{array}{c}\% \text { of } \\
\text { HV } \\
\text { freeway } \\
\text { RL. }\end{array}$ & $\begin{array}{c}\% \text { of } \\
\text { PC } \\
\text { freeway } \\
\text { RL } \\
\end{array}$ & $\begin{array}{c}\mathrm{SCL} \\
\text { Length }\end{array}$ & $\begin{array}{l}\text { Mean } \\
\text { PNC }\end{array}$ & $\begin{array}{l}\text { Std } \\
\text { PNC }\end{array}$ \\
\hline & & $\mathrm{km} / \mathrm{h}$ & $\mathrm{km} / \mathrm{h}$ & $\mathrm{km} / \mathrm{h}$ & $\mathrm{m} / \mathrm{s}^{2}$ & $\mathrm{pc} / \mathrm{h} / \mathrm{ln}$ & $\%$ & $\%$ & $\mathrm{~m}$ & & \\
\hline \multirow{4}{*}{$\begin{array}{l}\text { Parkdale } \\
\text { (NS-W) }\end{array}$} & Min & 70.90 & 38.42 & 54.45 & 0.193 & \multirow{4}{*}{588} & \multirow{4}{*}{3.5} & \multirow{4}{*}{96.5} & \multirow{4}{*}{188} & \multirow{4}{*}{0.197} & \multirow{4}{*}{0.380} \\
\hline & $\operatorname{Max}$ & 126.70 & 91.65 & 103.83 & 1.526 & & & & & & \\
\hline & Mean & 98.49 & 69.41 & 79.48 & 0.715 & & & & & & \\
\hline & SD & 11.75 & 9.61 & 10.0 & 0.288 & & & & & & \\
\hline \multirow{4}{*}{$\begin{array}{l}\text { Maitland } \\
\text { (NS-E) }\end{array}$} & Min & 78.20 & 41.88 & 63.72 & 0.282 & \multirow{4}{*}{1229} & \multirow{4}{*}{2} & \multirow{4}{*}{98} & \multirow{4}{*}{468} & \multirow{4}{*}{0.306} & \multirow{4}{*}{0.430} \\
\hline & Max & 119.70 & 77.40 & 111.21 & 1.517 & & & & & & \\
\hline & Mean & 96.64 & 62.13 & 86.67 & 0.843 & & & & & & \\
\hline & SD & 8.65 & 5.68 & 9.70 & 0.255 & & & & & & \\
\hline \multirow{4}{*}{$\begin{array}{l}\text { Moodie } \\
(\mathrm{N}-\mathrm{W})\end{array}$} & Min & 81.60 & 73.32 & 74.30 & -0.645 & \multirow{4}{*}{1244} & \multirow{4}{*}{4.9} & \multirow{4}{*}{95.1} & \multirow{4}{*}{323} & \multirow{4}{*}{0.332} & \multirow{4}{*}{0.442} \\
\hline & $\operatorname{Max}$ & 120.70 & 111.88 & 114.61 & 0.522 & & & & & & \\
\hline & Mean & 97.78 & 91.77 & 93.26 & 0.100 & & & & & & \\
\hline & $\mathrm{SD}$ & 7.85 & 7.90 & 8.80 & 0.224 & & & & & & \\
\hline & Min & 81.80 & 71.37 & 78.60 & -0.773 & \multirow{4}{*}{1092} & \multirow{4}{*}{3.2} & \multirow{4}{*}{96.8} & \multirow{4}{*}{327} & & \\
\hline Eagleson & Max & 117.20 & 122.23 & 123.21 & 0.601 & & & & & $0>282$ & 0472 \\
\hline$(S-E)$ & Mean & 98.29 & 95.71 & 98.54 & 0.232 & & & & & 0.282 & 0.422 \\
\hline & $\mathrm{SD}$ & 7.90 & 8.80 & 9.32 & 0.216 & & & & & & \\
\hline & Min & 77.10 & 58.31 & 60.91 & -0.253 & & & & & & \\
\hline Woodroffe & Max & 124.30 & 103.06 & 109.81 & 1.508 & 886 & 4 & 06 & 341 & $0 ? 24$ & 0205 \\
\hline (NS-W) & Mean & 102.87 & 78.85 & 88.50 & 0.649 & 880 & 4 & 90 & 340 & 0.234 & 0.395 \\
\hline & $\mathrm{SD}$ & 10.41 & 8.00 & 9.35 & 0.291 & & & & & & \\
\hline & Min & 72.80 & 63.84 & 68.31 & -0.409 & & & & & & \\
\hline Richmond & Max & 121.40 & 110.36 & 107.82 & 0.839 & 007 & 6 & & & & \\
\hline$(S-E)$ & Mean & 109.78 & 83.52 & 87.68 & 0.284 & 892 & 0 & 94 & 321 & 0.228 & 0.392 \\
\hline & SD & 10.30 & 8.22 & 9.74 & 0.228 & & & & & & \\
\hline & Min & 87.40 & 78.52 & 87.20 & -0.495 & & & & & & \\
\hline Carp & Max & 127.30 & 115.38 & 120.41 & 0.846 & 700 & 61 & 020 & 120 & 0725 & 0101 \\
\hline$(S-E)$ & Mean & 104.79 & 99.85 & 105.95 & 0.228 & 109 & 0.1 & 93.9 & 430 & 0.233 & 0.401 \\
\hline & SD & 7.52 & 8.20 & 7.00 & 0.199 & & & & & & \\
\hline & Min & 92.80 & 75.63 & 79.71 & -0.454 & & & & & & \\
\hline Terryfox & Max & 129.80 & 124.72 & 128.21 & 0.836 & 661 & 6 & 04 & & & \\
\hline$(\mathrm{N}-\mathrm{W})$ & Mean & 108.27 & 100.05 & 104.71 & 0.221 & 601 & 6 & 94 & 419 & 0.180 & 0.358 \\
\hline & SD & 7.51 & 9.48 & 8.44 & 0.206 & & & & & & \\
\hline
\end{tabular}


The following observations are found from Table 6.2:

- The largest mean PNC of 0.332 was found at Moodie (N-W). This can be attributed to the presence of highest freeway right lane traffic volume, and the lowest mean acceleration rate for all sites.

- A relatively high mean PNC of 0.306 was found at Maitland (NS-E) although Maitland (NS-E) has the longest SCL length and higher mean acceleration rate in comparison with other sites. This can be attributed to two reasons: firstly, the mean gore speed at Maitland (NS-E) was $62.1 \mathrm{~km} / \mathrm{h}$ which is the lowest for all sites and secondly, the traffic volume in the freeway right lane was $1229 \mathrm{pc} / \mathrm{h} / \mathrm{ln}$ which is higher in comparison to other SCLs.

- The lowest mean PNC of 0.180 was found at Terryfox (N-W) which has comparatively longer SCL length. At this site, the mean gore speed was 100.05 $\mathrm{km} / \mathrm{h}$ which is the highest for all sites and the freeway right lane traffic volume was $661 \mathrm{pc} / \mathrm{h} / \mathrm{ln}$ which is considerably low. All these conditions should contribute to comfortable merging.

- The length of SCL at Parkdale (NS-W) was $188 \mathrm{~m}$ which is the lowest among all SCLs. Although the gore speed, and the SCL length at this site were low in comparison to other sites, the calculated mean PNC was found0.197, which is relatively low. This can be attributed to the presence of low traffic volume of $588 \mathrm{pc} / \mathrm{h} / \mathrm{ln}$ in the freeway right lane.

In addition to mean and standard deviation of PNC, the output of the model can provide percentage of SCL vehicles with a PNC equal to or exceeding a specific 
threshold such as $0,0.1,0.2,0.3,0.4,0.5,0.6,0.7,0.8,0.9$. Table 6.3 shows the percentage of SCL vehicles having different PNC range.

Table 6.3: Percentage of SCL Vehicles Having Different PNC Range

\begin{tabular}{|l|c|c|c|c|c|c|c|c|c|c|}
\hline Name & $\begin{array}{c}\text { PNC } \\
=0\end{array}$ & $\begin{array}{c}\text { PNC } \\
j 0-1]\end{array}$ & $\begin{array}{c}\text { PNC } \\
j 0.1-1]\end{array}$ & $\begin{array}{c}\text { PNC } \\
j 0.2-1]\end{array}$ & $\begin{array}{c}\text { PNC } \\
10.4-1]\end{array}$ & $\begin{array}{c}\text { PNC } \\
j 0.5-1]\end{array}$ & $\begin{array}{c}\text { PNC } \\
j 0.7-1]\end{array}$ & $\begin{array}{c}\text { PNC } \\
j 0.8-1]\end{array}$ & $\begin{array}{c}\text { PNC } \\
j 0.9-1]\end{array}$ & $\begin{array}{c}\text { PNC } \\
=1\end{array}$ \\
\hline $\begin{array}{l}\text { Parkdale } \\
\text { (NS-W) }\end{array}$ & $59.8 \%$ & $40.2 \%$ & $22.7 \%$ & $21.7 \%$ & $20.3 \%$ & $19.6 \%$ & $18.4 \%$ & $17.7 \%$ & $16.6 \%$ & $1.0 \%$ \\
\hline $\begin{array}{l}\text { Richmond } \\
\text { (S-E) }\end{array}$ & $46.1 \%$ & $53.9 \%$ & $28.1 \%$ & $26.1 \%$ & $23.5 \%$ & $22.6 \%$ & $20.5 \%$ & $19.5 \%$ & $17.9 \%$ & $3.0 \%$ \\
\hline $\begin{array}{l}\text { Moodie } \\
\text { (N-W) }\end{array}$ & $34.0 \%$ & $66.0 \%$ & $39.0 \%$ & $37.0 \%$ & $34.5 \%$ & $33.4 \%$ & $31.1 \%$ & $29.5 \%$ & $26.9 \%$ & 0 \\
\hline $\begin{array}{l}\text { Woodroffe } \\
\text { (NS-W) }\end{array}$ & $46.2 \%$ & $53.8 \%$ & $28.7 \%$ & $26.8 \%$ & $24.5 \%$ & $23.6 \%$ & $21.5 \%$ & $19.9 \%$ & $18.1 \%$ & 0 \\
\hline $\begin{array}{l}\text { Eagleson } \\
\text { (S-E) }\end{array}$ & $39.6 \%$ & $60.4 \%$ & $33.6 \%$ & $31.9 \%$ & $29.4 \%$ & $28.5 \%$ & $26.1 \%$ & $24.5 \%$ & $22.4 \%$ & $1.4 \%$ \\
\hline $\begin{array}{l}\text { Carp Road } \\
\text { (S-E) }\end{array}$ & $52.5 \%$ & $47.5 \%$ & $27.9 \%$ & $26.2 \%$ & $24.3 \%$ & $23.7 \%$ & $22.2 \%$ & $20.7 \%$ & $18.9 \%$ & $3.6 \%$ \\
\hline $\begin{array}{l}\text { Maitland } \\
\text { (NS-E) }\end{array}$ & $35.9 \%$ & $64.1 \%$ & $36.9 \%$ & $34.8 \%$ & $31.7 \%$ & $30.4 \%$ & $28.0 \%$ & $26.5 \%$ & $24.4 \%$ & 0 \\
\hline $\begin{array}{l}\text { Terryfox } \\
\text { (N-W) }\end{array}$ & $57.1 \%$ & $42.9 \%$ & $22.4 \%$ & $20.9 \%$ & $18.9 \%$ & $18.2 \%$ & $16.4 \%$ & $15.1 \%$ & $13.4 \%$ & 0 \\
\hline
\end{tabular}

Symbol 10 1] implies that the percentage of SCL vehicles having range of PNC value greater equal to or less than 1 . The rests are explained in the same manner.

For the eight SCLs, $34.0 \%$ to $59.8 \%$ of SCL vehicles have PNC equal to zero. Besides this, $17.7 \%$ to $28.2 \%$ of SCL vehicles have PNC value of ]0 0.1], which implies that these percentage of vehicles have less chance of uncomfortable merging. It is also observed from Table 6.3 that the percentage of vehicles do not change remarkably, when SCL vehicles' PNC is in between 0.1 to 0.9 . Among the eight SCLs, $12.6 \%$ to $26.3 \%$ of SCL vehicles have PNC value of $] 0.91$ 1]. Figure 6.1 shows the percentage of SCL vehicles having different PNC range among eight study sites. 


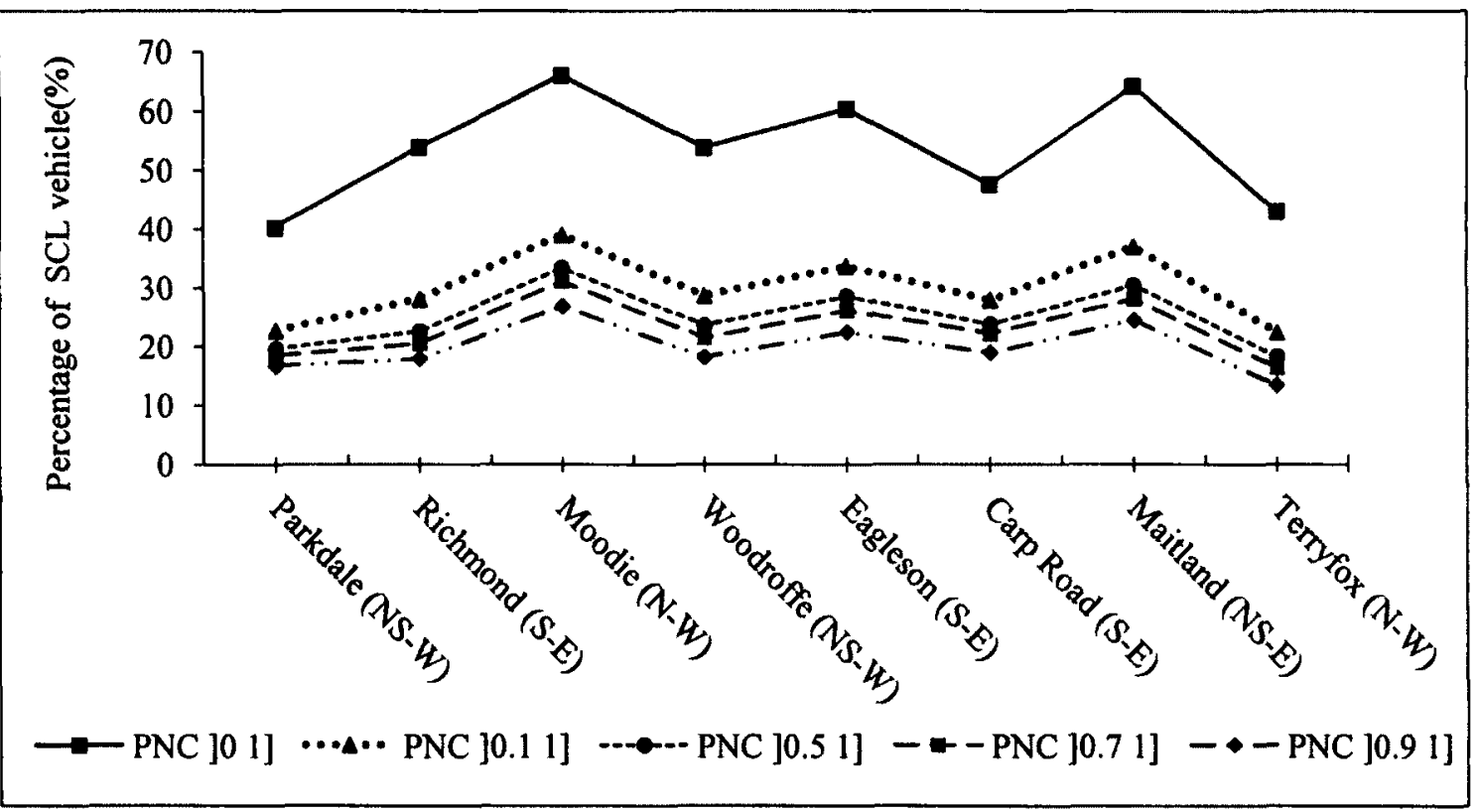

Figure 6.1: Percentage of SCL drivers having different PNC among eight SCLs

\subsection{Collisions and PNC}

A description of collision data has already been given in Chapter 3. Collision data are conceptually discrete and positive. Many people have already addressed that linear regression technique is not appropriate for the modelling collision frequency. The output of linear model may give a negative value which is inconsistent with the distribution of collision data. Sarhan (2004) and Ahammed (2005) used negative binomial regression technique successfully for collision prediction. This technique is positively skewed and discrete in nature, which supports the characteristics of collision data.

In the present study, collision data of only seven SCLs were available. The developed model in this study was validated by comparing the different PNC measures with the five-year collision frequency on seven sites. As the number of sites available 
was relatively small, developing a collision prediction model was not attempted. Instead, the trends of collision frequency against several reliability measures were checked to examine the validity of the model output and examine the potential of these measures as indicators of the expected safety performance at a specific site. It was observed that a strong trend existed between the collision frequency and almost all attempted reliability measures such as mean PNC, percentage of vehicles with PNC of zero, and percentage of vehicles with PNC greater than zero. Figures 6.2, 6.3, 6.4, 6.5, and 6.6 show the trends of collision frequency against several reliability measures. It has to be emphasized here that the linear trend and coefficient of determination are shown only as an indication of the model's validity and to highlight the potential of the developed reliability measures. The figures $6.2,6.3,6.4$ and 6.5 show that a positive trend existed between reliability measures and collision frequency when PNC of each SCL vehicle is greater than zero. Figure 6.6 shows a negative trend between percentage of SCL vehicle with PNC equal to zero and collision frequency. 


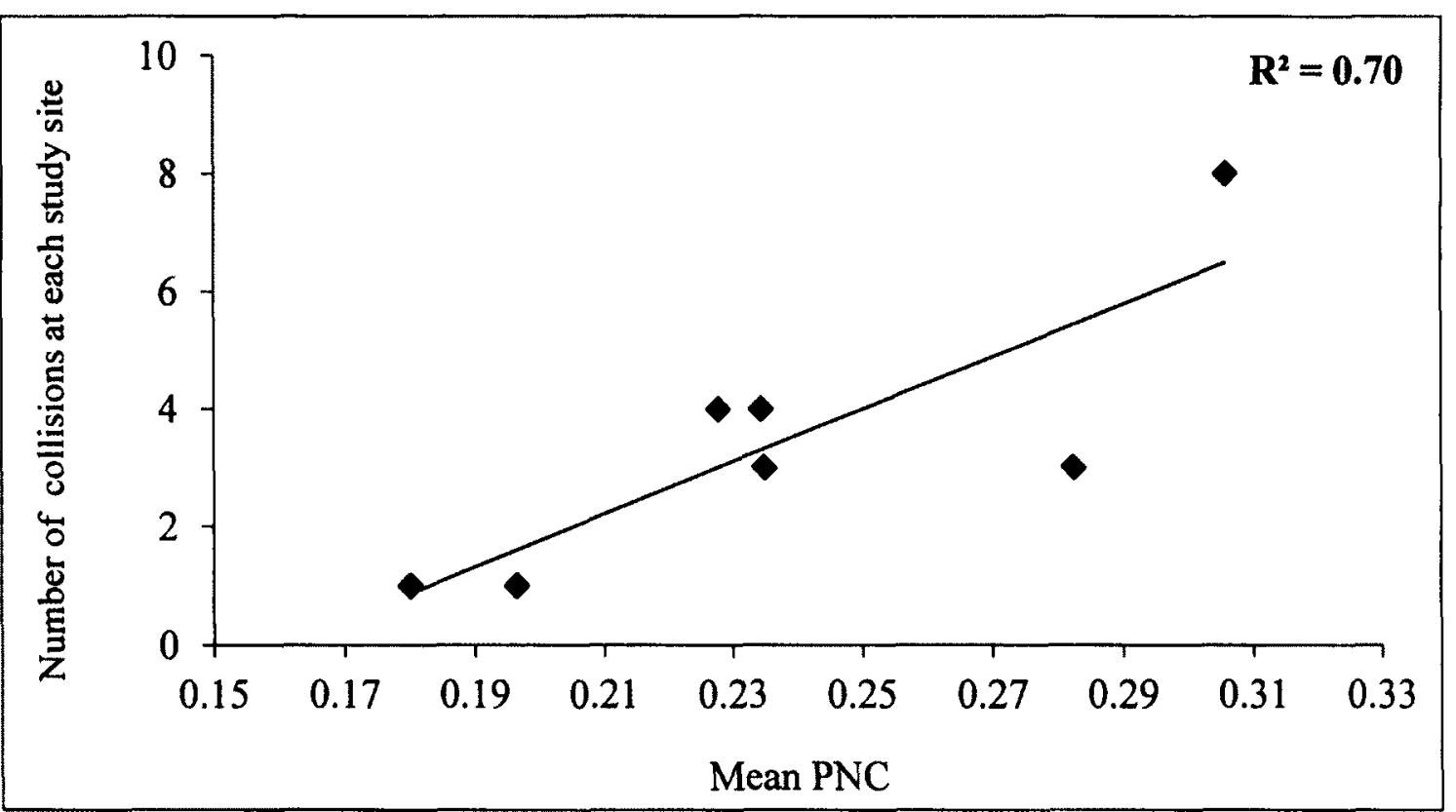

Figure 6.2: Mean PNC vs number of collisions at each study site.

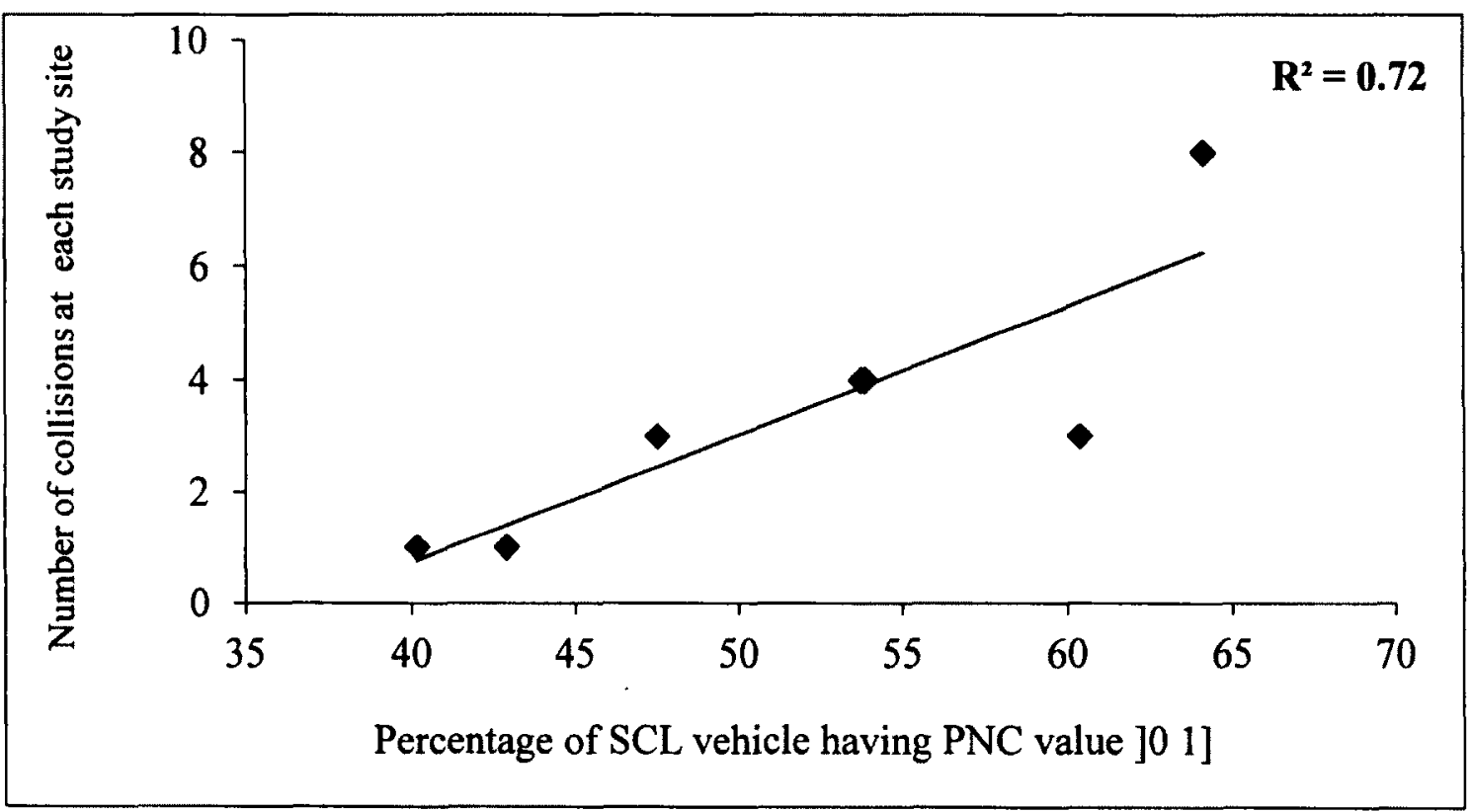

Figure 6.3: Percentage of SCL vehicles having PNC ]0 1] vs number of collisions 


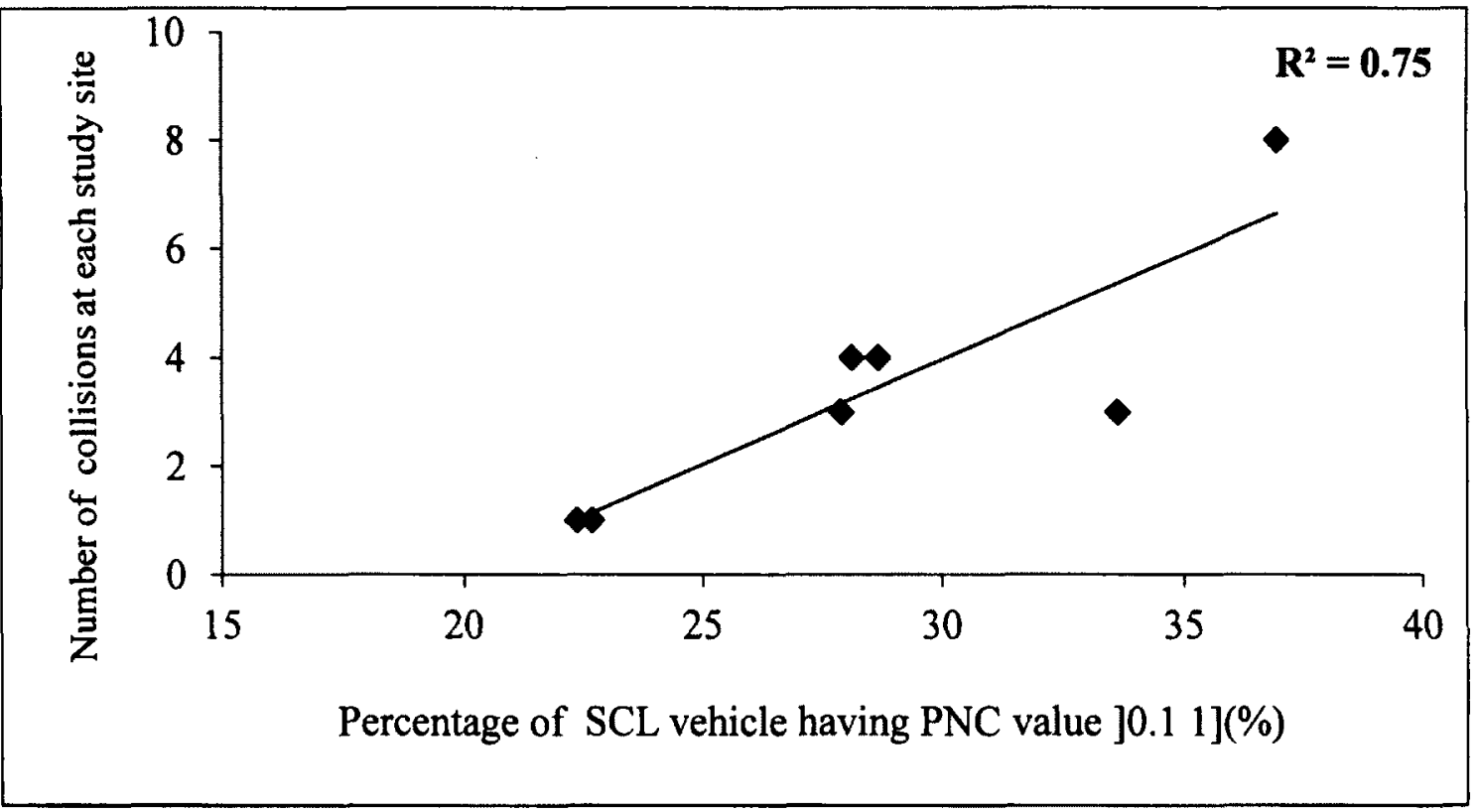

Figure 6.4: Percentage of SCL vehicles having PNC] 0.1 1] vs number of collisions

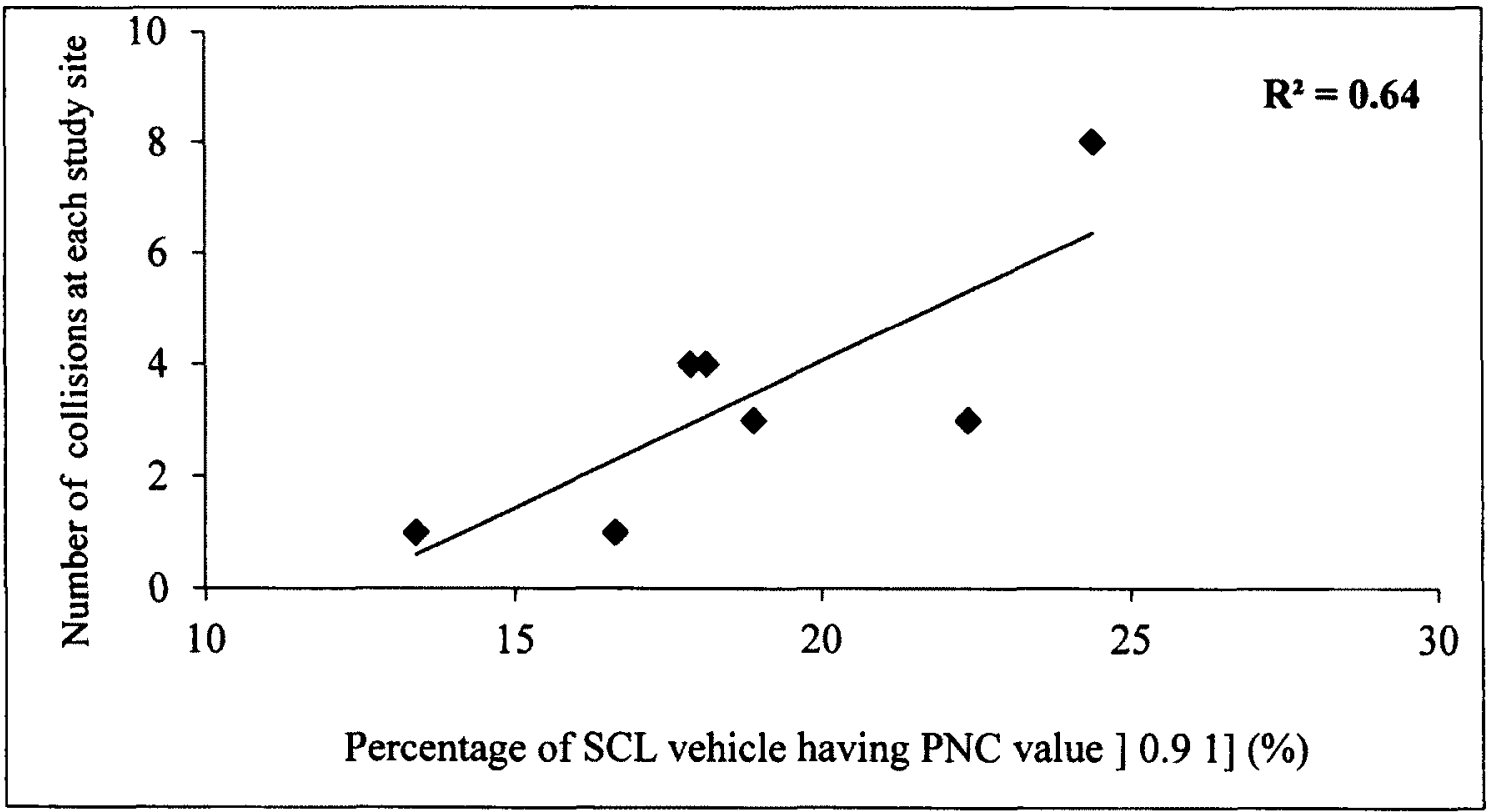

Figure 6.5: Percentage of SCL vehicles having PNC ]0.9 1] vs number of collisions 


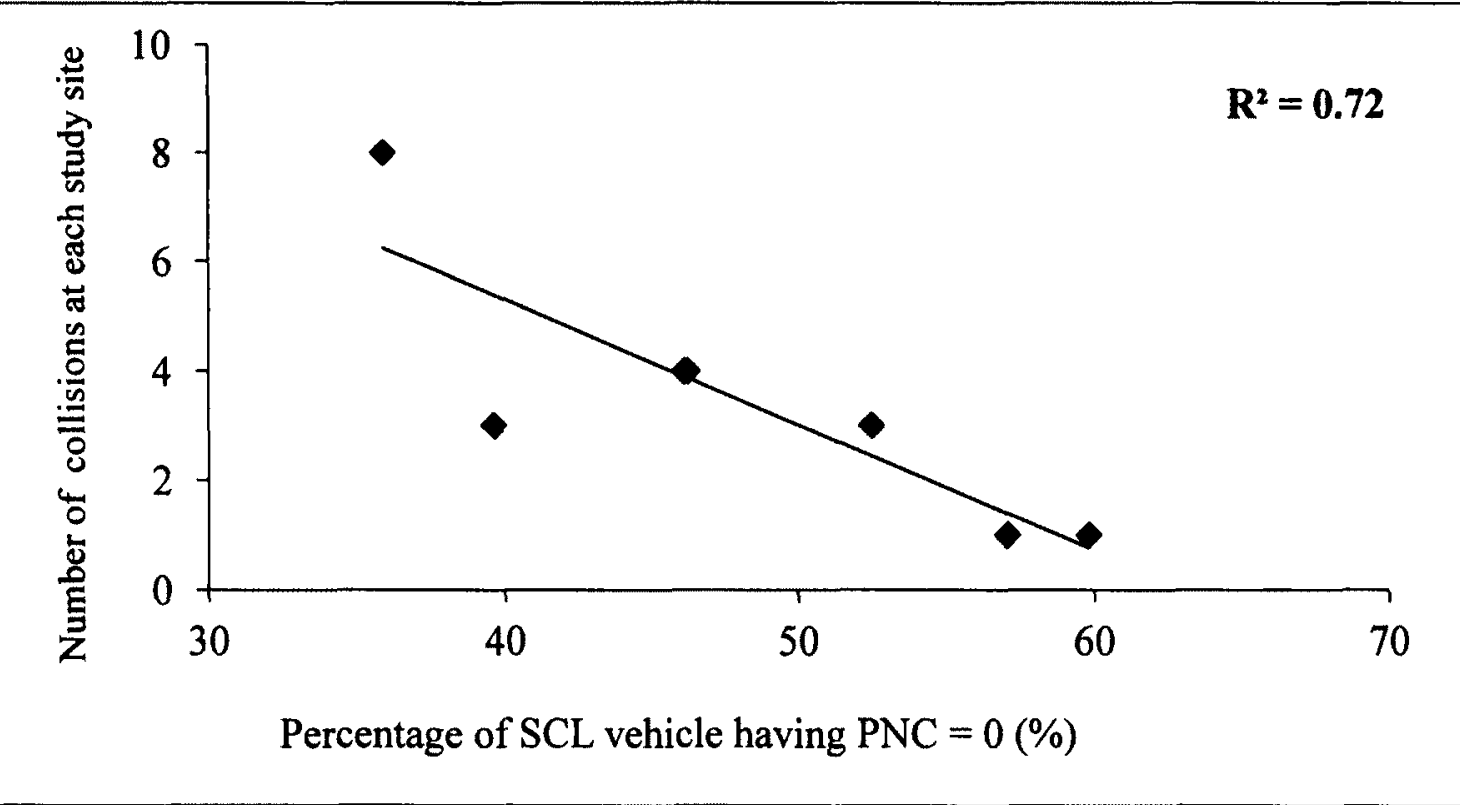

Figure 6.6: Percentage of $S C L$ vehicles having $P N C=0$ against number of collisions

\subsection{Design Application}

In this section, a case study is presented for applying the proposed model in the design of SCL length where both acceleration and gap searching behaviour of SCL drivers are considered. The new design approach will evaluate the quality of the SCL length design by estimating the PNC measures associated with a specific SCL length. As the model considers the search for and acceptance of a reasonable gap during the merging the process, the model is expected to be more realistic than the current design practice.

In order to estimate the PNC measures, the model was applied for different SCL lengths as recommended in the current design guides (AASHTO 2011 \& TAC 1999) for different controlling curve design speed. The input parameters in the model were predicted from the relationships that were established based on the field data. The 
following steps describe the assumptions made in calculating the PNC for a specific SCL length.

- According to the Ministry of Transportation of Ontario (MTO), the customary practice is to use the design speed of a freeway as $20 \mathrm{~km} / \mathrm{h}$ higher than the posted speed limit. Therefore, the freeway design speed was taken as $120 \mathrm{~km} / \mathrm{h}$.

- By examining the available data, no relationship was observed for the mean and standard deviation of the freeway right lane vehicles' speed. Therefore, constant values of $103.10 \mathrm{~km} / \mathrm{h}$ and $10.35 \mathrm{~km} / \mathrm{h}$ were assumed for the mean and standard deviation of freeway right lane vehicles' speeds, respectively based on the data of the eight study sites.

- Three different freeway right lane traffic volumes were used to check the PNC measures: 500,800 , and $1,200 \mathrm{veh} / \mathrm{h} / \mathrm{ln}$.

- Traffic composition on the freeway right lane was made of $90 \% \mathrm{PC}$ and $10 \%$ HV.

- The correlation coefficients among merge speed, gore speed and acceleration rate were taken based on the combined data of eight SCLs shown in Table 3.7.

- It was assumed in the model that the $85^{\text {th }}$ percentile of gore speed $\left(V_{85 \text { th }}\right.$ core $)$ at the end of ramp curve is equal to the design speed of entrance ramp curve.

- The mean gore speed was estimated based on the $85^{\text {th }}$ percentile of gore speed ( $\left.V_{85 t h \text { Gore }}\right)$ according to Equation 5.1.

- Using Equation 5.3 would yield mean merge speed $\left(\mu_{V M}\right)$ values that decrease with the decrease of the controlling curve design speed. To promote consistency in the design, a constant value of $\mu_{V M}=93.10 \mathrm{~km} / \mathrm{h}$ is used in all model runs. 
- The mean acceleration rate was also estimated based on the $85^{\text {th }}$ percentile of gore speed $\left(V_{85 t h}\right.$ Gore $)$ according to Equation 5.5. The standard deviation of gore speed $\left(\sigma_{G}\right)$, merge speed $\left(\sigma_{M}\right)$, and acceleration rate $\left(\sigma_{a}\right)$ were assumed from Equations 5.2, 5.4, and 5.6.

- Mean and standard deviation of acceptable gaps at each of the four segments of SCL were assigned to each vehicle using Equations 5.9, 5.10, 5.11, and 5.12.

- As the speed and acceleration rate were randomly assigned from the corresponding distribution curves, several steps were taken to avoid unrealistic or extreme values

-Negative values of the speed and acceleration rate were excluded.

-After generating the values of merge speed and gore speed, the speed difference between merge and gore speed was calculated.

-The values of speed difference deviating from the mean speed difference by more than two times of standard deviation were truncated. The mean and standard deviation of speed difference were estimated according to Equations 5.7 and 5.8.

-The values of acceleration rate deviating from the mean acceleration rate by more than two times of standard deviation were truncated.

The simulation model was run considering the above parameters. The mean and standard deviation of PNC associated with the SCL lengths recommended in the design guides for curve design speeds ranging from 50 to $80 \mathrm{~km} / \mathrm{h}$, were estimated. Tables 6.4 and 6.5 show the mean and standard deviation of PNC associated with the SCL lengths recommended by AASHTO (2011) and TAC (1999), respectively. 
Table 6.4: Mean and Standard deviation of PNC for SCL Lengths recommended by AASHTO (2011)

\begin{tabular}{|c|c|c|c|c|c|c|c|c|c|c|c|c|}
\hline & \multicolumn{12}{|c|}{ Entrance controlling curve design speed $(\mathrm{km} / \mathrm{h})$} \\
\hline & \multicolumn{3}{|c|}{50} & \multicolumn{3}{|c|}{60} & \multicolumn{3}{|c|}{70} & \multicolumn{3}{|c|}{80} \\
\hline & \multicolumn{12}{|c|}{ Mean gore Speed $(\mathrm{km} / \mathrm{h})$} \\
\hline & \multicolumn{3}{|c|}{45.06} & \multicolumn{3}{|c|}{54.28} & \multicolumn{3}{|c|}{63.50} & \multicolumn{3}{|c|}{72.72} \\
\hline & \multicolumn{12}{|c|}{ Standard deviation of gore speed $(\mathrm{km} / \mathrm{h})$} \\
\hline & \multicolumn{3}{|c|}{5.05} & \multicolumn{3}{|c|}{5.75} & \multicolumn{3}{|c|}{6.43} & \multicolumn{3}{|c|}{7.12} \\
\hline & \multicolumn{12}{|c|}{ Mean merge speed $(\mathrm{km} / \mathrm{h})$} \\
\hline & \multicolumn{3}{|c|}{93.10} & \multicolumn{3}{|c|}{93.10} & \multicolumn{3}{|c|}{93.10} & \multicolumn{3}{|c|}{93.10} \\
\hline & \multicolumn{12}{|c|}{ Standard deviation of merge speed $(\mathrm{km} / \mathrm{h})$} \\
\hline & \multicolumn{3}{|c|}{11.03} & \multicolumn{3}{|c|}{11.03} & \multicolumn{3}{|c|}{11.03} & \multicolumn{3}{|c|}{11.03} \\
\hline & \multicolumn{12}{|c|}{ Mean acceleration rate $\left(\mathrm{m} / \mathrm{s}^{2}\right)$} \\
\hline & \multicolumn{3}{|c|}{1.165} & \multicolumn{3}{|c|}{0.990} & \multicolumn{3}{|c|}{0.815} & \multicolumn{3}{|c|}{0.640} \\
\hline & \multicolumn{12}{|c|}{ Standard deviation of acceleration rate $\left(\mathrm{m} / \mathrm{s}^{2}\right)$} \\
\hline & \multicolumn{3}{|c|}{0.324} & \multicolumn{3}{|c|}{0.308} & & & 291 & & 0.274 & \\
\hline $\begin{array}{c}\text { Freeway } \\
\text { traffic }\end{array}$ & $\mathrm{L}$ & $\begin{array}{l}\text { Mean } \\
\text { PNC }\end{array}$ & $\begin{array}{l}\text { Stdev } \\
\text { PNC }\end{array}$ & $\mathrm{L}$ & $\begin{array}{l}\text { Mean } \\
\text { PNC }\end{array}$ & $\begin{array}{l}\text { Stdev } \\
\text { PNC }\end{array}$ & $\mathrm{L}$ & $\begin{array}{l}\text { Mean } \\
\text { PNC }\end{array}$ & $\begin{array}{l}\text { Stdev } \\
\text { PNC }\end{array}$ & $\mathrm{L}$ & $\begin{array}{l}\text { Mean } \\
\text { PNC }\end{array}$ & $\begin{array}{l}\text { Stdev } \\
\text { PNC }\end{array}$ \\
\hline $\mathrm{veh} / \mathrm{h} / \mathrm{ln}$ & $\mathrm{m}$ & & & $\mathrm{m}$ & & & $\mathrm{m}$ & & & $\mathrm{m}$ & & \\
\hline 500 & 460 & 0.156 & 0.345 & 410 & 0.152 & 0.343 & 325 & 0.236 & 0.412 & 245 & 0.370 & 0.473 \\
\hline 800 & 460 & 0.240 & 0.403 & 410 & 0.232 & 0.399 & 325 & 0.302 & 0.441 & 245 & 0.428 & 0.480 \\
\hline 1200 & 460 & 0.369 & 0.450 & 410 & 0.341 & 0.442 & 325 & 0.397 & 0.464 & 245 & 0.506 & 0.478 \\
\hline
\end{tabular}


Table 6.5: Mean and Standard deviation of PNC for SCL lengths recommended by

TAC (1999)

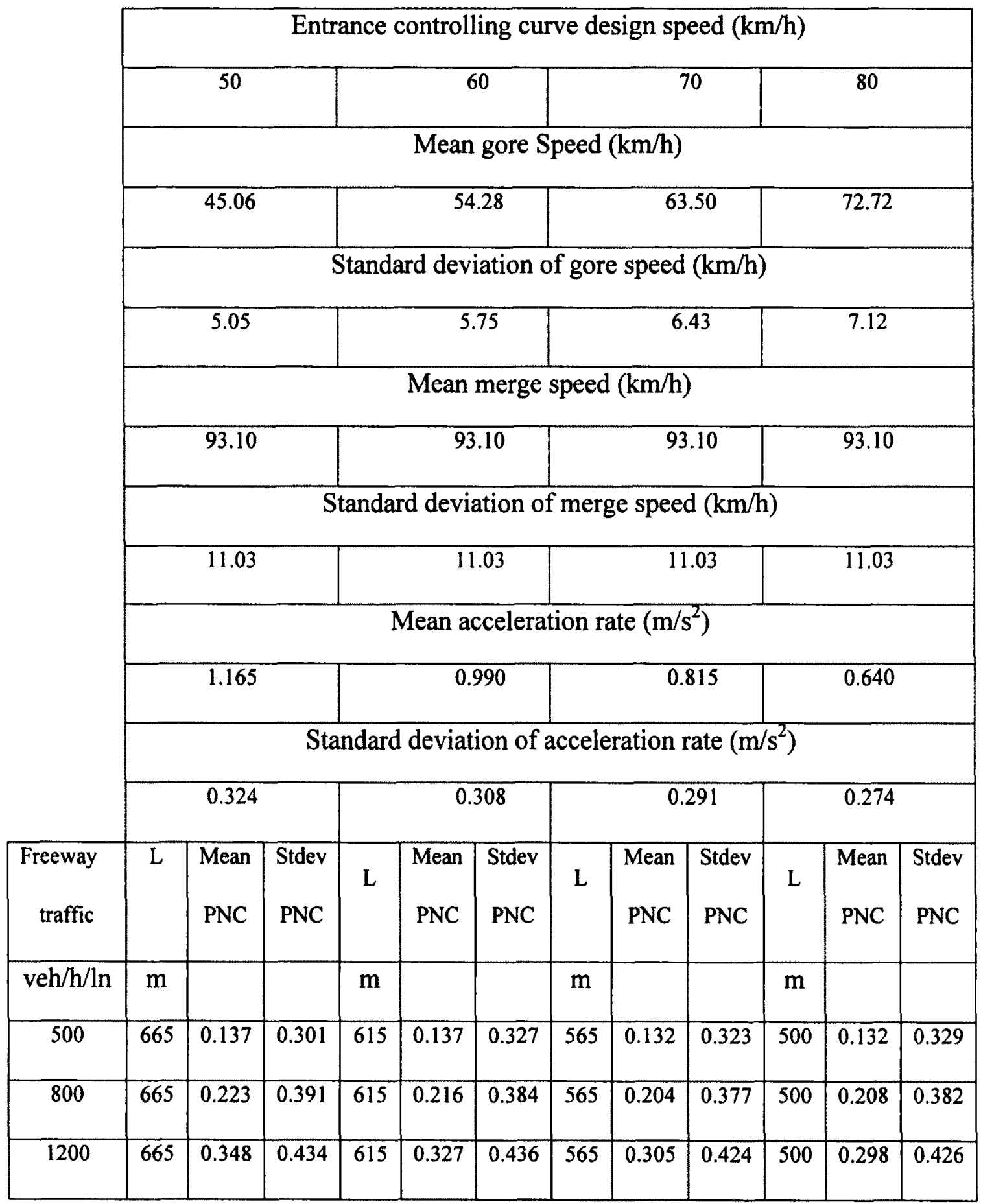


Comparing Tables 6.4 and 6.5 , it can be seen that

- The SCL lengths recommended by TAC (1999) provide lower mean PNC values than those recommended in the AASHTO (2011).

- In AASHTO (2011), the mean PNC value increases as the entrance curve speed increases from $50 \mathrm{~km} / \mathrm{h}$ to $80 \mathrm{~km} / \mathrm{h}$ for a specific freeway right lane traffic volume. This increase may be due to the decrease of the SCL length. Although the SCL length decreases in TAC (1999) with the increase of curve design speed, the estimated mean PNC value still decreases.

- The mean PNC correspond to TAC (1999) are more consistent than those corresponding to the AASHTO (2011).

- Tables 6.4 and 6.5 show that freeway right lane traffic volume has a significant influence on the mean PNC values. Figures 6.7 and 6.8 show a comparison of the mean PNC values for different traffic volume in the case of AASHTO (2011) and TAC (1999) recommended SCL lengths. It is observed from Figures 6.7 and 6.8 that the mean PNC increases for a specific curve design speed as the freeway traffic volume increases from $500 \mathrm{veh} / \mathrm{h} / \mathrm{ln}$ to $1200 \mathrm{veh} / \mathrm{h} / \mathrm{ln}$. Such an observation confirms the importance of considering freeway right lane traffic volume in determining the SCL length. 


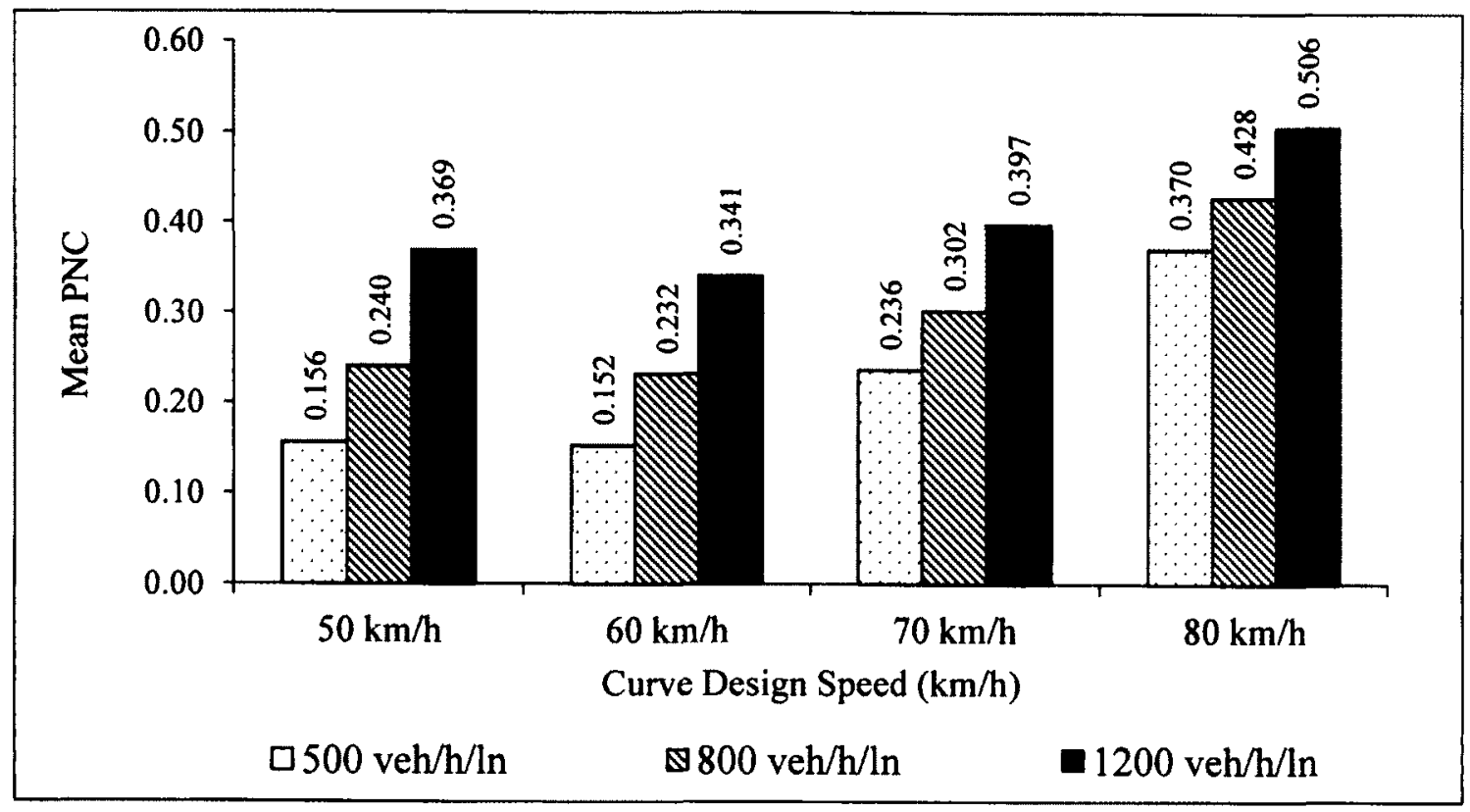

Figure 6.7: Comparison of the mean PNC for different traffic volume (AASHTO 2011).

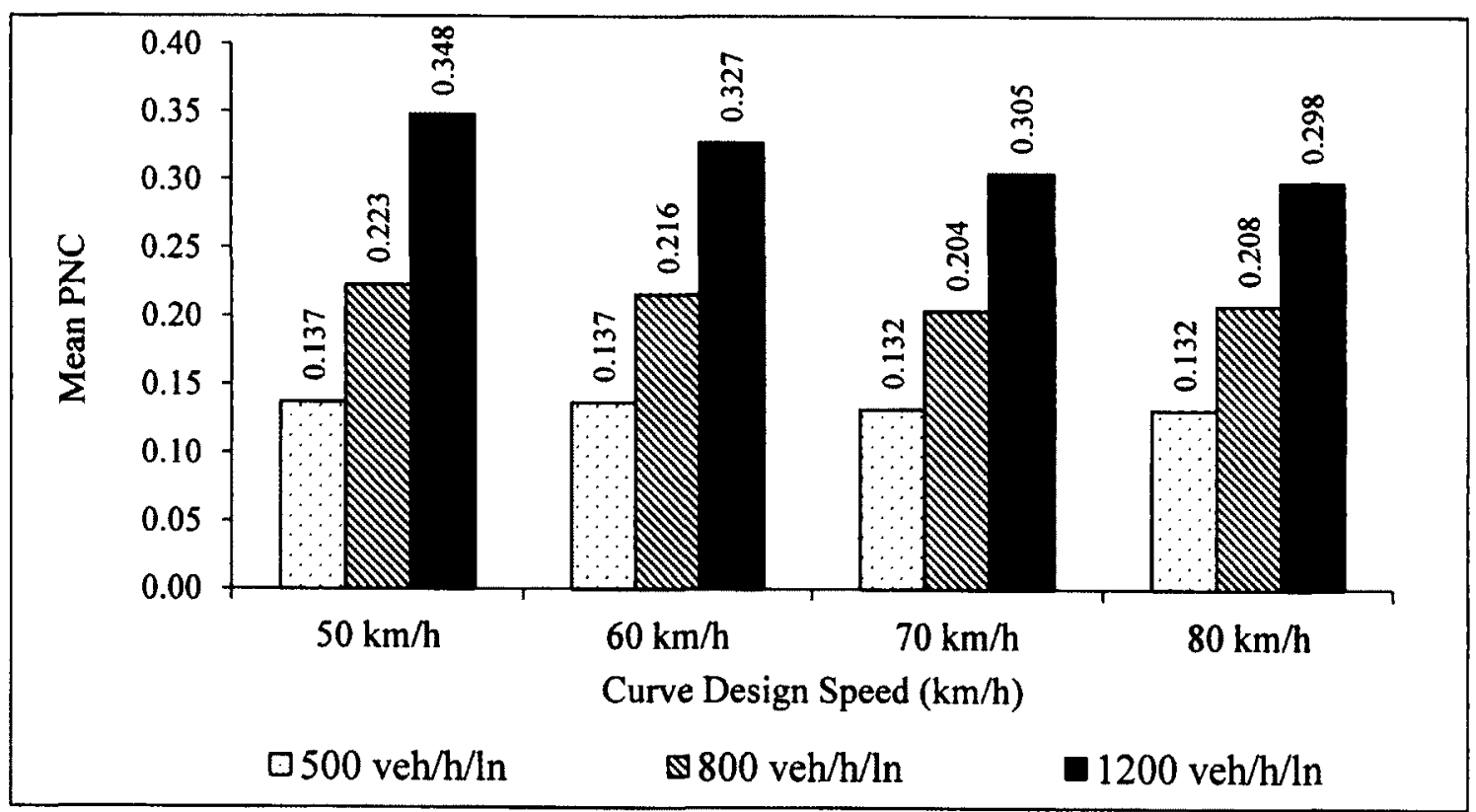

Figure 6.8: Comparison of the mean PNC for different traffic volume (TAC 1999). 


\subsection{Sensitivity Analysis}

In the sensitivity analysis, one input parameter was changed keeping all others parameter unchanged. The parameters considered in the simulation model are the mean and standard deviation of gore speed, the mean and standard deviation of merge speed, the mean and standard deviation of acceleration rate, the mean and standard deviation of freeway speed, traffic volume in the freeway right lane, traffic compositions and vehicles length in the freeway right lane, SCL length, mean acceptable gap in each of the four segments of SCL, correlation coefficients among the merge speed, gore speed and acceleration rate. In the proposed model, all input parameters are assumed based on the relationships found from the eight study sites. This relationship may be changed for other study sites, so the values of input parameters may also change. The sensitivity analysis was done to examine the effect of the change in the main input parameters. The base values of input parameters considered for the sensitivity analysis are given below:

- $85^{\text {th }}$ percentile of gore speed $\left(V_{85 \text { th Gore }}\right)=70 \mathrm{~km} / \mathrm{h}$ (assumed).

- Mean gore speed $\left(\mu_{G}\right)=64 \mathrm{~km} / \mathrm{h}$ (assumed).

- Mean merge Speed $\left(\mu_{M}\right)=90 \mathrm{~km} / \mathrm{h}$ (assumed).

- Mean acceleration rate $\left(\mu_{a}\right)=0.800 \mathrm{~m} / \mathrm{s}^{2}$ (assumed).

- SCL length $=400 \mathrm{~m}$.

- The mean and standard deviation of freeway right lane speed $103.11 \mathrm{~km} / \mathrm{h}$ and $10.35 \mathrm{~km} / \mathrm{h}$. 
- The freeway right lane traffic volume $=800 \mathrm{veh} / \mathrm{h} / \ln$ (assumed).

- Percentage of heavy vehicles in freeway right lane $=10 \%$.

- Percentage of passenger cars in freeway right lane $=90 \%$.

- Standard deviation of gore speed $\left(\sigma_{G}\right)$ was estimated as a function of $85^{\text {th }}$ percentile gore speed using Equation 5.2.

- Standard deviation of merge speed $\left(\sigma_{M}\right)$ was estimated as a function of $85^{\text {th }}$ percentile gore speed using Equation 5.4.

- Standard deviation of acceleration rate $\left(\sigma_{a}\right)$ was estimated as a function of $85^{\text {th }}$ percentile gore speed using Equation 5.6.

- The correlation coefficients among merge speed, gore speed and acceleration rate were

- Mean and standard deviation of speed difference were estimated as a function of $85^{\text {th }}$ percentile gore speed according to Equations 5.7 and 5.8 .

- Mean and standard deviation of acceptable gap size at each of the four segments of SCL were assigned to each vehicle using Equations 5.9, 5.10,

In the present study, input parameters (gore speed, acceleration rate, SCL length, freeway traffic volume, freeway speed, traffic composition in the freeway) were increased and decreased $10 \%, 20 \%$, and $30 \%$ to test the sensitivity of the model output. Table 6.6 shows the values of input parameters and Table 6.7 shows the values of mean PNC for corresponding assigned input parameters. 
Table 6.6: The Values of Input Parameters for the Sensitivity Analysis

\begin{tabular}{|l|c|c|c|c|c|c|c|}
\hline \multirow{2}{*}{ Sensitivity } & \multicolumn{7}{|c|}{ Input Parameter } \\
\cline { 2 - 8 } & $-30 \%$ & $-20 \%$ & $-10 \%$ & Base & $10 \%$ & $20 \%$ & $30 \%$ \\
\hline$\mu_{85 \text { th gore speed }(\mathrm{km} / \mathrm{h})}$ & 49 & 56 & 63 & 70 & 77 & 84 & 91 \\
\hline$\mu_{G}(\mathrm{~km} / \mathrm{h})$ & 44.80 & 51.20 & 57.60 & 64 & 70.40 & 76.80 & 83.20 \\
\hline$\mu_{a}\left(\mathrm{~m} / \mathrm{s}^{2}\right)$ & 0.560 & 0.640 & 0.720 & 0.800 & 0.880 & 0.960 & 1.040 \\
\hline $\begin{array}{l}\text { Freeway RL traffic volume } \\
\text { (veh/h/ln) }\end{array}$ & 560 & 640 & 720 & 800 & 880 & 960 & 1040 \\
\hline SCL length $(\mathrm{m})$ & 280 & 320 & 360 & 400 & 440 & 480 & 520 \\
\hline Freeway speed $(\mathrm{km} / \mathrm{h})$ & 72.17 & 82.48 & 92.79 & 103.10 & 113.41 & 123.72 & 134.03 \\
\hline $\begin{array}{l}\text { Heavy vehicle percentage } \\
\text { (\%) }\end{array}$ & $7 \%$ & $8 \%$ & $9 \%$ & $10 \%$ & $11 \%$ & $12 \%$ & $13 \%$ \\
\hline
\end{tabular}

Table 6.7: The Values of Mean PNC for Corresponding Assigned Input Parameters

\begin{tabular}{|l|c|c|c|c|c|c|c|}
\hline \multirow{2}{*}{ Sensitivity } & \multicolumn{7}{|c|}{ Value of Mean PNC } \\
\cline { 2 - 8 } & $-30 \%$ & $-20 \%$ & $-10 \%$ & Base & $10 \%$ & $20 \%$ & $30 \%$ \\
\hline$\mu_{G}(\mathrm{~km} / \mathrm{h})$ & 0.350 & 0.337 & 0.292 & 0.252 & 0.215 & 0.212 & 0.206 \\
\hline$\mu_{a}\left(\mathrm{~m} / \mathrm{s}^{2}\right)$ & 0.425 & 0.353 & 0.287 & 0.252 & 0.218 & 0.221 & 0.222 \\
\hline $\begin{array}{l}\text { Freeway RL traffic } \\
\text { (veh/h/h) }\end{array}$ & 0.196 & 0.212 & 0.226 & 0.252 & 0.272 & 0.283 & 0.300 \\
\hline SCL length (m) & 0.411 & 0.323 & 0.278 & 0.252 & 0.222 & 0.220 & 0.212 \\
\hline Freeway speed (km/h) & 0.249 & 0.247 & 0.257 & 0.252 & 0.247 & 0.242 & 0.241 \\
\hline $\begin{array}{l}\text { Heavy vehicle percentage } \\
\text { (\%) }\end{array}$ & 0.253 & 0.252 & 0.251 & 0.252 & 0.252 & 0.251 & 0.250 \\
\hline
\end{tabular}


Table 6.7 shows that the change in mean output is not substantial due to increase and decrease of freeway speed and traffic composition. For increasing and decreasing the freeway speed and traffic composition, the changes in the output of model range from $4 \%$ to $0.39 \%$. The findings in Table 6.7 related to the sensitivity of mean PNC to other parameters are described in the following paragraphs:

\subsubsection{Change in Acceleration Rate}

Figure 6.9 shows the values of mean PNC for change in acceleration rate. Figure 6.10 shows the variations of output for the change in acceleration rate. When the mean acceleration rate increases by $10 \%, 20 \%$, and $30 \%$ from the base value, the mean PNC does not decrease remarkably in any of the cases, but when the mean acceleration rate decreases by $10 \%, 20 \%$ and $30 \%$, the mean PNC increases substantially. In the sensitivity analysis, these variations are observed due to the fact that when acceleration rate increases, the SCL vehicle attains the acceptable merge speed earlier and looks for the acceptable gap, so the availability of gap in the freeway right lane becomes the controlling factor. As the freeway traffic volume was kept constant in all cases, the observed variation for increasing the acceleration rate is not substantial. On the other hand, the SCL vehicle travels more distance on the acceleration lane to attain the acceptable merge speed when the acceleration rate decreases, so the mean PNC increases considerably. But it was observed from the eight study sites that when the initial speed at the beginning of SCL length is lower, the SCL driver adopts higher acceleration rate to compensate for this situation and vice versa. 


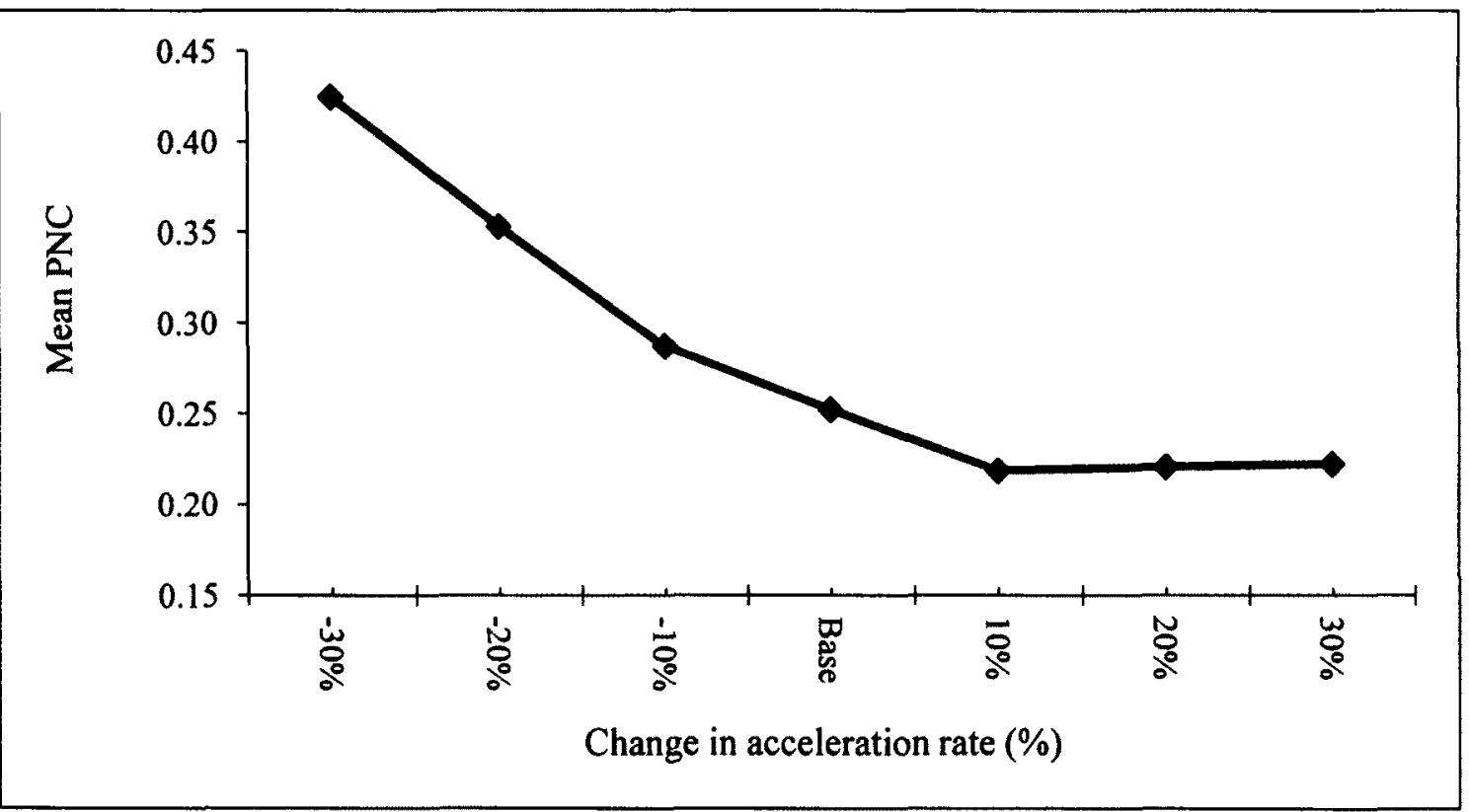

Figure 6.9: Mean PNC vs change in mean acceleration rate.

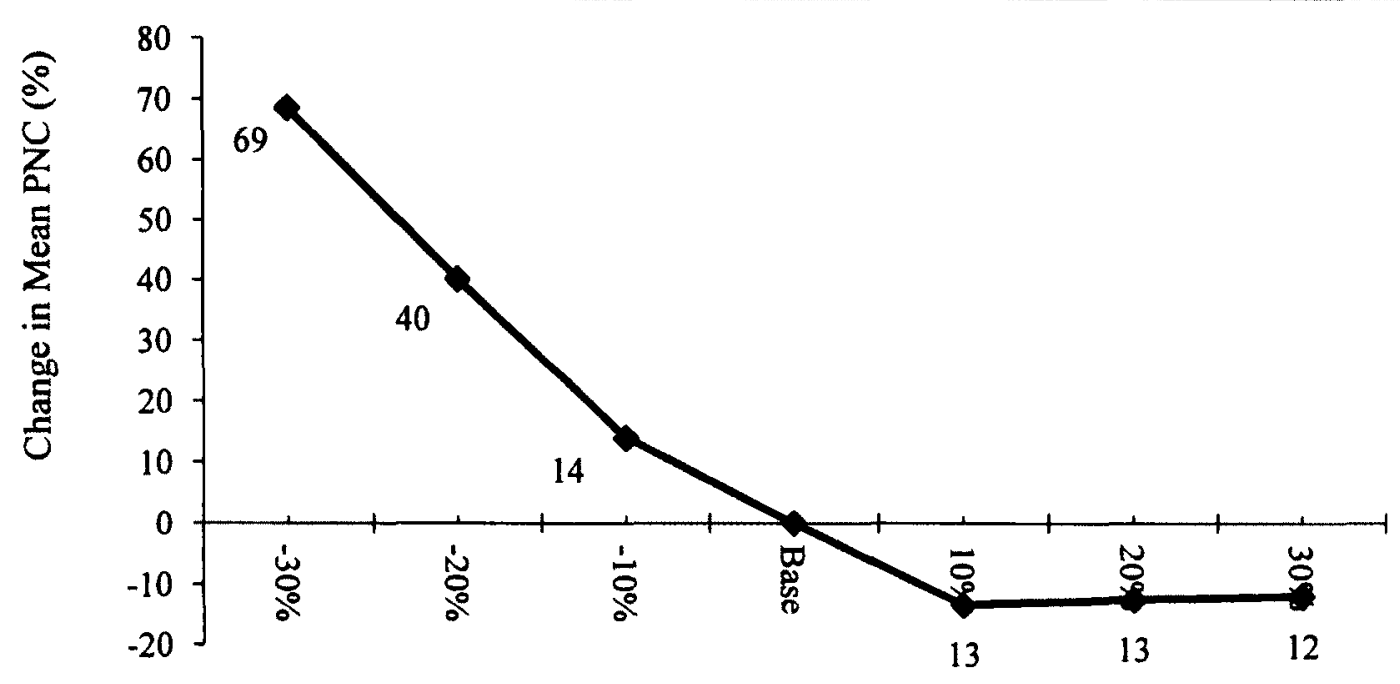

Change in acceleration rate (\%)

Figure 6.10: Change in mean PNC vs change in mean acceleration rate 


\subsubsection{Change in Gore Speed}

Figure 6.11 shows the values of mean PNC for change in gore speed. Figure 6.12 shows the variations of output for the change in gore speed. When the mean gore speed increases $10 \%, 20 \%$, and $30 \%$ from the base value, the mean PNC decreases $15 \%, 16 \%$, and $18 \%$ respectively, and when the mean gore speed decreases $10 \%, 20 \%$, and $30 \%$, then the mean PNC increases $16 \%, 34 \%$, and $39 \%$ respectively. In the sensitivity analysis, these variations are observed due to the fact that when the mean gore speed increases, the SCL vehicle attains the acceptable merge speed earlier and looks for the acceptable gap, so the availability of gap in the freeway right lane becomes the controlling factor. As the freeway traffic volume was kept constant in all cases, the observed variation for increasing the mean gore speed is not substantial. It has been already mentioned that in the proposed model, the acceleration rate increases when intial speed increases and vice versa based on the relationship observed from eight study sites. In the sensitivity analysis, as the acceleration rate was not changed for decrease in the mean gore speed, the SCL vehicle travels more distance on the speed change lane to attain the acceptable merge speed, so the mean PNC increases considerably. 


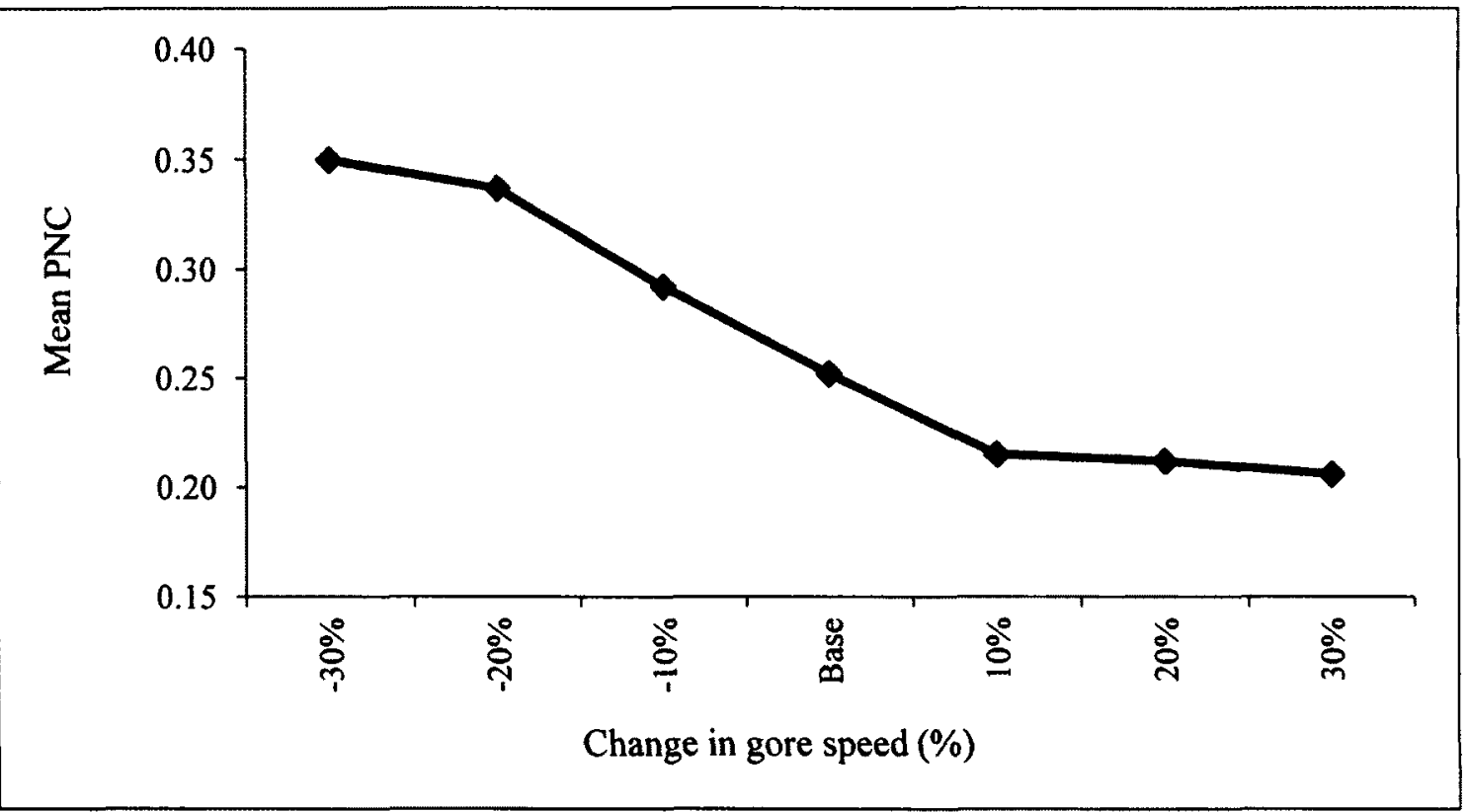

Figure 6.11: Mean PNC vs change in mean gore speed

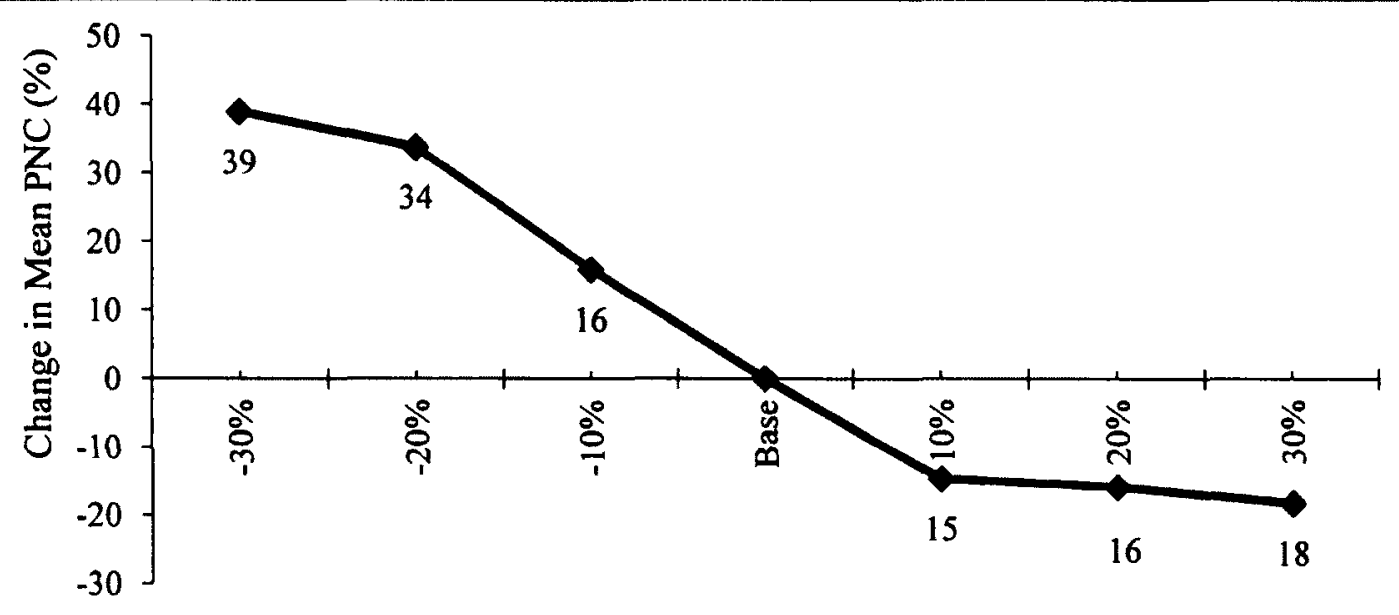

Change in gore speed (\%)

Figure 6.12: Change in PNC vs change in mean gore speed 


\subsubsection{Change in Freeway Right Lane Traffic Volume}

It is observed from Table 6.6 that the output of the model is sensitive to the traffic volume in the freeway right lane. Figures 6.13 and 6.14 show the mean PNC and percentage change in PNC with the change in traffic volume. When the traffic volume increases, the generated headway between consecutive two freeway vehicles decreases and vice versa. As a result, the mean PNC decreases when freeway right lane traffic volume decreases and the mean PNC increases when freeway right lane traffic volume increases.

Additional simulation runs were also done to examine the trend of mean PNC against different freeway right lane traffic volume. Figure 6.15 shows the mean PNC for different traffic volume. It is observed from Figure 6.15 that the mean PNC increases linearly as the traffic volume increases where coefficient of determination, $\mathrm{R}^{2}=0.99$.

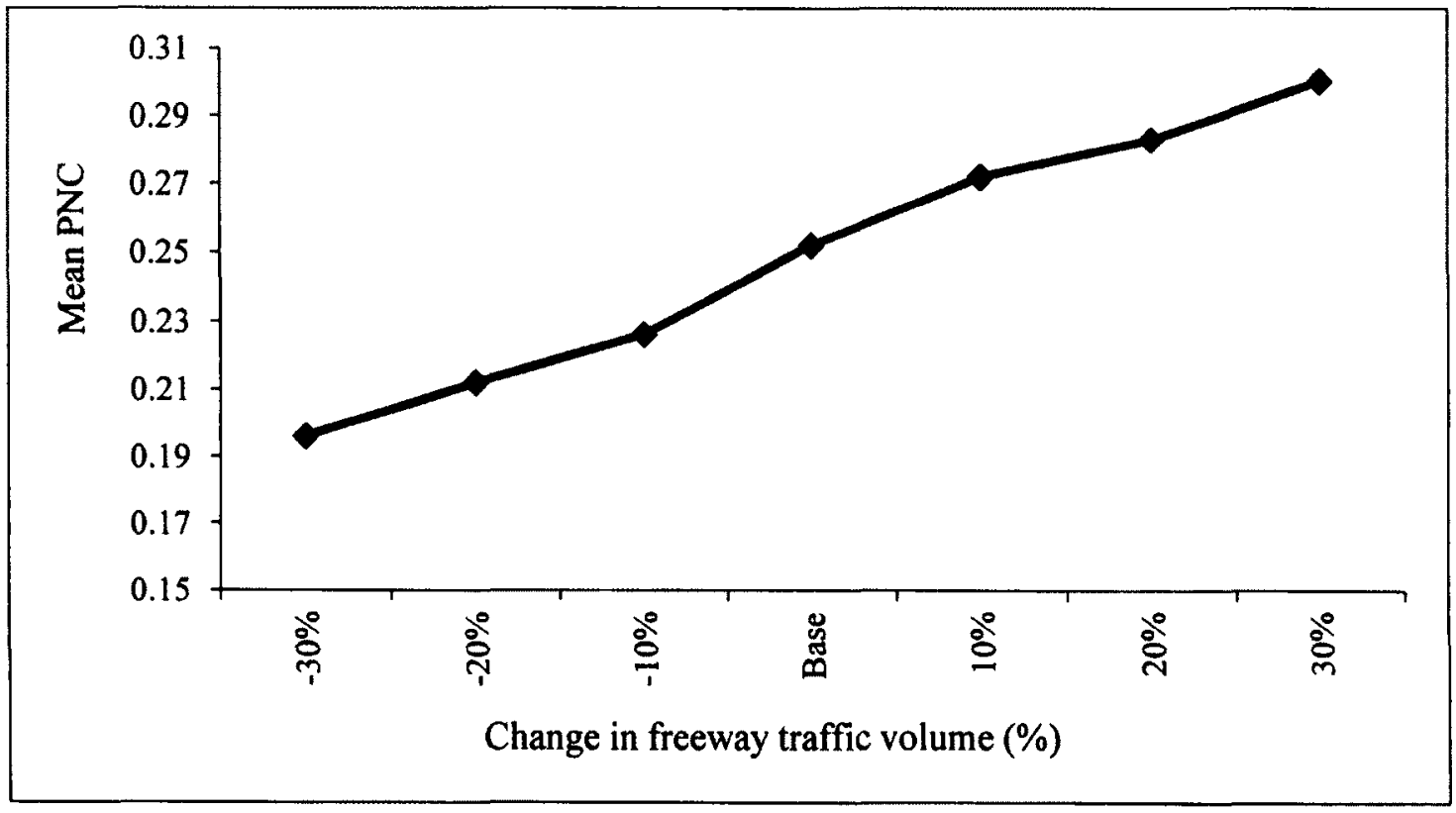

Figure 6.13: Mean PNC vs change in traffic volume. 


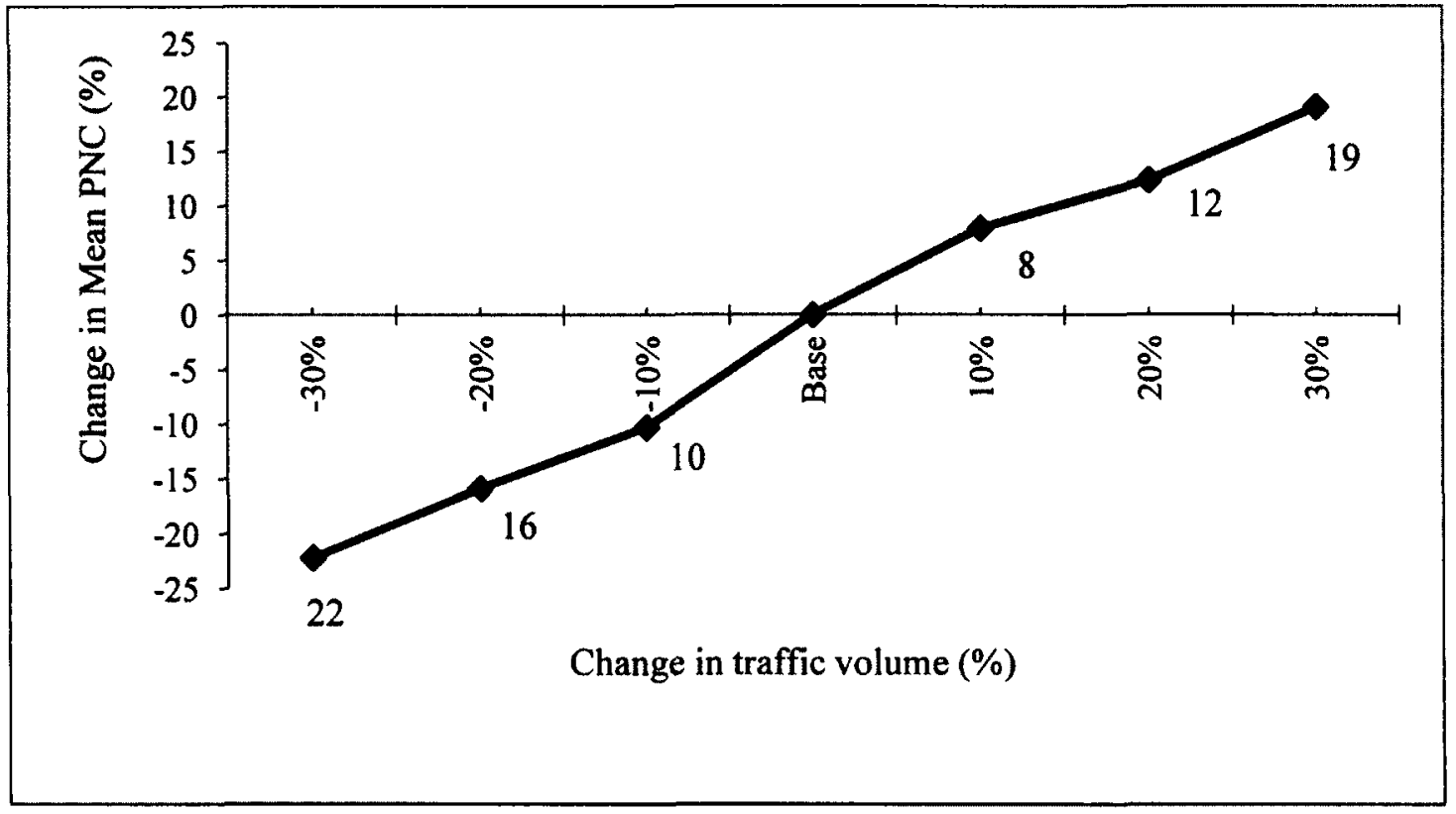

Figure 6.14: Change in PNC vs change in traffic volume

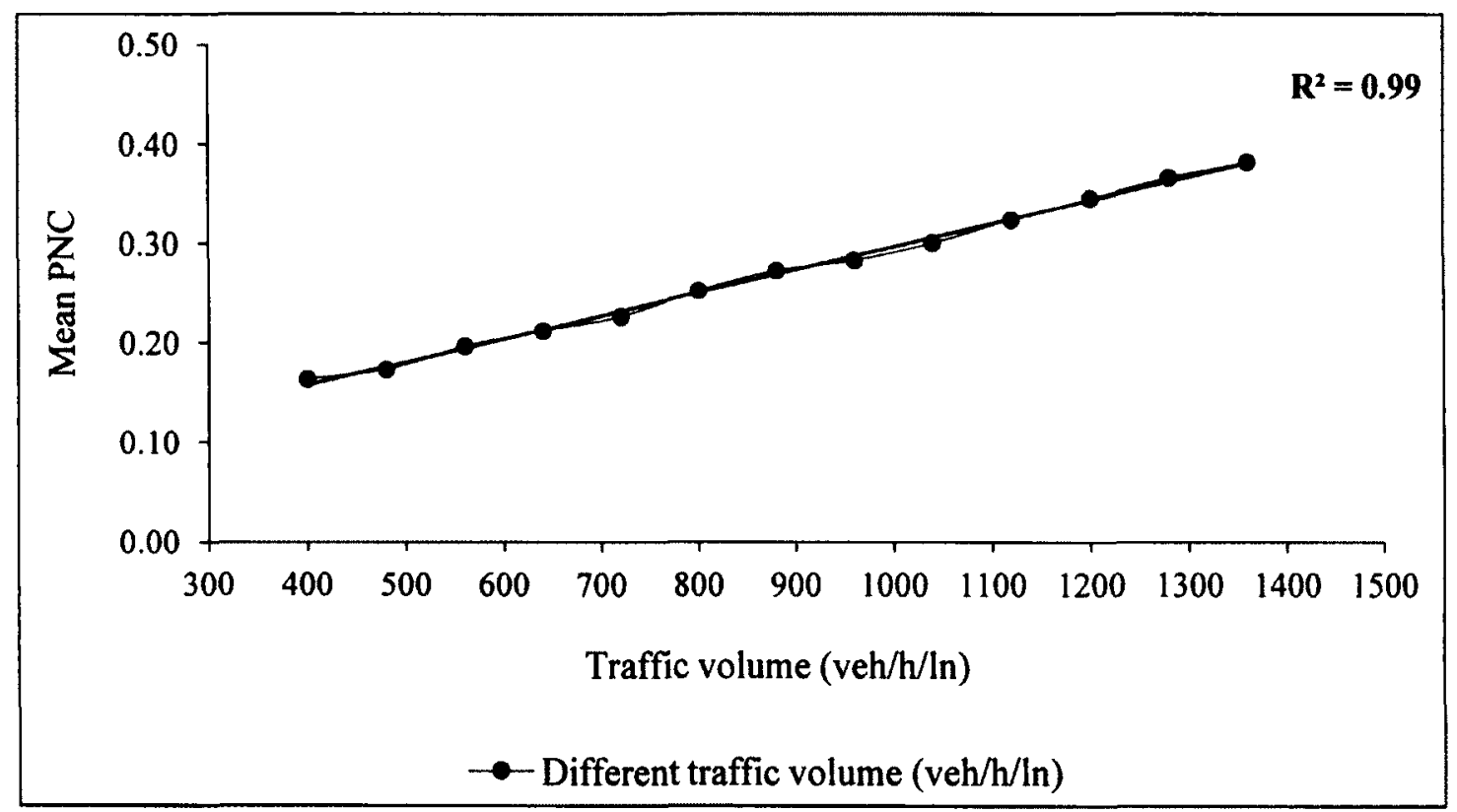

Figure 6.15: Mean PNC vs different traffic volume (veh/h/ln) 


\subsubsection{Change in SCL length}

Figures 6.15 and 6.16 show the mean PNC and percentage change in PNC with the change in SCL length. When the SCL length decreases, the value of PNC increases substantially. It is observed from Figure 6.16 that decreasing the SCL length by $10 \%$, $20 \%$, and $30 \%$, the value of mean PNC rises by $11 \%, 28 \%$, and $68 \%$ and increasing the SCL length by $10 \%, 20 \%$, and $30 \%$, the value of mean PNC falls by $12 \%, 13 \%$, and $16 \%$ respectively.

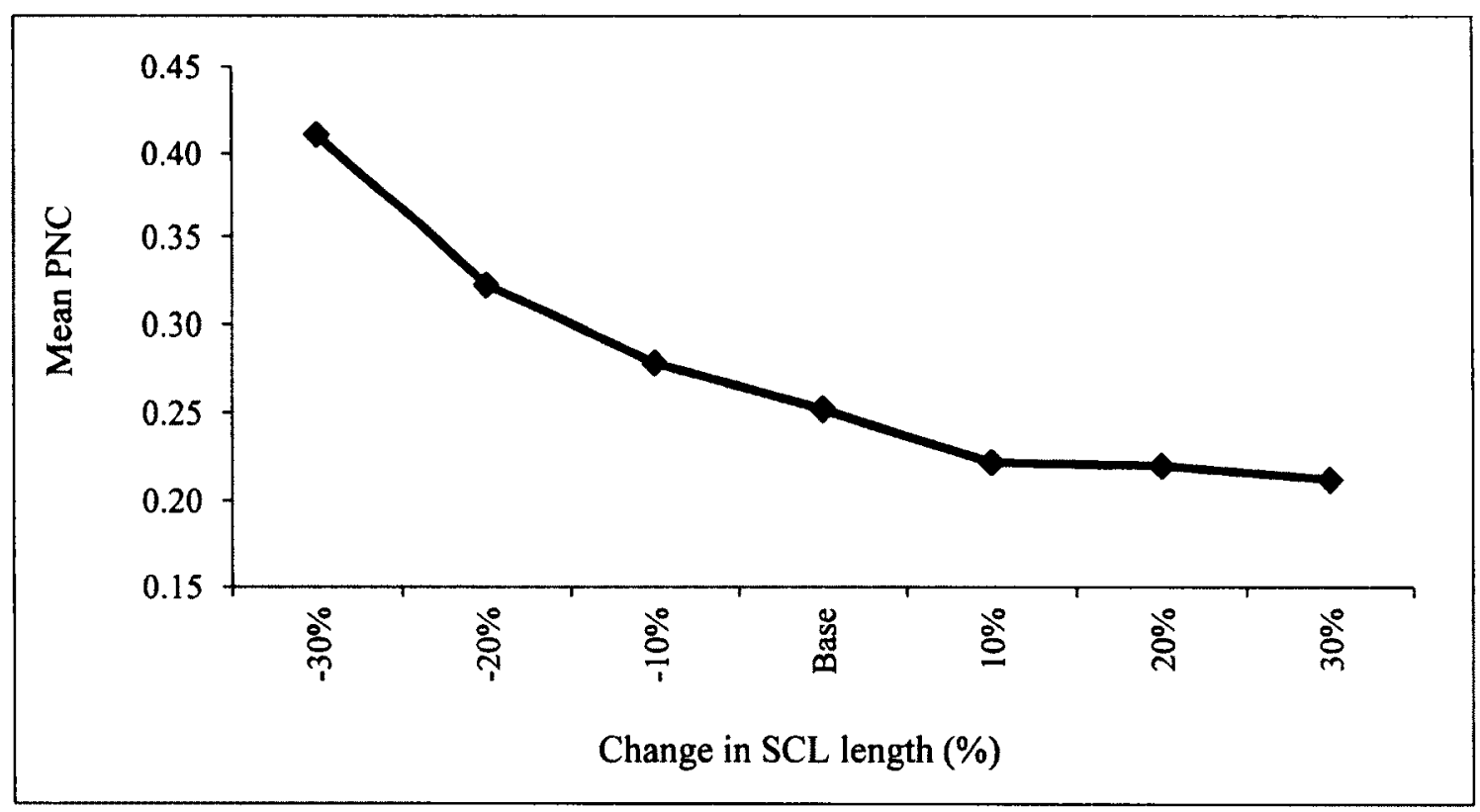

Figure 6.16: Mean PNC vs change in SCL length. 


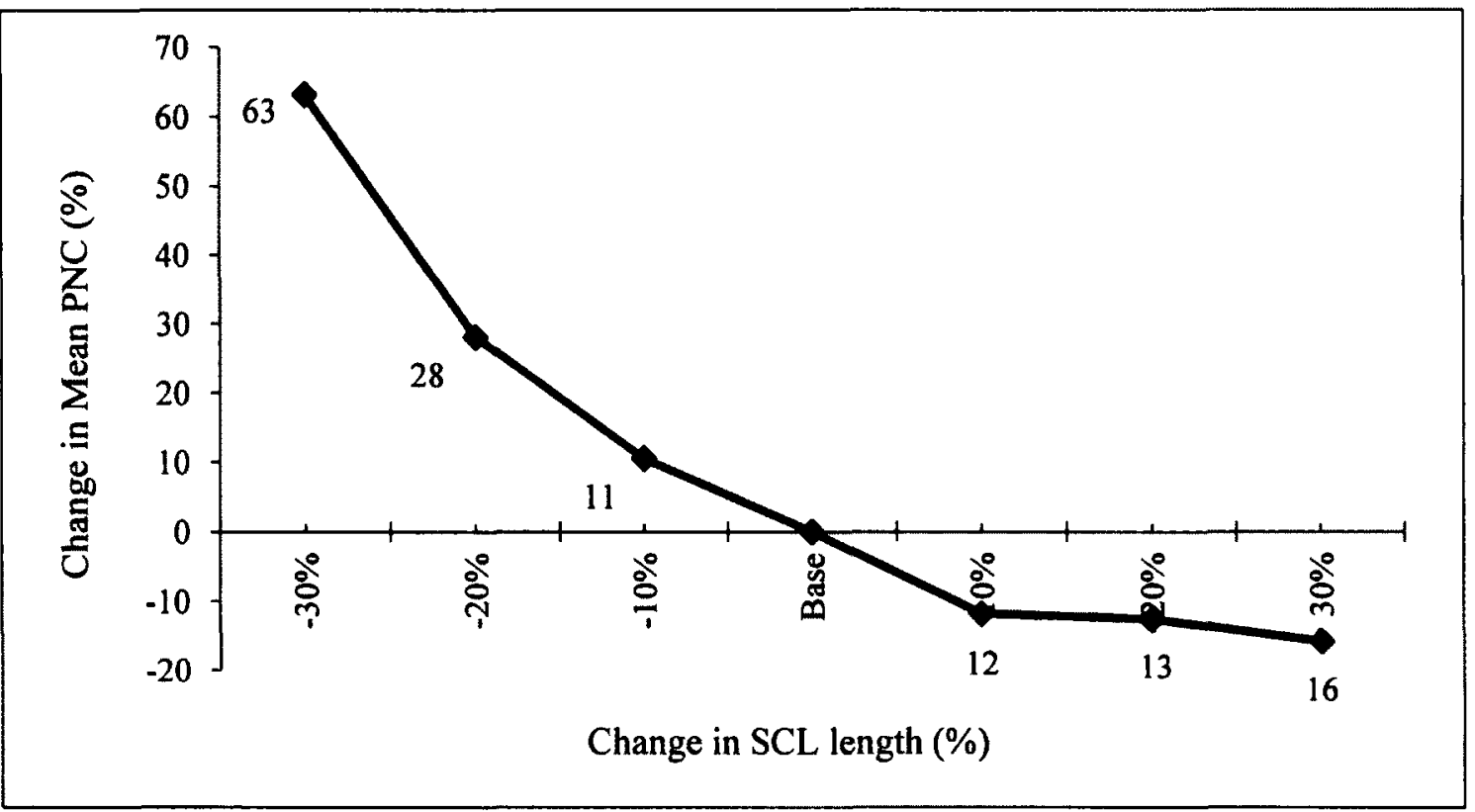

Figure 6.17: Change in mean PNC vs change in SCL length

Additional simulation runs were also done to examine the trend of mean PNC against different SCL lengths under different traffic volumes. Figure 6.18 shows the trend between mean PNC and SCL length for different traffic volumes. The following observations are revealed from Figure 6.18:

- When the SCL length decreases, the SCL vehicle does not get enough space to accelerate to a proper merging speed and search for an acceptable gap in the freeway traffic, so the mean PNC increases. It is observed from Figure 6.18 that the output of the model decreases substantially as the SCL length decreases below $320 \mathrm{~m}$. 
- In the proposed model, the SCL driver does not take the advantage of increasing SCL length for merging as freeway right lane vehicles do not perform any accomodating manoeuvers to allow the SCL vehicle to merge onto the freeway. As a result, availability of gap in the freeway right lane becomes the controlling factor after achieving the acceptable merge speed. It is observed from Figure 6.18 that when the SCL length increases more than a specific length i.e $440 \mathrm{~m}$, the mean PNC does not change considerably.

- The mean PNC increases linearly as the traffic volume increases.

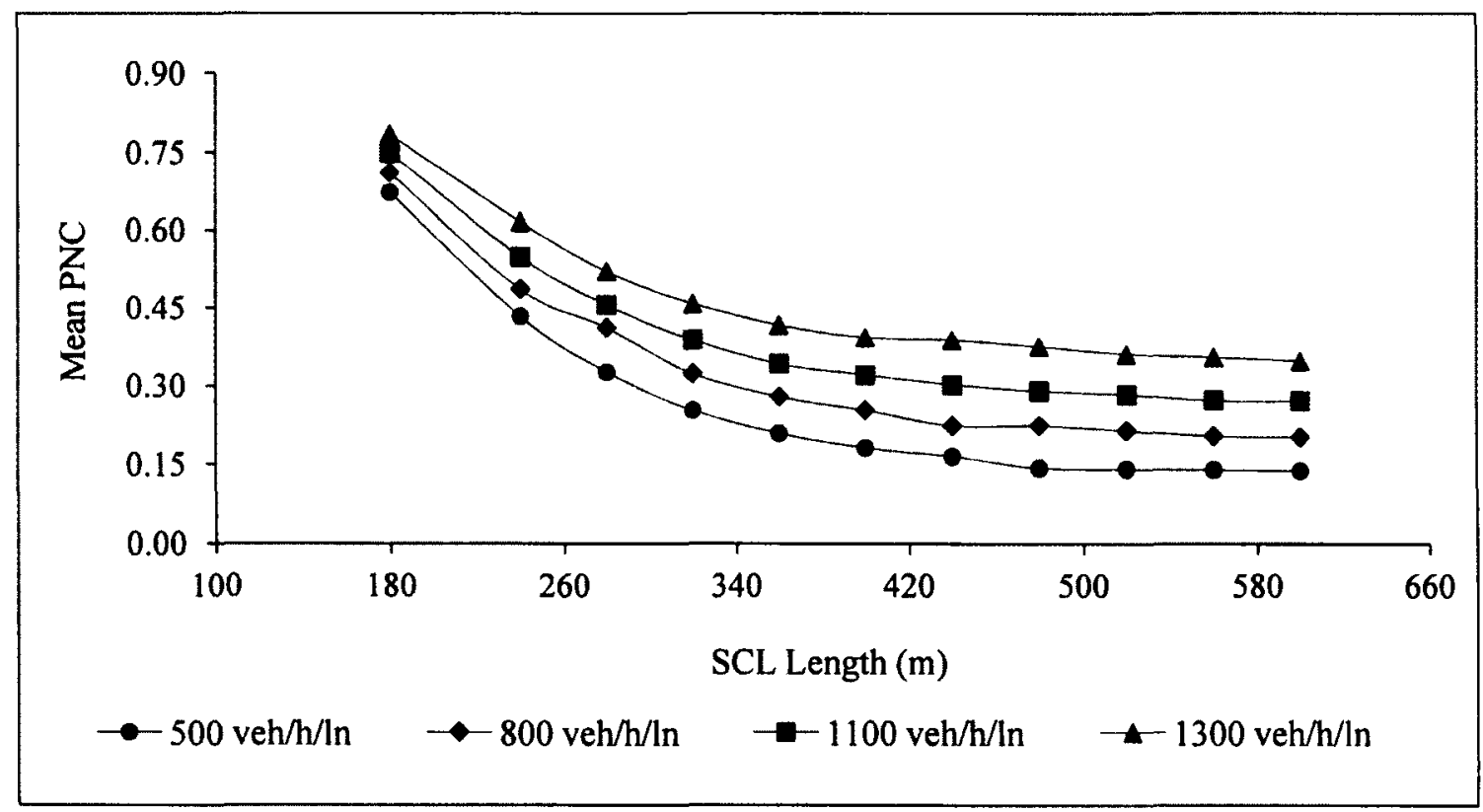

Figure 6.18: The mean PNC vs different SCL length 


\section{CONCLUSION}

The current design guides use a deterministic approach for the determination of SCL length which is a conservative design and do not consider the whole population. In this approach, a single conservative value is considered for each parameter, and the output of this design is a single value. Furthermore, the gap acceptance behaviour over the SCL length is ignored in the current design guides which is an important characteristic during the merging process besides the acceleration behaviour. The concept of designing the SCL length in the current design practice remains far away from reflecting the real situations. The probabilistic approach is the alternative method where the variations of the design parameters are considered. The study presented a detailed description of a simulation model for vehicles' movement on freeway entrance SCL and merging onto the freeway through lanes. The model uses a micro-simulation technique to account for the needs of SCL vehicles to accelerate to a target merge speed as well as searching for and finding an acceptable gap in the freeway through traffic. In addition, a Monte Carlo simulation technique is used in the model to account for the variability in driver's speed, acceleration, and gap acceptance characteristics in a probabilistic approach based on field data. The model can be run for a specific SCL site with a specific length to produce the probability of forced merge for each SCL vehicle, which was termed in this research as the probability of non-compliance (PNC). 


\subsection{Conclusions}

The following conclusions can be drawn from the research work reported in this thesis:

1. In the present study, the variations of the design parameters were considered which represent the whole population and thus, the stochastic characteristics of the drivers were captured.

2. Drivers' gap acceptance behaviour is obvious during the merging process over the SCL length, so it must be included in the SCL length design. The present research incorporated the gap searching and acceptance phenomena in addition to acceleration.

3. The model was needed to be considered the variability of SCL vehicles' gap acceptance behaviour along the SCL length. It was observed from statistical analysis that the SCL length needs to be divided into four segments to capture the drivers' gap acceptance behaviour.

4. The software MATLAB 7.8 is used successfully in this research work to simulate the SCL vehicles' merging process onto the freeway. The outcome of the model provides the SCL vehicle's PNC which represents the probability of forced or uncomfortable merging.

5. In this research, different reliability measures can be obtained for the whole site such as mean PNC, standard deviation of PNC, and percentage of SCL 
vehicles with a PNC equal to or exceeding a specific threshold. Intuitively, these reliability measures should correlate to the expected safety performance on the SCL site, although it is noted that a specific vehicle with a high PNC value will not necessarily be involved in a collision. The trend between the reliability measures and safety performance was confirmed by comparing different reliability measures estimated for the study sites with the five-year SCL collision frequency at these sites. However, a database with more sites needs to be investigated to quantitatively relate the proposed reliability measures to safety performance.

6. The developed model was also used to estimate the mean PNC on the recommended SCL length in the North American design guides. The results indicated that the AASHTO (2011) recommendations may produce a trend of increasing mean PNC as the design speed of the ramp controlling curve increases. On the other hand, the TAC (1999) produces more consistent mean PNC values for different design speeds of the ramp controlling curve given that the traffic volume on the FRL remains the same.

7. Freeway right lane traffic volume has a significant effect on the merging process, which confirms the need to consider this variable in the design of SCL length 
8. It was observed by doing sensitivity analysis that the mean PNC is found more sensitive to the SCL length and acceleration rate compare to the other parameters.

\subsection{Recommendations}

Some recommendations are made below for future research work

1. During the merging process from the SCL to freeway, the drivers on the freeway through lanes try to accommodate the merging vehicle through lane changes or speed adjustment. These interactions were not considered in the model due to unavailability of data. Therefore, field data are required to capture those freeway drivers' behaviour who performed some actions while SCL vehicles try to merge in the freeway right lane.

2. The present study considers only the freeway right lane traffic volume. However, traffic data of other lanes should also be considered for understanding the freeway vehicles' interaction with the SCL vehicles.

3. The current study considers eight study sites in Highway 417 which are located on highly populated urban areas. The SCL vehicles' behaviour in sub-urban or rural areas may vary from the urban areas, so more SCL sites in different locations can be used to understand the drivers' behaviour in different situations. 
4. The present study considers speed data from gore area to the merge point, but speed data from the beginning of entrance curve would be more accurate to understand the drivers' acceleration behaviour for merging. Therefore, speed data should be collected from the very beginning of the entrance curve in order to improve the quality of data.

5. In the present study, only one SCL is located in the upgrade, and one SCL type is taper, so dataset from different geometric configurations of SCL such as upgrade, downgrade, taper type SCL, parallel type, can be collected from the field to examine the effect of these factors on the drivers' merging behaviour.

6. The number of study sites should be increased, and more detailed collision data corresponding to these study sites should be required to evaluate the sites' safety performance in terms of PNC. 


\section{REFERENCES}

Ang, A. H-S., and Tang, W. H. 1975. Probability Concepts in Engineering Planning and Design, Vol. 1, Basic Principles, John Wiley, NewYork.

Ahmed, K. I., Ben-Akiva, M. E., Koutsopoulos, H. N., and Mishalani, R. G. 1996. Models of Freeway Lane Changing and Gap Acceptance Behaviour. Transportation and Traffic Theory: 501-515.

Ahmed, K. I. 1999. Modeling Driver's Acceleration and Lane Changing Behavior, PhD dissertation, Department of Civil and Environmental Engineering, MIT.

Ahammed, A. M. 2005. Freeway Merging Behaviour and Safety of Acceleration Lanes: Field Study. Master of Applied Science Thesis, Civil and Environmental Engineering Department, Carleton University. Ottawa, Ontario.

Ahammed, A. M., Hassan, Y., and Sayed, T. A. 2006. Effect of Geometry of Entrance Terminals on Freeway Merging Behavior. Transportation Research Board. Preprint CD for 2006 Annual Meeting.

Ahammed, A. M., Hassan, Y., and Sayed, T. A. 2008. Modeling Driver Behavior and Safety on Freeway Merging Areas. Journal of Transportation Engineering, American Society of Civil Engineers, ASCE, $134(9): 370-377$.

AASHTO (2011). A Policy on Geometric Design of Highways and Streets. American Association of State Highway and Transportation Officials. $6^{\text {th }}$ Edition Washington, D. C., 2011. 
Ben-Akiva, M., Hirsh, M., and Prashker, J. 1985. Probabilistic and Economic Factors in Highway Geometric Design. Transportation Science, 19 (1): 38 - 57.

Bham, G. H. and Benekohal, R. F. 2004, A High Fidelity Traffic Simulation Model Based on Cellular Automata and Car-Following Concepts, Transportation Research Part C: Emerging Technologies, 12(1):1-32.

Brewer, M. A., Fitzpatrick, K., and Stanley, J. 2011. Driver Behavior on Speed-change Lane at Freeway Ramp Terminals. Transportation Research Record: Journal of Transportation Research Board, 2223: 54-62.

Choi, S.-K., Grandhi, R.V., and Canfield, R. A. 2006. Reliability-based Structural Design. Springer-37 Verlag London Ltd, London.

Canadian motor vehicle traffic collision statistics, 2009. www.tc.gc.ca. Consulted on 2012-09-05.

Drew, D. R. 1968. Traffic Flow Theory and Control. McGraw-Hill Inc., New York.

Ditlevsen, O. D. 1981. Uncertainty Modelling with Application to Multi-dimensional Civil Engineering Systems. McGraw-Hill, New York.

Daamen, W., Loot, M., and Hoogendoorn, S. P. 2010. Empirical Analysis of Merging Behavior at a Freeway On-Ramp. Transportation Research Record: Journal of the Transportation Research Board, 2188:108-118.

Evans D. H. 1972. An Application of Numerical Integration Techniques to Statistical Tolerancing, III: General Distributions. Technometrics, 14(1): 23-35.

Easa, S. M. 1994. Reliability-based Design of Sight Distance at Rail-Road Grade Crossings. Transportation Research Part A-Policy and Practice, 28(1): 1-15. 
Easa, S. M. 2000. Reliability Approach to Intersection Sight Distance Design. Transportation Research Record, 1701: 42-52.

Khoury, J. E., and Hobeika, A.G. 2007. Assessing the Risk in the Design of Passing Sight Distances. ASCE Journal of Transportation Engineering, 133(6): 370-377.

Fitzpatrick, K., and Zimmerman, K. 2007. Potential Updates to the 2004 Green Book's Acceleration Lengths for Entrance Terminals. Transportation Research Record: Journal of the Transportation Research Board, 2023:130- 139.

Fuller, R. and Santos, J. A. 2002. Human Factors for Highway Engineers. Elsevier Science Ltd., Kidlington, Oxford, UK.

Gipps, P. G. 1986. A Model for the Structure of Lane Changing Decisions. Transportation Research Part B: Methodological, 20 (5): 403 - 414.

Garber, N.J. and Hoel, L.A. 2009 Traffic \& Highway Engineering. Fourth Edition, Cengage Learning,.

Hasofer, A. M., and Lind, N. C. 1974. Exact and Invariant Second-Moment Code Format. Journal of the Engineering Mechanics Division, 100 (1): 111-121.

Huberman, M. 1982. The Development and Evaluation of a Technique for Measuring Vehicle Acceleration on Highway Entrance Ramps. Road and Transportation Association of Canada. RTAC Forum, 4 (2): 90-96.

Harr, M. E. 1987. Reliability- Based Design in Civil Engineering. McGraw-Hill, New York. 
Hunter, M., Machemehl, R., and Tsyganov, A. 2001. Operational Evaluation of Freeway Ramp Design. Transportation Research Record, Transportation Research Board, National Research Council, Washington, D.C: 1751: 90-100.

Hwang, S. Y., and Park, C. H. 2005. Modeling of the Gap Acceptance Behavior at a Merging Section of Urban Freeway. Proceedings of the Eastern Asia Society for Transportation Studies, 5: 1641-1656.

HCM. 2000. Highway Capacity Manual. Transportation Research Board. National Research Council, Washington D.C

Hassan, Y., Sarhan, M., and Salehi, M. 2012. Probabilistic Model for Design of Freeway Acceleration Speed-Change lanes. Paper submitted for $91^{\text {th }}$ Annual Meeting of the Transportation Research Board, Washington, D.C.

Ismail, K., and Sayed, T. 2009. Risk-Based Framework for Accommodating Uncertainty in Highway Geometric Design. Canadian Journal of Civil Engineering. 36(5):743-753.

Kaiser, H.F. and Dickman, K. 1962. Sample and Population Score Matrices and Sample Correlation Matrices from an Arbitrary Population Correlation Matrix. Psychomerika.Vol. 27(2): 179-182.

Kita, H. 1993. Effects of Merging Lane Length on the Merging Behaviour at Expressway On-Ramps. Transportation and Traffic Theory, In C.F. Daganzo (Ed.), Elsevier Science Publishers, 37-51.

Kita, H. 1999. A Merging Giveaway Interaction Model of Cars in a Merging Section: A Game Theoretic Analysis. Transportation Research Part A, 33: 305-312. 
Kim, J. T., Kim, J., and Chang, M. 2008. Lane Changing Gap Acceptance Model for Freeway Merging in Simulation. Canadian Journal of Civil Engineering, 35: 301311.

Kondyli, A., and Elefleriadou, L. 2009. Driver Behavior at Freeway-Ramp Merging Areas: Focus Group Findings. Transportation Research Record: Journal of the Transportation Research Record, 2124: 157-166.

Lee, G. 2006. Modeling Gap Acceptance at Freeway Merges, Master of Applied Science. Department of Civil and Environmental Engineering, MIT.

Li. W., Wang. W., Cheng. J., and Li, X. 2007. Field Study and Modeling of Vehicles' Merging Behavior from an Acceleration Lane to Expressway Traffic. Advances in Transportation Studies an International Journal, 12: 59-70.

Marek, P., Gustar, M., and Anagnos, T. 1995. Simulation Based Reliability Assessment for Structural Engineers. Boca Raton, Fl: CRC Press.

McCartt, A. T., Northrup, V. S., and Retting, R. A. 2004. Types and Characteristics of Ramp- Related Motor Vehicle Crashes on Urban Interstate Roadways in Northern Virginia. Journal of Safety Research. 35 (1): 107 - 114.

Navin, F. P. D. 1990. Safety Factors for Road Design: Can they be estimated? Transportation Research Record, 1280: 181-189.

Polus, A., Livneh, M., and Factor, J. 1985. Vehicle Flow Characteristics on Acceleration Lanes. Journal of Transportation Engineering, 111 (6): 595-606. 
Reuven, Y. R. and Kroese, D. P. 1981. Simulation and Monte Carlo Method. Second Edition.Wiley Series in Probability and Statistics.

Richl, L., and Sayed, T. 2006. Evaluation the Safety Risk of Narrow Medians Using Reliability Analysis. Journal of Transportation Engineering, 132 (5): 366-375.

Seneviratene, P.N., and Islam, M. N. 1992. Speed Estimation for Roadway Design and Traffic Control. Transportation Research Record, 1375: 37-43.

Sarhan, M. E. A. 2004. Safety Performance of Freeway Merge and Diverge Areas. Master of Applied Science Thesis, Department of Civil and Environmental Engineering Department, Carleton University. Ottawa, Ontario.

Sarhan, M. 2008. Risk-Based Approach in Highway Geometric Design. PhD dissertation, Department of Civil and Environmental Engineering, Carleton University. Ottawa, Ontario.

Sarhan, M., and Hassan, Y. 2008. Three-Dimensional, Probabilistic Highway Design: Sight Distance application. TRB $87^{\text {th }}$ Annual Meeting Compendium of Papers DVD, Transportation Research Board, National Research Council, Washington, D.C. 2060: 10-18.

Salehi, M. 2010. Reliability-Based Design of Freeway Acceleration Speed-Change Lanes. Master of Applied Science Thesis, Civil and Environmental Engineering Department, Carleton University. Ottawa, Ontario.

TAC, 1999. Geometric Design Guide for Canadian Roads. Transportation Association of Canada, Ottawa, Ontario. 
Traffic Safety Facts, 2012. National Highway Traffic Safety Administration, U.S Department of Transportation

www.gm.ca Consulted in 2012-05-24.

US Census Bureau. United States 2002 - Economic Census - Vehicle Inventory and Use Survey. Report EC02TV-US, Washington, DC, 2004.

Yang, Q., and Koutsopoulos, H.N. 1996. A Microscopic Traffic Simulator for Evaluation of Dynamic Traffic Management Systems. Transportation Research Part C, 4 (3): 113-129.

Yi, Hanwen., and Mulinazzi, E. T. 2007. Observed distribution patterns of on-ramp merge lengths on urban freeways. Journal of the Transportation Research Board, 2023: $120-129$.

Zhang, G., Wang, Y., Wei, H., and Chen, Y. 2007. Examining Headway Distribution Models With Urban Freeway Loop Event Data. Transportation Research Record: Journal of the Transportation Research Board. 1999: 141-149. 


\section{APPENDIX A}

\section{CORRELATION COEFFICIENTS OF PARAMETERS AT EIGHT SCL SITES}


Table A: Correlation Coefficients among Parameters At Study Sites

\begin{tabular}{lccc}
\hline SCL & \multicolumn{3}{c}{ Correlation Coefficient } \\
\cline { 2 - 4 } & Vm \& Vg & Vm \& Acc & Vg \& Acc \\
\hline Parkdale (NS-W) & 0.920 & 0.522 & 0.252 \\
\hline Maitland (NS-E) & 0.565 & 0.506 & 0.214 \\
\hline Moodie (N-W) & 0.874 & 0.335 & -0.129 \\
\hline Eagleson (S-E) & 0.882 & 0.256 & -0.177 \\
\hline Woodroffe (NS-W) & 0.862 & 0.317 & 0.061 \\
\hline Richmond (S-E) & 0.887 & 0.390 & 0.035 \\
\hline Carp (S-E) & 0.785 & 0.205 & -0.367 \\
\hline Terryfox (N-W) & 0.900 & 0.327 & -0.069 \\
\hline All Combined & 0.830 & -0.242 & -0.580 \\
\hline
\end{tabular}




\section{APPENDIX B}

\section{SUMMARY OF PARAMETERS AT EIGHT SCL SITES}


Table B: Summary of received data from Ahammed (2005) site by site and all sites combined.

\begin{tabular}{|c|c|c|c|c|c|}
\hline \multirow{3}{*}{$\begin{array}{l}\text { SCL } \\
\text { sites }\end{array}$} & \multicolumn{5}{|c|}{ All Vehicles (Passenger Cars + Heavy Vehicles) } \\
\hline & & $\begin{array}{c}\text { Freeway } \\
\text { speed }\end{array}$ & $\begin{array}{l}\text { Gore } \\
\text { Speed }\end{array}$ & $\begin{array}{l}\text { Merge } \\
\text { Speed }\end{array}$ & $\begin{array}{l}\text { Accelaration } \\
\text { Rate }\end{array}$ \\
\hline & & $\mathrm{km} / \mathrm{h}$ & $\mathrm{km} / \mathrm{h}$ & $\mathrm{km} / \mathrm{h}$ & $\mathrm{m} / \mathrm{s}^{2}$ \\
\hline \multirow{5}{*}{$\begin{array}{l}\text { All Sites } \\
\text { Combined }\end{array}$} & Min & 72.80 & 38.42 & 54.45 & -0.773 \\
\hline & $\operatorname{Max}$ & 129.80 & 124.72 & 128.20 & 1.517 \\
\hline & Mean & 103.11 & 87.78 & 94.52 & 0.322 \\
\hline & SD & 10.35 & 14.43 & 12.29 & 0.325 \\
\hline & $85^{\text {th }}$ Percentile & 112.50 & 102.2 & 107.2 & 0.661 \\
\hline \multirow{5}{*}{$\begin{array}{l}\text { Parkdale } \\
\text { (NS-W) }\end{array}$} & Min & 70.90 & 38.42 & 54.45 & .0 .193 \\
\hline & Max & 126.70 & 91.65 & 103.83 & 1.526 \\
\hline & Mean & 98.49 & 69.41 & 79.48 & 0.715 \\
\hline & $\mathrm{SD}$ & 11.75 & 9.61 & 10.00 & 0.288 \\
\hline & $85^{\text {th }}$ Percentile & 110.7 & 77.94 & 90.00 & 0.969 \\
\hline \multirow{5}{*}{$\begin{array}{l}\text { Maitland } \\
\text { (NS-E) }\end{array}$} & Min & 78.20 & 41.88 & 63.72 & 0.282 \\
\hline & Max & 119.70 & 77.40 & 111.21 & 1.517 \\
\hline & Mean & 96.64 & 62.13 & 86.67 & 0.843 \\
\hline & $\mathrm{SD}$ & 8.65 & 5.68 & 9.70 & 0.255 \\
\hline & $85^{\text {th }}$ Percentile & 106.4 & 67.06 & 96.56 & 1.120 \\
\hline \multirow{5}{*}{$\begin{array}{l}\text { Moodie } \\
(\mathrm{N}-\mathrm{W})\end{array}$} & Min & 81.60 & 73.32 & 74.30 & -0.645 \\
\hline & $\operatorname{Max}$ & 120.70 & 111.88 & 114.61 & 0.522 \\
\hline & Mean & 97.78 & 91.77 & 93.21 & 0.100 \\
\hline & SD & 7.85 & 7.90 & 8.80 & 0.224 \\
\hline & $85^{\text {th }}$ Percentile & 106.5 & 101.03 & 102.21 & 0.327 \\
\hline \multirow{5}{*}{$\begin{array}{l}\text { Eagleson } \\
\text { (S-E) }\end{array}$} & Min & 81.80 & 71.37 & 78.60 & -0.773 \\
\hline & Max & 117.20 & 122.23 & 123.21 & 0.601 \\
\hline & Mean & 98.29 & 95.71 & 98.54 & 0.232 \\
\hline & $\mathrm{SD}$ & 7.90 & 8.80 & 9.32 & 0.216 \\
\hline & $85^{\text {th }}$ Percentile & 106.9 & 105.72 & 108.31 & 0.316 \\
\hline
\end{tabular}


Table B Continued

\begin{tabular}{|c|c|c|c|c|c|}
\hline \multirow{2}{*}{$\begin{array}{l}\mathrm{SCL} \\
\text { sites }\end{array}$} & & $\begin{array}{c}\text { Freeway } \\
\text { speed }\end{array}$ & $\begin{array}{c}\text { Gore } \\
\text { Speed }\end{array}$ & $\begin{array}{l}\text { Merge } \\
\text { Speed }\end{array}$ & $\begin{array}{l}\text { Accelaration } \\
\text { Rate }\end{array}$ \\
\hline & & $\mathrm{km} / \mathrm{h}$ & $\mathrm{km} / \mathrm{h}$ & $\mathrm{km} / \mathrm{h}$ & $\mathrm{m} / \mathrm{s}^{2}$ \\
\hline \multirow{5}{*}{$\begin{array}{l}\text { Woodroffe } \\
\text { (NS-W) }\end{array}$} & Min & 77.10 & 58.31 & 60.91 & -0.253 \\
\hline & Max & 124.30 & 103.06 & 109.81 & 1.508 \\
\hline & Mean & 102.87 & 78.85 & 88.50 & 0.649 \\
\hline & SD & 10.41 & 8.00 & 9.35 & 0.291 \\
\hline & $85^{\text {th }}$ Percentile & 115.9 & 86.55 & 98.62 & 0.860 \\
\hline \multirow{5}{*}{$\begin{array}{l}\text { Richmond } \\
\text { (S-E) }\end{array}$} & Min & 72.80 & 63.84 & 68.31 & -0.409 \\
\hline & Max & 121.40 & 110.36 & 107.82 & 0.839 \\
\hline & Mean & 109.78 & 83.52 & 87.68 & 0.284 \\
\hline & SD & 10.30 & 8.22 & 9.74 & 0.226 \\
\hline & $85^{\text {th }}$ Percentile & 109.7 & 91.81 & 96.41 & 0.505 \\
\hline \multirow{5}{*}{$\begin{array}{l}\text { Carp } \\
(\mathrm{S}-\mathrm{E})\end{array}$} & Min & 87.40 & 78.52 & 87.20 & -0.495 \\
\hline & $\operatorname{Max}$ & 127.30 & 115.38 & 120.41 & 0.846 \\
\hline & Mean & 109.29 & 99.85 & 105.95 & 0.228 \\
\hline & SD & 7.52 & 8.20 & 7.00 & 0.199 \\
\hline & $85^{\text {th }}$ Percentile & 117.5 & 108.05 & 112.30 & 0.402 \\
\hline \multirow{5}{*}{$\begin{array}{l}\text { Terryfox } \\
(\mathrm{N}-\mathrm{W})\end{array}$} & Min & 92.80 & 75.63 & 79.71 & -0.454 \\
\hline & Max & 129.80 & 124.72 & 128.21 & 0.836 \\
\hline & Mean & 108.27 & 100.05 & 104.71 & 0.221 \\
\hline & $\mathrm{SD}$ & 7.51 & 9.48 & 9.94 & 0.206 \\
\hline & $85^{\text {th }}$ Percentile & 116.2 & 109.06 & 114.76 & 0.416 \\
\hline
\end{tabular}




\section{APPENDIX C SUMMARY OF ACCEPTED GAPS AT EIGHT SCL SITES}


Table C: Accepted Gap at Different Segments of SCL

\begin{tabular}{|c|c|c|c|c|c|c|c|c|c|}
\hline & & Seg 2 & Seg 3 & Seg 4 & Seg 5 & Seg 6 & Seg 7 & Seg 8 & Seg 9 \\
\hline \multirow{2}{*}{$\begin{array}{l}\text { Parkdale } \\
\text { (NS-W) }\end{array}$} & Mean & 4.38 & 4.00 & 3.55 & 3.33 & 3.33 & 2.75 & 2.67 & 2.00 \\
\hline & SD & 1.46 & 1.35 & 1.36 & 0.57 & 1.15 & 0.50 & 0.77 & \\
\hline \multirow{2}{*}{$\begin{array}{l}\text { Carp } \\
\text { (S-E) }\end{array}$} & Mean & 4.67 & 4.50 & 4.00 & 3.91 & 3.71 & 3.62 & 3.33 & 2.34 \\
\hline & SD & 0.58 & 0.58 & 1.41 & 1.22 & 1.20 & 1.12 & 0.58 & 0.45 \\
\hline \multirow{2}{*}{$\begin{array}{l}\text { Maitland } \\
\text { (NS-E) }\end{array}$} & Mean & & 4.00 & 4.20 & 4.02 & 3.68 & 3.54 & 2.91 & 2.46 \\
\hline & SD & & 1.22 & 1.52 & 1.45 & 1.42 & 1.36 & 1.13 & 0.52 \\
\hline \multirow{2}{*}{$\begin{array}{c}\text { Moodie } \\
(\mathrm{N}-\mathrm{W})\end{array}$} & Mean & 4.40 & 3.80 & 3.77 & 3.33 & 3.33 & 3.00 & 2.75 & \\
\hline & SD & 1.17 & 1.42 & 1.30 & 1.00 & 0.58 & 1.00 & 0.53 & \\
\hline \multirow{2}{*}{$\begin{array}{l}\text { Eagleson } \\
\text { (S-E) }\end{array}$} & Mean & 4.23 & 4.05 & 3.66 & 3.54 & 3.00 & 3.00 & 2.00 & \\
\hline & SD & 1.21 & 1.06 & 1.32 & 1.22 & 1.37 & 1.41 & 0.5 & \\
\hline \multirow{2}{*}{$\begin{array}{l}\text { Richmond } \\
\text { (S-E) }\end{array}$} & Mean & 4.00 & 3.75 & 3.70 & 3.70 & 3.58 & 3.17 & 2.8 & \\
\hline & SD & 0.57 & 0.50 & 1.33 & 1.31 & 1.35 & 0.98 & 0.79 & \\
\hline \multirow{2}{*}{$\begin{array}{l}\text { Terryfox } \\
(\mathrm{N}-\mathrm{W})\end{array}$} & Mean & 5.375 & 5.00 & 3.43 & & & & & \\
\hline & SD & 1.00 & 1.19 & 1.81 & & & & & \\
\hline \multirow{2}{*}{$\begin{array}{l}\text { Woodroffe } \\
\text { (NS-W) }\end{array}$} & Mean & 4.5 & 4.00 & 3.30 & 3.30 & 3.29 & 3.00 & 2.66 & \\
\hline & SD & 0.71 & 1.00 & 1.16 & 0.85 & 1.12 & 1.24 & 0.89 & \\
\hline
\end{tabular}




\section{APPENDIX D}

\section{Passenger Car Lengths}


Table D: Passenger Cars Length

\begin{tabular}{llc}
\hline Passenger cars type & Name & Length $(\mathrm{m})$ \\
\hline Small & 2012 Sonic & 4.399 \\
\hline Small & 2012 Verano & 4.671 \\
\hline Sport & 2012 Camaro & 4.836 \\
\hline Sport & 2012 Cts Cedan & 4.789 \\
\hline Sport & 2012 Cts Coupe & 4.789 \\
\hline Sport & 2012 CTS Sport Wagon & 4.877 \\
\hline Sport & 2012 Corvette & 4.435 \\
\hline Mid size & 2012 Cruze & 4.597 \\
\hline Mid size & 2012 Chevrolet Malibu & 4.872 \\
\hline Mid size & 2012 Buick Regal & 4.831 \\
\hline Mid size & 2012 Buick Lacrosse & 5.001 \\
\hline Mid size & 2012 Chevrolet Volt & 4.498 \\
\hline Full-size & 2012 Impala & 5.09 \\
\hline Luxury & 2012 Buick Verano & 4.671 \\
\hline Luxury & 2012 Buick Legal & 4.831 \\
\hline Luxury & 2012 Buick Lacrosse & 5.001 \\
\hline Luxury & 2012 Cadillac CTS Sedan & 4.789 \\
\hline Luxury & 2012 Cadillac SRX & 4.834 \\
\hline Luxury & 2012 Cadillac CTS Coupe & 4.789 \\
\hline Luxury & 2012 Chevrilet Orlando & 4.665 \\
\hline Suv & 2012 Chevrilet Equinox & 4.771 \\
\hline Suv & 2012 GMC Terrain & 4.711 \\
\hline Suv & 2012 Chevrilet Traverse & 5.207 \\
\hline Suv & 2012 GMC Acadia & 5.098 \\
\hline Suv & 2012 Cadillac SRX & 4.834 \\
\hline Suv & 2012 Buick Enclave & 5.126 \\
\hline Suv & 2012 Chenrolet Tahoe & 5.131 \\
\hline Suv & 2012 GMC Yukon & 5.131 \\
\hline
\end{tabular}

